\title{
Population genetics of New Zealand Scampi
}

\author{
(Metanephrops challengeri)
}

\section{Alexander Verry}

A thesis submitted to Victoria University of Wellington in partial fulfilment of the requirements for the degree of Master of Science in Ecology and Biodiversity.

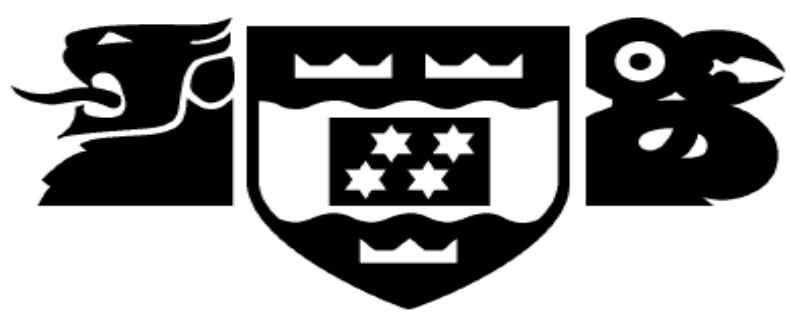

Victoria University of Wellington 


\section{$\underline{\text { Abstract }}$}

A fundamental goal of fisheries management is sustainable harvesting and the preservation of properly functioning populations. Therefore, an important aspect of management is the identification of demographically independent populations (stocks), which is achieved by estimating the movement of individuals between areas. A range of methods have been developed to determine the level of connectivity among populations; some measure this directly (e.g. markrecapture) while others use indirect measures (e.g. population genetics). Each species presents a different set of challenges for methods that estimate levels of connectivity. Metanephrops challengeri is a species of nephropid lobster that supports a commercial fishery and inhabits the continental shelf and slope of New Zealand. Very little research on population structure has been reported for this species and it presents a unique set of challenges compared to finfish species. $M$. challengeri have a short pelagic larval duration lasting up to five days which limits the dispersal potential of larvae, potentially leading to low levels of connectivity among populations. The aim of this study was to examine the genetic population structure of the New Zealand M. challengeri fishery.

DNA was extracted from $M$. challengeri samples collected from the eastern coast of the North Island (from the Bay of Plenty to the Wairarapa), the Chatham Rise, and near the Auckland Islands. DNA from the mitochondrial CO1 gene and nuclear ITS-1 region was amplified and sequenced. The aligned dataset of DNA sequences was then used to estimate levels of both genetic diversity and differentiation, and examine demographic history. Analyses of population structure indicate that $M$. challengeri from the Auckland Islands region are genetically distinct from $M$. challengeri inhabiting the Chatham Rise, and those collected from waters off the eastern coast of the North Island. There appears to be gene flow among the sampling sites off the eastern coast of the North Island and on the Chatham Rise, but some isolation by distance was detected. These results indicate that some of these populations may be demographically uncoupled. Genetic diversity estimates combined with Bayesian skyline plots and demographic history parameters suggest that $M$. challengeri populations have recently undergone a size expansion.

The genetic structuring between the Auckland Islands site and all others may be due to a putative habitat disjunction off the Otago shelf. In contrast, a largely continuously distributed population along the eastern coast of the North Island and the Chatham Rise most likely promotes gene flow as larvae can be transported limited distances by oceanic currents. Historical changes in climate may have influenced the patterns of present-day structure and genetic diversity of $M$. challengeri, by altering habitat availability and other characteristics of their environment. This study provides 
evidence that species which appear to have limited dispersal potential can still maintain connected populations, but there are situations where large breaks in suitable habitat appear to limit gene flow. The results of this study will help inform stock structure of the $M$. challengeri fishery, which will enable stock assessments to be more precisely aligned to natural population boundaries. 


\section{Acknowledgements}

To begin I'd to thank my supervisor Dr Peter Ritchie for his continued support throughout this project. He has been a constant source of help and advice ever since I first entered his office, even on topics not immediately pertaining to this work. Thanks also go to Dr Ian Tuck who obtained the samples utilised in this study, and who was always quick to answer my many questions concerning sampling methods and scampi biology, and provide valuable comments on earlier drafts of this work.

To my fellow lab and class mates, thank you for making my time spent working on this thesis so enjoyable. Special mention goes to the Ritchie lab group; Ange, Balam, Jana, and Kate- your help throughout this has been invaluable. From getting my PCRs back in order, to answering my questions on various topics and offering constructive criticism and advice. Kerry gets an extra special mention for all of his help with critiquing drafts of this work, emails to various contacts, and long discussions about interpreting my results. Thanks again for all the wonderful dinners. I'm also grateful to Conor who put up with my incessant questioning on statistics and for his proofreading skills.

Finally, I'd like to thank my parents Ron and Anita, without whom I would never have been given this opportunity. You've always supported me no matter what I've chosen to do in life, and for that I am eternally grateful, thank you. 


\section{Population genetics of New Zealand Scampi}

LIST OF FIGURES

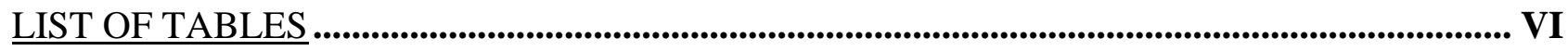

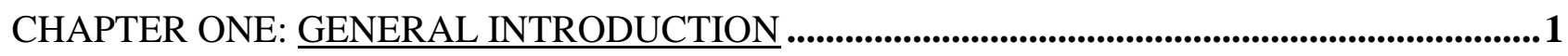

1.1: Population Connectivity \& Genetic StRucture ...................................................... 1

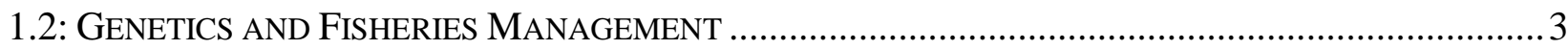

1.3: GENETIC CONNECTIVITY IN MARINE ECOSYSTEMS .............................................................. 6

1.4: NEW ZEALAND’s MARINE ENVIRONMENT AND GENETIC CONNECTIVITY ................................. 8

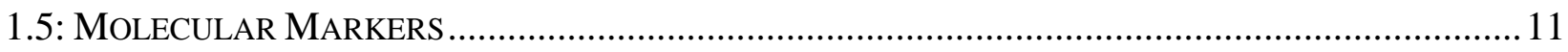

1.6: STUDY SPECIES: NEW ZEALAND SCAMPI (METANEPHROPS CHALLENGERI) ............................. 13

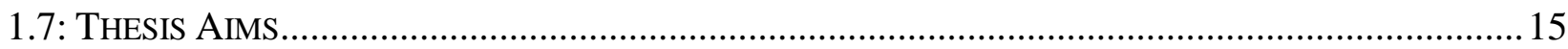

CHAPTER TWO: THE GENETIC POPULATION STRUCTURE AND DEMOGRAPHIC HISTORY OF NEW ZEALAND SCAMPI (METANEPHROPS CHALLENGERI) INFERRED FROM MITOCHONDRIAL AND NUCLEAR DNA SEQUENCES ................................................16

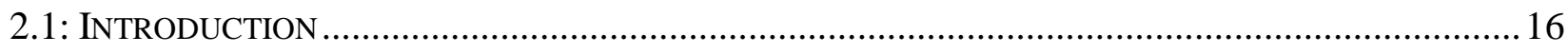

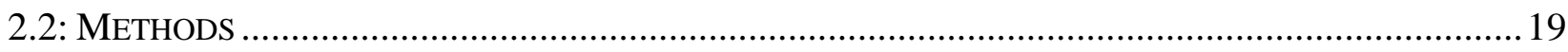

2.2.1: Sample Collection............................................................................................................ 19

2.2.2: DNA Extraction, Polymerase Chain Reaction, and DNA Sequencing ............................. 20

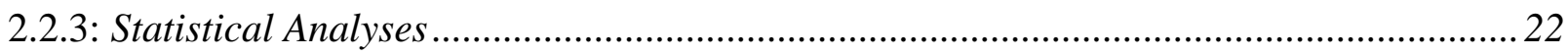

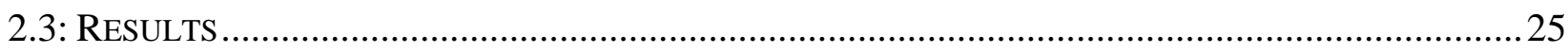

2.3.1: Mitochondrial DNA Cytochrome C Oxidase Subunit 1 (CO1) Sequences....................... 25

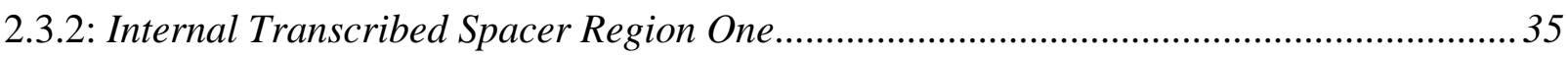

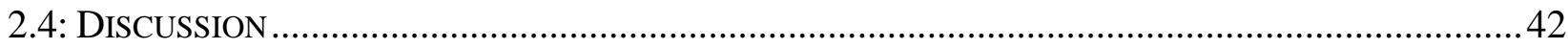

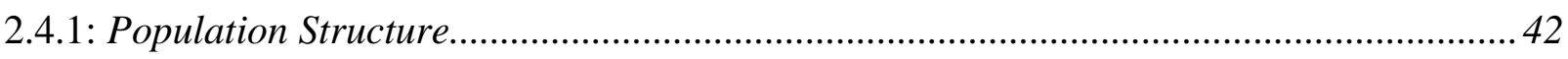

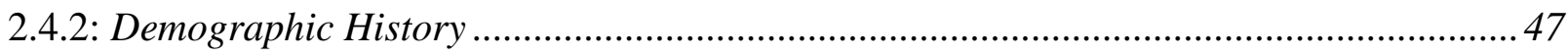

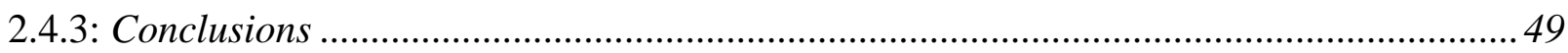

CHAPTER THREE: GENERAL DISCUSSION \& IMPLICATIONS FOR FISHERIES

MANAGEMENT .................................................................................................................................................5 51

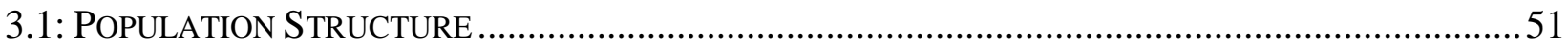

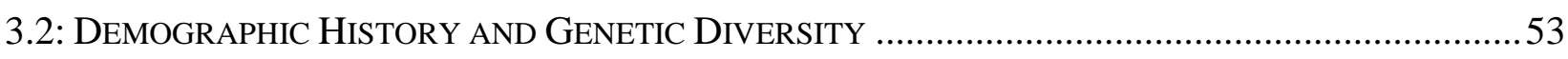

3.3: MANAGEMENT IMPLICATIONS FOR METANEPHROPS CHALLENGERI …...................................54

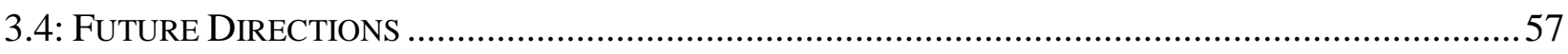

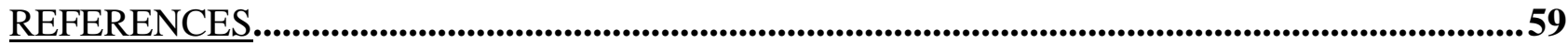

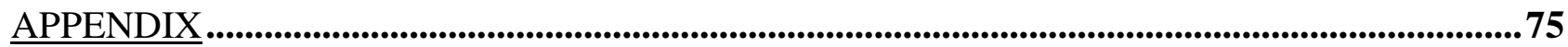




\section{$\underline{\text { List of Figures }}$}

Figure 1.1: Three potential patterns of population structure $\quad 2$

Figure 1.2: Quota Management Areas for Metanephrops challengeri $\quad 5$

Figure 1.3: The major surface currents of New Zealand's waters $\quad 9$

Figure 2.1: Bathymetric map of New Zealand displaying sampling locations 20

Figure 2.2: Rarefaction curve of CO1 haplotype frequency $\quad 25$

Figure 2.3: Linked loci clustering of 321 partial M. challengeri CO1 sequences 27

Figure 2.4: Median joining haplotype network of 321 partial $M$. challengeri CO1 sequences 28

Figure 2.5: Pairwise comparisons of Slatkin's linearised genetic distance derived from CO1 haplotype frequencies plotted against geographic distance. A) All sites included. B) Auckland Islands site excluded

Figure 2.6: Bayesian Skyline Plots generated by CO1 DNA sequences. A) Auckland Islands sampling site. B) All other sampling sites

Figure 2.7: Rarefaction curve of ITS-1 DNA-sequence-type frequency

Figure 2.8: BAPS of 67 partial ITS-1 sequences. A) Linked loci clustering analysis. B) Admixture analysis based on mixed clustering

Figure 2.9: Median joining network of 67 partial M. challengeri ITS-1 sequences

Figure 2.10: Pairwise comparisons of Slatkin's linearised genetic distance derived from ITS-1

DNA-sequence-type frequencies plotted against geographic distance. A) All sites included. B) Auckland Islands site excluded

\section{List of Tables}

Table 2.1: Sampling information, summary statistics, and estimates of genetic diversity for CO1 sequences

Table 2.2: AMOVA results obtained from analysis of CO1 data

Table 2.3: Pairwise $\phi$ st values determined by CO1 haplotype frequencies

Table 2.4: Estimated number of migrants exchanged per generation according to $\mathrm{CO} 1$ data

Table 2.5: Neutrality tests, mismatch analyses, and demographic expansion parameters generated by $\mathrm{CO} 1$ data

Table 2.6: Sampling information, summary statistics, and estimates of genetic diversity for ITS-1 sequences 
Table 2.7: Pairwise $\phi_{\text {ST }}$ values determined by ITS-1 sequence-type frequencies. 38

Table 2.8: AMOVA results obtained from analysis of ITS-1 data $\quad \mathbf{4 0}$

Table 2.9: Estimated number of migrants exchanged per generation according to ITS-1 data 40

Table 2.10: Neutrality tests, and mismatch analysis values generated by ITS-1 data 41 


\section{Chapter One: General Introduction}

\section{1: Population Connectivity \& Genetic Structure}

Connectivity of populations through the exchange of individuals is a fundamental process that influences demographic stability and evolutionary processes (Lowe \& Allendorf, 2010; Faurby \& Barber, 2012). Populations are often defined using ecological or evolutionary paradigms which respectively emphasise demographic or reproductive cohesion (Waples \& Gaggiotti, 2006). Under an evolutionary paradigm populations can be defined as groups of conspecific individuals that live in close proximity to one another which allows interactions between individuals and random mating to occur (Waples \& Gaggiotti, 2006). Population connectivity is driven by realised dispersal, but the movement of individuals from one population to another has been difficult to quantify in the marine environment (Cowen \& Sponaugle, 2009). Various approaches have been developed, which include indirect methods that examine the changes and components of calcified structures (e.g. otoliths in fish: Thorrold et al., 2007), and tests for genetic structure. Along with direct approaches that use tagged individuals and satellite telemetry (Webster et al., 2002). DNA-based approaches have also been used as a direct method, as molecular markers can be used to identify individuals in a capturerecapture programme. The advantage of molecular markers is that they can be used as either indirect or direct methods, and provide information about levels of genetic diversity, population structure, and the evolutionary history of populations. Molecular markers are also unique in that they are able to detect whether or not an individual has successfully contributed to reproduction in its new population (Ovenden, 2013).

Gene flow is the movement of alleles of reproductively successful individuals from one population to another. High levels of gene flow typically result in low levels of genetic differentiation, and the homogenization of genetic diversity among populations (Slatkin, 1987). A lack of gene flow can lead to genetic divergence among populations as evolutionary processes such as genetic drift and mutation are able to operate on each population independently. These stochastic processes change allele frequencies and can eliminate alleles from a population (via genetic drift), or introduce new alleles (mutations) into populations. If populations are isolated for a long period of time then the potential for reproductive incompatibility between them increases, potentially leading to speciation (Slatkin, 1987). It only takes the exchange of a few individuals between populations to homogenise genetic diversity. A single migrant (that contributes to reproduction in its new population) can be enough to prevent the loss of genetic variation through inbreeding and genetic drift (Wright, 1931). 
The degree of genetic structure between populations is the result of evolutionary (genetic drift, selection, mutation, migration) and demographic processes (Gaggiotti et al., 2009). The extent of population structure often varies among species, both biological characteristics and environmental constraints can influence dispersal potential, and drive changes in genetic population structure (e.g. Butler et al., 2011; Teske et al., 2016). Laikre et al. (2005) described three generalised models of genetic population structure within a species, referring to these as: "distinct populations", "continuous change" (also known as "isolation by distance"), and "no differentiation" (Figure 1.1). "No differentiation" or "panmixia" (Figure 1.1A) refers to a lack of genetic structure throughout a given part of a species' distribution, this pattern is found when there are high levels of gene flow and random mating across the geographic range of a population (Laikre et al., 2005). "Continuous change/isolation by distance" (Figure 1.1B) describes a gradient of genetic differences across a geographic space, where the level of gene flow is higher between nearby areas and lower between more distant locations (Wright, 1943; Laikre et al., 2005). When populations form a part of an isolation by distance pattern of genetic structure it can be difficult to identify basic genetic units. Genetically "distinct populations" (Figure 1.1C) form when there is little or no gene flow between populations, allowing evolutionary forces to act independently upon each population. A species may conform to any one of these models (or any combination of them) over a specific geographic area, as levels of gene flow may continuously vary and the distinction between models is not always sharp (Laikre et al., 2005).
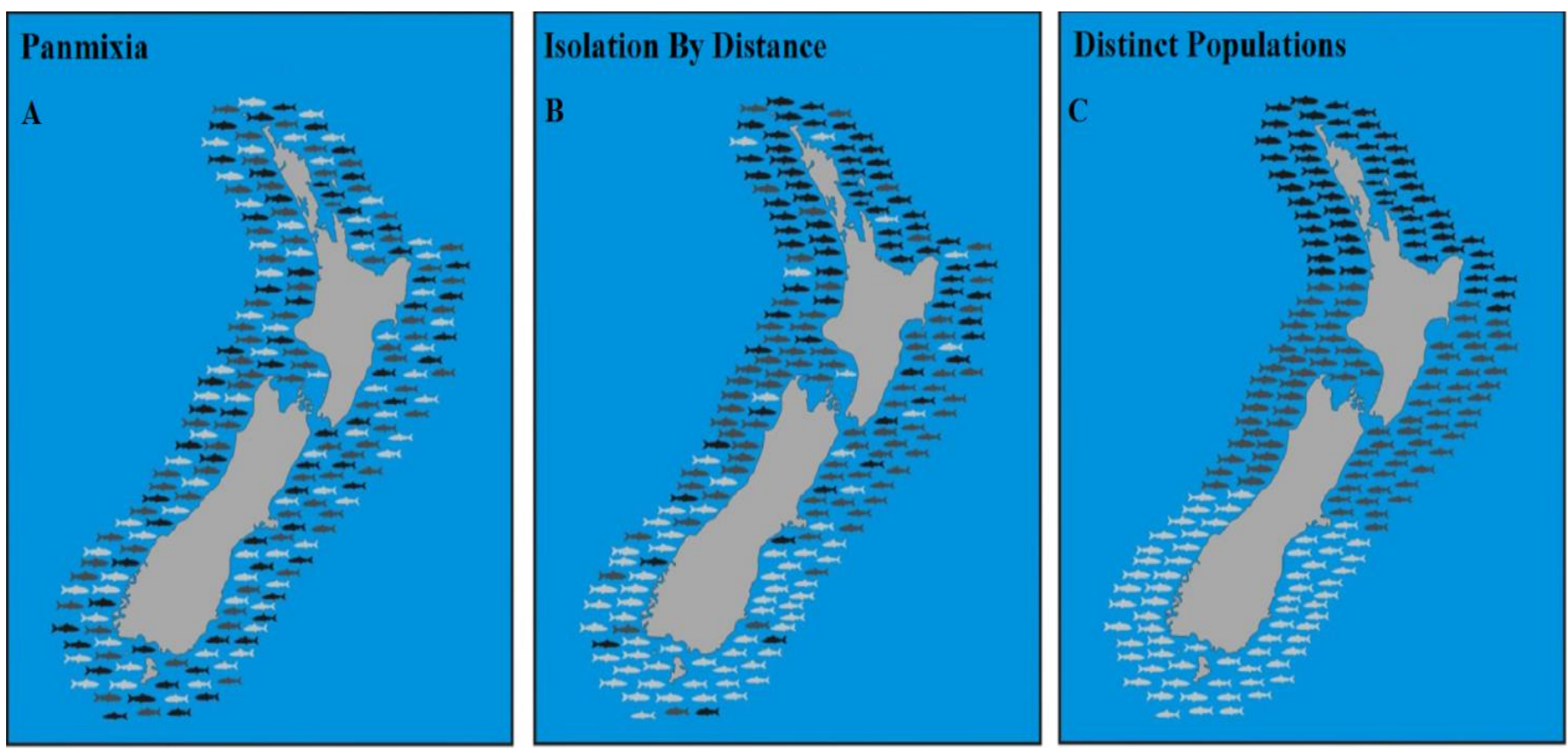

Figure 1.1: Three forms of population structure as defined by Laikre et al. (2005) A: Panmixia where populations display high levels of gene flow and random mating occurs. B: Isolation by Distance or "continuous change" where nearby neighbours display high levels of gene flow; but low levels of gene flow occur between geographically separate populations. C: Distinct Populations where low levels of gene flow occur between each population and they are not genetically connected. Figure adapted from Wilcox (2015) 
Populations might be genetically connected but that does not necessarily mean they are demographically connected (Ovenden, 2013). Genetic markers, along with traditional direct measures of demographic connectivity (e.g. tagging and tracking data), can be used together to determine the magnitude of each connectivity type (Ovenden, 2013). An absolute number (e.g. 5 migrants per 1000 individuals) of effective migrants are needed for genetic connectivity, while it is the proportion of migrants (e.g. $10 \%$ of individuals exchanged) that determines demographic connectivity (Ovenden, 2013). Therefore, it follows that the population size of the species studied plays a large role in determining demographic connectivity among populations. Many marine organisms have exceedingly large population sizes and would require large numbers of migrants between populations to render them demographically connected. Genetic methods may not provide an informative measure of demographic connectivity in cases such as these due to the small number of effective migrants needed to homogenise genetic diversity. Small numbers of migrants may not be enough to demographically connect populations, leading to a so-called "crinkled" pattern of population connectivity where populations are genetically connected and demographically decoupled (Ovenden, 2013). Understanding the patterns of both genetic and demographic connectivity within a species is important for properly informing short- and long-term management decisions.

\section{2: Genetics and Fisheries Management}

Patterns of demographic and genetic connectivity can be used to aid the sustainable management of harvested species. Such species should be managed to ensure that populations are not exploited to the point that they cannot recover from harvesting-induced mortality. One way to achieve this is by assigning independent populations to separate management units, allowing each population to be managed independently. Management units (MUs) are typically defined as demographically independent populations, the dynamics of which depend upon birth- and death-rates, rather than immigration (Palsboll et al., 2007). The accurate identification and delineation of MUs is crucial to the sustainable management of harvested species (Laikre et al., 2005; Palsboll et al., 2007; Allendorf et al., 2008). MUs for fisheries species are generally labelled as "stocks", which have been identified by a number of means, including morphological characters (Cadrin, 2000), and genetics (Carvalho \& Hauser, 1994). However, within fisheries management the term "stock" often refers to a group of conspecific individuals that are exploited in a specific area or by a specific method, which may not necessarily reflect the biological substructure of the targeted species (Laikre et al., 2005). A fishery "stock" may encompass multiple genetically distinct populations, or only part of a singular population (Laikre et al., 2005). Therefore, a mismatch often exists between the 
knowledge of genetic structure within a commercially harvested species and its associated fisheries management units, even though the presence of genetic differentiation may indicate reproductively independent populations (Reiss et al., 2009).

New Zealand uses the Quota Management System (QMS) to manage and regulate its fisheries. New Zealand's Exclusive Economic Zone (EEZ) is the fourth largest in the world and is partitioned into MUs, which are called Quota Management Areas (QMA) (Figure 1.2). A Total Allowable Catch (TAC) is set for each area. The TAC incorporates catch limits from commercial, recreational, and customary fishing. The portion of the TAC allowed to commercial operators, known as the total allowable commercial catch (TACC), is then translated into quota shares that can be bought and sold to companies or individuals. The share owner then has the right to harvest, and sell, their portion of the TACC. Partitioning of the exclusive economic zone varies on a species by species basis and is typically based on the distribution and/or characteristics of the species, geographic features, or administrative convenience. Ideally, QMAs are determined by stock assessment (Connor, 2001), and are modified to better reflect stock dynamics when new information becomes known.

Management units that are defined using genetic data can also incorporate information about evolutionarily significant units (ESUs). An ESU can be broadly defined as a distinct population that is reproductively isolated and contains significantly different genetic variation from other populations (Palsboll et al., 2007; Funk et al., 2012). Preservation of unique genetic variation is considered an important part of long-term management because an ESU could be adapted to its local environment or undergoing speciation. A loss of genetic variation is usually associated with a reduction in population size. Declining population size can increase the occurrence of inbreeding depression and lower the adaptive potential of a population. The net fitness effect of inbreeding can be low population productivity and increased extinction risk when a population is faced with a new environmental challenge (Allendorf et al., 2008). Overfishing of stocks has been linked to a decrease in both heterozygosity and allelic diversity (Pinsky \& Palumbi, 2014). More recently, sizeselective fishing methods have been considered a potential evolutionary force of selection and (if the pressure is strong enough) could cause genetic changes to characteristics such as individual size and age of maturation. "Fisheries-induced evolution" could cause an adaptive response to fishing by leading fish to mature at a younger age, which occurs if harvesting mortality is uniform across all size classes (Law, 2007), or a smaller size if the larger individuals are targeted (Swain et al., 2007). If harvesting times, means, or regulations favour a specific sex it could skew the sex ratio of stocks and reduce the genetically effective population size, which would increase the effect of genetic drift and potentially lead to a loss of alleles (Allendorf et al., 2008). 
The effective population size of marine organisms can be significantly lower than their census population size (Hauser \& Carvalho, 2008; Palstra \& Ruzzante, 2008) and fisheries practises may have a larger impact on populations than fisheries managers have initially realised. Some genetic change due to human harvesting is most likely unavoidable (Allendorf et al., 2008; Allendorf et al., 2014). Harvesting reduces population size (Pinsky \& Palumbi, 2014) and it can impose strong selection pressures on specific traits (Nielsen et al., 2009b). These issues highlight the importance of well-informed research to enable fisheries management to meet its key goal of sustainability. It is important that genetic structure and diversity is taken into account when developing harvest management plans. This would ensure that any negative effects of reduced stock size, disruptions to gene flow, and size-selective fishing are minimised and groups that contain unique genetic diversity have appropriate protection. Fisheries managers can utilise evolutionary impact assessments (EvoIAs: Laugen et al., 2014) that assess the evolutionary/genetic impact of fisheries on populations, or genetic monitoring which examines changes in genetic composition through time (Schwartz et al., 2007).

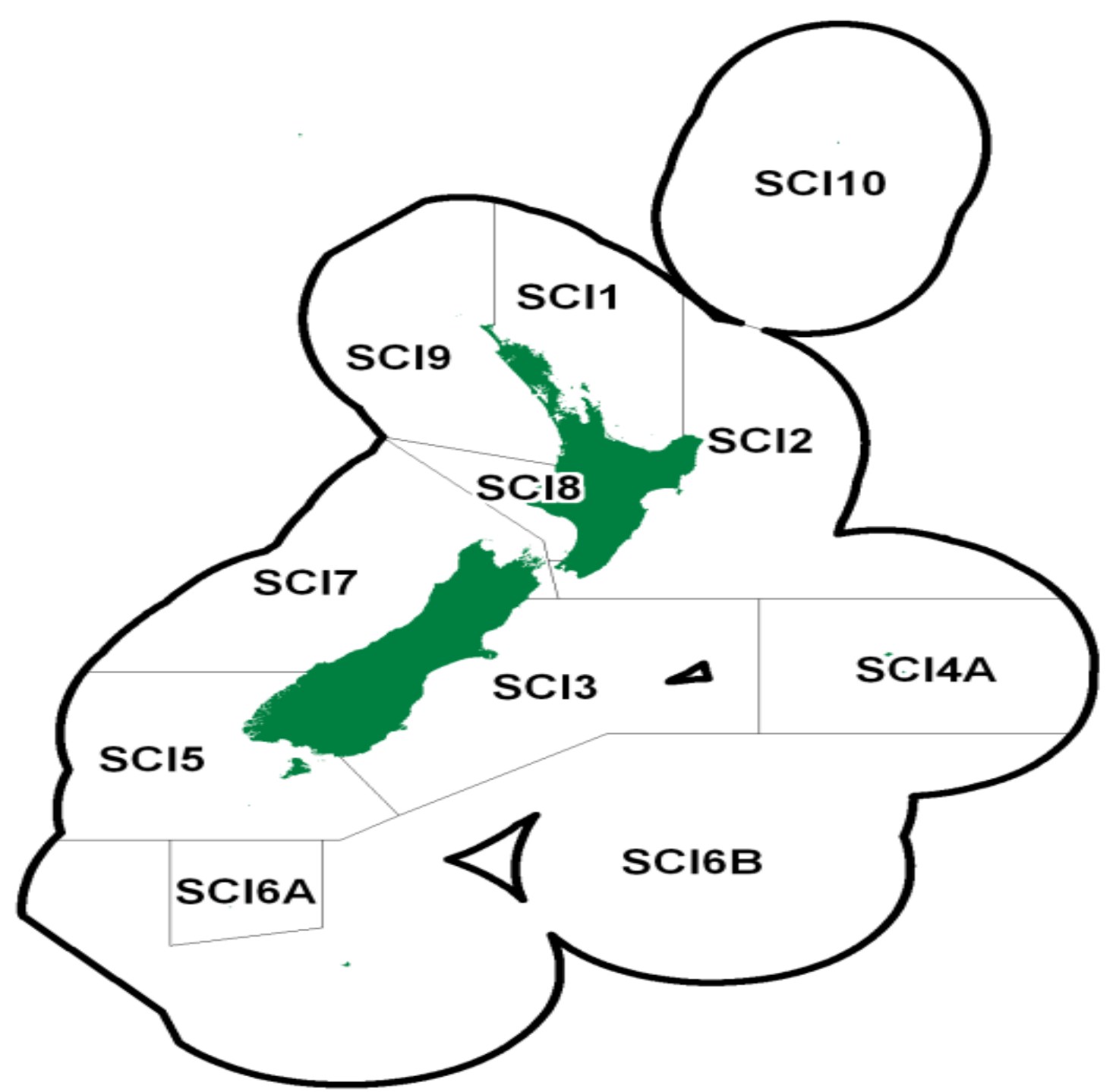

Figure 1.2: Quota Management Areas for New Zealand Scampi (Metanephrops challengeri) in New Zealand's Exclusive Economic Zone. (Figure retrieved from the May 2016 Plenary Report, Ministry for Primary Industries 2016) 


\section{3: Genetic Connectivity in Marine Ecosystems}

Marine populations have traditionally been considered well-connected with few barriers to dispersal (Scheltema, 1986). This paradigm has shifted in recent years as numerous empirical studies have reported genetically structured populations in a wide range of marine species (Hauser \& Carvalho, 2008; Baco et al., 2016), and the prevalence and importance of self-recruitment is better understood (Jones et al., 2005). Many benthic marine species have a bipartite life cycle comprising a pelagic larval phase (during which most dispersal potential is realised), preceding a largely sedentary adult phase. Species with direct development (those that produce offspring that are essentially miniature adults) typically have fewer opportunities for dispersal (Thorson, 1950). The small size of pelagic larvae and the vast areas that need to be sampled severely limit the opportunities for directly measuring larvae dispersal (Levin, 2006; Cowen \& Sponaugle, 2009; Weersing \& Toonen, 2009). Genetic sampling of adults has been used to infer patterns of larval dispersal in species where the larval phase is the dominant dispersal period (Lowe \& Allendorf, 2010). It was initially assumed that dispersal potential would be positively correlated with the duration of the pelagic larval life phase. Extended pelagic larval duration (PLD) can increase both the number of migrants and the distance they can cover. This has the potential to increase gene flow, and thus reduce genetic structure between distant populations (Faurby \& Barber, 2012). However, PLD often fails to be a good predictor of genetic structure. Genetic structure has been reported in species with extremely long PLDs such as Jasus edwardsii (Thomas \& Bell, 2013), and its use in predicting or explaining population connectivity remains contentious.

Ross et al. (2009) report a significant correlation between PLD and genetic differentiation in the coastal benthic fauna of New Zealand $\left(\mathrm{r}^{2}=0.39, \mathrm{p}=<0.001\right)$. However, greater variability was detected in species with shorter PLDs ( $<10$ days) reflecting other factors that affect the connectivity of populations. Weersing and Toonen (2009) found a statistically significant but weak correlation $\left(\mathrm{r}^{2}=0.097 \mathrm{p}=<0.001\right)$ between PLD and genetic structure, but this correlation was due to the inclusion of species with direct development (i.e. PLD $=0$ ). When these were excluded from the analysis there was no statistically significant correlation between PLD and genetic structure $\left(\mathrm{r}^{2}=\right.$ 0.028, p = 0.053) (Weersing \& Toonen, 2009). Direct developing species also appeared to influence the relationship between PLD and genetic differentiation in the analysis conducted by Ross et al. (2009), and when they were removed from the dataset no statistically significant correlation was found (Selkoe \& Toonen, 2011).

Genetic differentiation can be measured using F $_{\text {ST }}$ values. These can range from zero to one where zero indicates panmixia and one represents complete separation. F $_{S T}$ is obtained by the equation 


$$
F s t=\frac{1}{(1+4 N e m)}
$$

under the classical island model (Wright, 1931), meaning that both the migration rate $(m)$ and effective population size $\left(N_{e}\right)$ influence this parameter, so variation in these may also influence the correlation between FST and PLD (Faurby \& Barber, 2012). A computerised simulation approach (Faurby \& Barber, 2012) concluded that variation in $N_{e}$ had the largest impact on correlation estimates between F $_{\mathrm{ST}}$ and PLD, and that the correlation between $\mathrm{F}_{\mathrm{ST}}$ and PLD may be stronger than previously reported. The classical island model used to calculate $\mathrm{F}_{\mathrm{ST}}$ has a long list of assumptions (e.g. mutation-drift equilibrium, infinite populations), which natural populations may violate, so its application to real world examples can be limited (Whitlock \& McCauley, 1999). Selkoe and Toonen (2011) reviewed numerous studies investigating the use of PLD as a predictor of genetic differentiation using Isolation by Distance (IBD) slopes. They reported a moderate correlation between PLD and IBD $\left(r^{2}=0.34\right)$, and that marker type and sampling design had a significant effect upon this relationship. Selkoe and Toonen (2011) called for more robust sampling as F ST $_{\text {and IBD }}$ slope values are higher when the number of individuals sampled per population is low, and suggest investigation into other measures of connectivity (such as emigration rate or population size).

The dispersal ability of marine species is influenced by a variety of factors including larval behaviour (Paris et al., 2007; Butler et al., 2011) and oceanic currents (Treml et al., 2008). Oceanic currents can facilitate or otherwise influence the dispersal of passive (non-swimming) and active (swimming) larvae depending on current and swimming behaviour characteristics. Aided dispersal is also possible through adherence to, or association with, a passively floating object (Nikula et al., 2010), or to an actively moving object such as another organism (Green \& Figuerola, 2005), or vessel (Leung et al., 2006). Aided dispersal can enable organisms to disperse over very long distances (Fraser et al., 2011) because the object they attach to may provide support, protection, and/or a food source. Ocean currents and temperature or salinity changes also impede connectivity. Ocean currents could block the movement of individuals and crossing environmental gradients can be an overwhelming physiological challenge. Attempts have been made to model larval dispersal within the marine environment (White et al., 2010). These models can then be used to attempt to explain the observed genetic patterns within a species (e.g. Chiswell, 2009). Using simulated dispersal models and oceanic current data Chiswell (2009) demonstrated that only a small number of larvae from the gastropod Cellana strigilis are likely to successfully disperse from one subantarctic island population to another. Chiswell (2009) concludes that if larval dispersal maintains the genetic connectivity between some islands, then such events occur extremely infrequently, and so successful long distance dispersal events are probably rare for most species. 
Even if an individual manages to successfully disperse to a new geographic area it may not contribute alleles to its new population. The presence of an established population can exclude new arrivals of conspecifics, or different species that occupy the same ecological niche. This theory of competitive exclusion is widely accepted when examining interspecies interactions, but is not as prevalent within the phylogeographic literature (Waters, 2011). Competitive exclusion may maintain genetic structure between populations despite ongoing dispersal as new immigrants are rare and vastly outnumbered by local recruits, and so they are unlikely to make a substantial genetic contribution to the local population (Waters, 2011). Recent anthropogenic extinction events provide evidence of competitive exclusion as species undergo rapid range expansions when closely related taxa are removed from the environment. Studies utilising ancient DNA have reported recent colonization events by new lineages of coastal fauna from the subantarctic to mainland New Zealand after mainland extinction events due to human harvesting (Boessenkool et al., 2009; Collins et al., 2014). Evidence suggests that such species have always had the capacity to disperse and colonise mainland New Zealand, but were previously thwarted by the presence of established populations of closely related species (Waters, 2011; Waters et al., 2013). These cases emphasise the importance of competitive exclusion where release from this constraint via the extinction of a congeneric or conspecific population allows species to expand their occupied range (Waters et al., 2013).

\section{4: New Zealand's Marine Environment and Genetic Connectivity}

New Zealand is an archipelago of over 700 islands, ranging from the subantarctic Auckland and Campbell islands to the subtropical Kermadec Islands, creating a region that stretches over $2700 \mathrm{~km}$ and $23^{\circ}$ of latitude (Ross et al., 2009). The oceanography of New Zealand is complex and variable with depth (Chiswell et al., 2015). The New Zealand archipelago encompasses the subtropical front, where subtropical water from the north meets subantarctic water from the south. Warm subtropical water from the Tasman Front travels from Australia to North Cape and down the eastern coast of the North Island in the form of the East Auckland and East Cape Currents. It then diverges eastward into the Pacific, creating the Wairarapa and Rekohu Eddies (Figure 1.3). In the southern Pacific Ocean the Southland Current travels up the south eastern coast of the South Island then is mostly diverted eastward by the Chatham Rise, whilst some continues on to mix with the waters of the Cook Strait. Subtropical and subantarctic waters meet and mix at the Subtropical Front, which circumvents the southern South Island before extending eastward along the Chatham Rise. In the Southern Ocean the main force of the Subantarctic Front skirts the southern edge of the Campbell Plateau then some flows northward to contribute cooler waters to the Subtropical Front. While other 
flows continue eastward as the Antarctic Circumpolar Current, which flows endlessly around Antarctic and constitutes a major oceanic barrier to dispersal (Thornhill et al., 2008). See Chiswell et al. 2015 for a recent review of New Zealand "blue-water" (off the continental shelf) oceanography, and Heath (1985) for an older, broader review that includes coastal associated New Zealand oceanography.

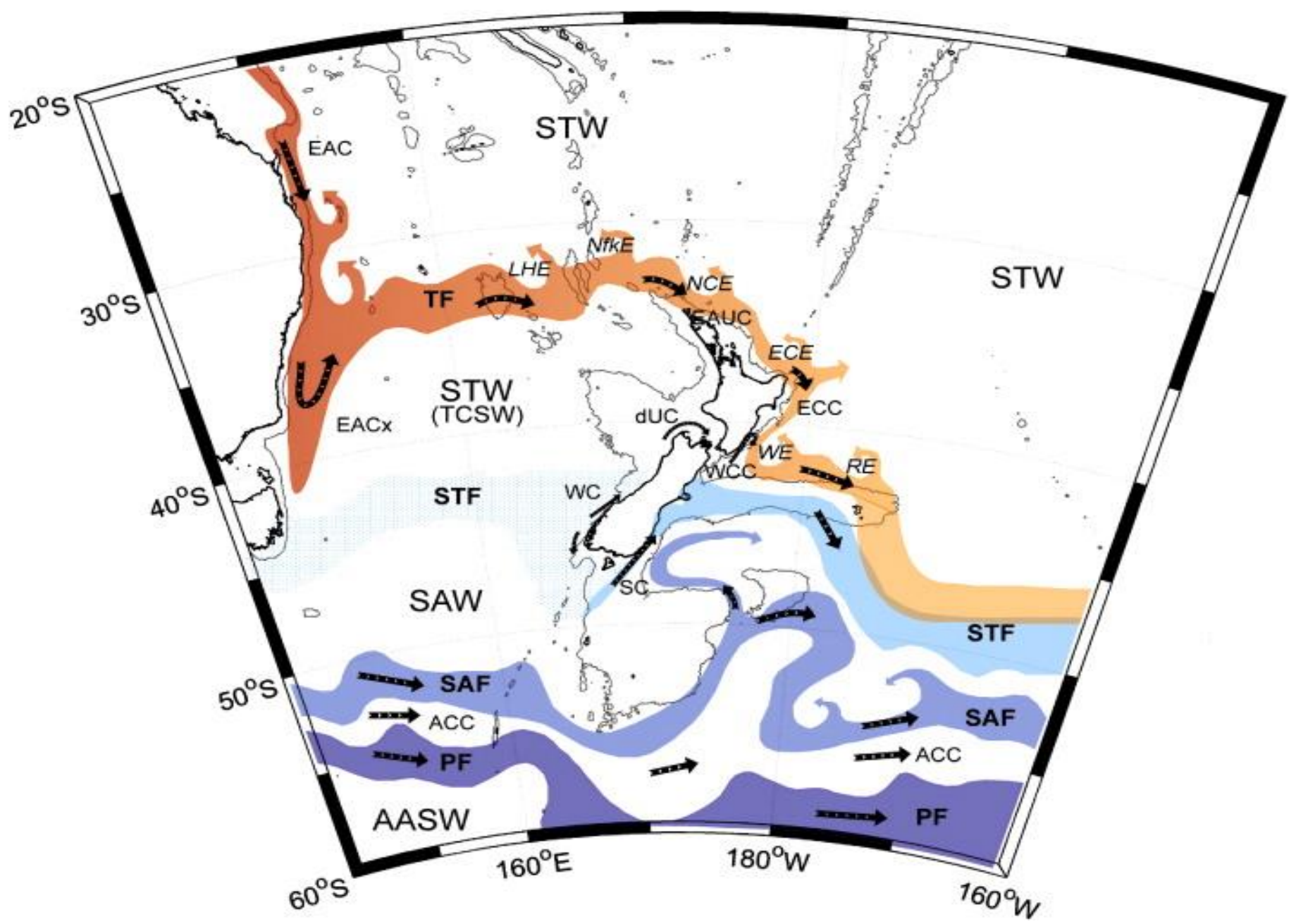

Figure 1.3: The major surface currents of New Zealand waters. These are represented by the coloured regions; colour also denotes temperature with the red colouration indicating warmer water whilst blue colours indicate cooler water. Water masses: Subtropical Water (STW), Tasman Sea Central Water (TSCW), Subantarctic Water (SAW) and Antarctic Surface Water (AASW). Ocean fronts: Tasman Front (TF), Subtropical Front (STF), Subantarctic Front (SAF) and Polar Front (PF). Ocean currents: East Australia Current (EAC), East Australia Current extension (EACx), East Auckland Current (EAUC), East Cape Current (ECC), d'Urville Current (dUC), Wairarapa Coastal Current (WCC), Westland Current (WC), Southland Current (SC) and Antarctic Circumpolar Current (ACC). Eddies: Lord Howe Eddy (LHE), Norfolk Eddy (NfkE), North Cape Eddy (NCE), East Cape Eddy (ECE), Wairarapa Eddy (WE) and Rekohu Eddy (RE). Figure retrieved from Chiswell et al. (2015). 
Reviews of the literature surrounding marine genetic population structure in New Zealand have reported that a pattern of north-south differentiation is common in a variety of marine taxa (Ross et al., 2009; Gardner et al., 2010). Genetic disjunctions are frequently reported near the Cook Strait, around the northern end of the South Island (Ross et al., 2009; Gardner et al., 2010; Hannan et al., 2016), but it is difficult to determine precisely where genetic disjunctions occur due to few and differing sampling sites between studies, and differing potential causes between species (Ross et al., 2009). Upwelling zones have been put forward as a possible barrier to dispersal for marine propagating species around this area (Apte \& Gardner, 2002; Waters \& Roy, 2004; Veale \& Lavery, 2011), and the common occurrence of genetic disjunction in this region among benthic invertebrates suggests that modern hydrology continues to influence population connectivity and maintains antiquated genetic subdivision (Veale \& Lavery, 2011). The Cook Strait is a variable oceanographic area that has only recently assumed its current features due to repeated changes in sea level during the Pleistocene (Lewis et al., 1994). It contains a complex system of oceanographic features including thermoclines and eddies (Heath, 1985), which may influence the recruitment of pelagic larvae and disrupt population connectivity.

Comparative multispecies studies can be used to try and identify consistent patterns of genetic population structure and biogeographic barriers within a geographic region. A study of three intertidal limpet species within the genus Cellana has reported a common pattern of genetic structure between North and South Island populations (Goldstien et al., 2006), and various patterns of population structure have been reported in populations of New Zealand's estuarine and sandy shore taxa (Paphies australis, P. subtriangulata, Pecten novaezelandiae, Rhombosolea plebeia, and R. leporina; Hannan et al., 2016). While it is possible to identify common biogeographic barriers and patterns of genetic structure, it is important to note the often species-specific nature of population structure. Different species can have disparate life-histories, prefer specific habitat, or respond differently to environmental change. The similar life-histories of the studied Cellana species may have led to similar patterns of genetic population structure, but these patterns are not identical. Species-specific ecological and demographic characteristics, or different responses to the same historic event, may produce different patterns of population structure (Goldstien et al., 2006). Habitat specificity, ocean currents, and philopatry have all been cited as possible explanations for the genetic structure observed by Hannan et al. (2016), depending on the species studied. Hannan et al. (2016) cover a wider range of taxa with different life-histories and dispersal potential, and these differences may explain the contrasting patterns of population structure observed. 


\section{5: Molecular Markers}

A variety of molecular methods have been developed to examine the genetic diversity within populations as well as the connectivity between them. Methods include (but are not limited to) measuring differentiation at the protein level (allozymes), examining different sized fragments of DNA on an electrophoretic gel, or by directly sequencing mitochondrial and/or nuclear DNA. Molecular markers can differ in their rate of mutation and mode of inheritance. Marker choice is important as different markers can produce different results. If populations of a species are actively managed, different results can lead to opposing management decisions. In populations of Perna canaliculus (greenshell mussel) no significant genetic differentiation was originally detected using allozyme markers (Apte \& Gardner, 2001). Contrastingly, further studies that utilised mitochondrial DNA single strand conformation polymorphism, restriction fragment length polymorphism, and nuclear randomly amplified polymorphic DNA markers all detected differing levels of significant genetic differentiation (Apte \& Gardner, 2002; Apte et al., 2003; Star et al., 2003). If no further research had been conducted after the initial findings of no genetic structure among populations of $P$. canaliculus then multiple populations may have been mismanaged as a singular population under this assumption, potentially leading to a loss of genetic diversity and/or local extinctions.

Microsatellites and DNA sequences (both mitochondrial and nuclear) have been the most widely used genetic markers for investigating the population structure of fisheries stocks (Cuellar-Pinzon $e t$ al., 2016). Mitochondrial DNA refers to DNA found within the mitochondria of eukaryotes. Separate from the majority of DNA found within the nucleus (nuclear DNA), a single copy of the mitochondrial genome is maternally inherited in most taxa and does not undergo the process of recombination. Maternal inheritance of mitochondrial DNA leads to a smaller effective population size for mitochondrial loci as the effective population size is roughly proportional to the number of females within the population (Birky et al., 1989). Therefore, genetic drift has a greater influence upon mitochondrial loci compared to nuclear loci. Maternal inheritance coupled with a lack of recombination also means that all regions of the mitochondrial genome are linked and represent a single locus (Avise, 1994). The mitochondrial genome often displays a higher mutation rate than nuclear DNA (Wilson et al., 1985), but mutation rates vary among genomic regions and taxa (Meyer, 1993; Papadopoulou et al., 2010; Bromham, 2011). Therefore, some areas of the mitochondrial or nuclear genome that are informative for population and taxonomic studies in one organism may be uninformative in another.

Cytochrome c oxidase subunit one (CO1) is a mitochondrial protein coding gene that is widely used within phylogenetic and population level genetic studies, and has been proposed as a barcoding 
gene in animals to identify different species (Hebert et al., 2003; Savolainen et al., 2005). Generally, to be informative for genetic population studies, molecular markers must be selectively neutral, have a known means of inheritance, and display intraspecific variation (Hellberg et al., 2002). Sanger sequencing of polymerase chain reaction (PCR) products offers a cheap, effective means for population level studies. Markers such as $\mathrm{CO} 1$ are often amplified using generic resources and protocols (e.g. Folmer et al., 1994) and can be easily applied to multiple taxa with little resource investment. Other molecular markers (e.g. microsatellites and single nucleotide polymorphisms) can provide greater statistical power by sampling multiple independent points on the genome, but can be expensive to develop or apply.

Microsatellites are short, non-coding, repeating sequences of DNA interspersed throughout the biparentally inherited nuclear genome. These regions often have a high mutation rate, where they gain or lose entire repeats due to a mutational process known as replication slippage (Bhargava \& Fuentes, 2010). Therefore, microsatellites can be used to genotype individuals by quantifying the number of repeats found in each individual. Microsatellites are widely used throughout the field of molecular ecology (Bhargava \& Fuentes, 2010), but are not always practical or available as they often need to be identified within individual species so that species-specific primers can be developed. Next generation sequencing technology (NGS) has simplified the identification of microsatellites (Gardner et al., 2011), and facilitated the characterisation of single nucleotide polymorphisms (SNPs) within non-model organisms (Seeb et al., 2011). Techniques such as Restriction site Associated DNA Sequencing (RAD-Seq) (Miller et al., 2007) and Genotyping-bySequencing (GBS) (Elshire et al., 2011) have been developed, and these techniques allow large numbers of SNPs to be sampled. Genomic data can be used to examine genetic diversity, connectivity, and the historical demography of populations in greater detail (Garrick et al., 2015). RAD-Seq has been used to resolve shallow genetic structure within populations of chinook salmon (Oncorhynchus tshawytscha) from western Alaska. Larson et al. (2014) detected similar levels of population structure as previous studies of the same populations that used allozymes and SNPs (Gharrett et al., 1987; Templin et al., 2011) but were able to accurately assign individuals to their region of origin. Increases in sequencing capability and computing power have also allowed researchers to forgo neutral genetic markers and examine the effects of selection on harvested species using genomic tools (Nielsen et al., 2009a; Nielsen et al., 2009b). 


\section{6: Study Species: New Zealand Scampi (Metanephrops challengeri)}

Metanephrops challengeri, also known as New Zealand Scampi, are part of the family Nephropidae, which comprises a number of commercially significant species including congeners and species from the genera Homarus, and Nephrops. Metanephrops species were originally placed within the genus Nephrops until Jenkins (1972) revised their taxonomy using morphological characters, erecting the genus Metanephrops. Metanephrops likely originated in the Antarctic region during the Cretaceous period, which was followed by dispersal and diversification along the continental shelf of various continents due to vicariant events associated with the breakup of Gondwana (Chan et al., 2009). M. challengeri are regarded as a basal extant species within the genus (Chan et al., 2009), and fossilised remains of extinct Metanephrops species within Antarctica have been found (Feldmann, 1989; Feldmann et al., 1993). M. challengeri have a widespread distribution throughout New Zealand, inhabiting muddy substrates on the continental shelf and slope at depths of 140-670 m (Yaldwyn \& Webber, 2011), in highest abundance between 200-500 m (Smith, 1999). These are targeted by a commercial, trawl-based fishery, with the primary fishery areas comprising east of the Coromandel Peninsula, the Bay of Plenty, the Wairarapa coastline, including off Cape Kidnappers, the Chatham Rise, and near the Auckland Islands (Ministry for Primary Industries, 2016).

Little biological information is presently available on the behaviour and ecology of wild $M$. challengeri. They exhibit a bipartite life cycle with a short pelagic larval stage that lasts for 3-5 days (Wear, 1976) before juveniles settle on the seafloor, living within burrows and maturing into adults. Emergence from these burrows determines their accessibility to trawl-based fisheries and is related to both tidal current and time of day (Tuck et al., 2015b). Metanephrops species have much lower fecundity than other nephropid lobsters; including the morphologically similar species Nephrops norvegicus which produces anywhere from 800 to 5000 eggs per individual (Farmer, 1974). Approximately 1500 eggs per individual are produced by Australian Metanephrops species (Wallner \& Phillips, 1990), a range of 400-1600 eggs have been found in the clutches of $M$. mozambicus (Robey \& Groeneveld, 2014), and an average of 400 eggs per individual has been reported for $M$. challengeri (Fenaughty, 1989). Egg loss during incubation was also reported in $M$. challengeri as eggs are lost from the pleopods during egg development, leading to individual variability in reproductive success. Incubation duration was dependant on water temperature and lasted for 123 days at $12.7{ }^{\circ} \mathrm{C}$ and 185 days at $10.3{ }^{\circ} \mathrm{C}$ (Fenaughty, 1989). M. challengeri likely spawn in the spring/summer months with larvae hatching in autumn/winter. M. challengeri offspring may take up to six years to recruit into the fishery (Ministry for Primary Industries, 2016), 
as they exhibit slow growth rates consistent with Australian Metanephrops species (Rainer, 1988; Wallner \& Phillips, 1990).

M. challengeri are thought to primarily prey upon invertebrates (Meynier et al., 2008), and are an important prey item for other fishery species such as Ling (Genypterus blacodes) (Dunn et al., 2009), with tags previously attached to M. challengeri found within the stomachs of captured individuals (e.g. Cryer \& Stotter, 1999). Fisheries targeting M. challengeri were first developed in the late 1980 s with restrictions placed upon each vessel that utilised the stocks. M. challengeri were then added to the QMS in 2004, which coincided with changes to their management areas on the Chatham Rise and within the subantarctic (Ministry for Primary Industries, 2016). Prior to this addition $M$. challengeri were managed using both competitive and individually allocated catch limits (Ministry for Primary Industries, 2016).

Only one study investigating the genetic diversity and differentiation of $M$. challengeri populations has been previously published. Smith (1999) utilised allozymes to detect genetic differentiation among populations, concluding that there is significant genetic heterogeneity among $M$. challengeri populations around New Zealand. Thirty-five loci were examined via gel electrophoresis with only five of these displaying electrophoretic variations among the four populations sampled (Auckland Island, Bay of Plenty, Chatham Rise, and Wairarapa). Significant heterogeneity was detected at three of these five loci (Smith, 1999). M. challengeri from the Auckland Islands were considered genetically distinct from all other sampled regions, with significant genetic differentiation also detected between the Bay of Plenty and Chatham Rise sampling sites (Smith, 1999). Genetic differentiation suggests that $M$. challengeri fisheries may consist of multiple reproductive groups.

Genetic differentiation among populations could be explained by the short duration of the pelagic larval life stage of $M$. challengeri (Smith, 1999). A short pelagic stage, coupled with the limited movement of adults places a limit upon the dispersal potential of M. challengeri; so the potential for genetic and demographic connectivity between geographically isolated populations is also limited. If gene flow is limited between populations each may differ in effective population size or contain evolutionarily significant genetic variation; prompting different management strategies to conserve genetic variation and maintain commercially viable populations. 


\section{7: Thesis Aims}

This thesis aims to investigate the genetic structure of $M$. challengeri populations throughout the New Zealand region by comparing DNA sequences from individuals of geographically differing locations. Chapter Two describes the sequencing of fragments of the mitochondrial cytochrome $\mathrm{c}$ oxidase subunit one (CO1) gene and the nuclear internal transcribed spacer region one (ITS-1) region of $M$. challengeri. DNA sequence data is then used to investigate the genetic diversity, structure, and demographic history of $M$. challengeri populations. Chapter Three provides a general discussion of the results of Chapter Two including their implications for the management of $M$. challengeri. 


\section{Chapter Two: The genetic population structure and demographic history of New Zealand Scampi (Metanephrops challengeri) inferred from mitochondrial and nuclear DNA sequences}

\section{1: Introduction}

A well-informed understanding of the patterns of population connectivity and genetic structure within a commercially exploited species is essential to their effective management (Palumbi, 2003; Palsboll et al., 2007; Allendorf et al., 2008). Sustainable harvesting being one of the primary goals of modern fisheries management. To avoid the overharvest of populations the locations, methods, and magnitude of fishing efforts need to be managed so that harvesting mortality is balanced by recruitment from reproduction and migration. Stock units are typically defined as independent populations or groups of conspecific individuals that are harvested within the same area or by the same technique. If the genetic structure among populations is ignored or overlooked, reductions in genetic diversity and/or local extinctions may occur (Laikre et al., 2005), decreasing the adaptive potential of the affected populations. However, identification of independent reproductive units and delineation of stock boundaries can be difficult. Some species only come together for short periods of time to form breeding groups, marine species can disperse over a wide range, particularly if they have a planktonic larval phase (Shanks et al., 2003), and it is difficult to determine what might be natural migration barriers in a marine environment. In particular, patterns of population connectivity in the deep-sea remain poorly understood (Hilário et al., 2015; Baco et al., 2016), most studies target coastal, shallow-water species because sampling of deep-sea organisms is often limited by inaccessibility (Bors et al., 2012). Populations of deep-sea species are generally considered to exhibit higher levels of connectivity than shallow-water populations because the deep-sea environment appears to lack biogeographic barriers to dispersal (Baco et al., 2016). DNA based methods are able to offer both direct and indirect estimates of connectivity among populations by either genetically identifying individuals in mark-recapture studies, or testing for localised evidence of inbreeding as a proxy for reproductive groups.

Dispersal potential at the larval stage has long been considered a key determinate of population connectivity and its duration is thought to negatively correlate with levels of genetic structure (Bohonak, 1999). However, a meta-analysis that compared pelagic larval duration (PLD) and levels of genetic differentiation showed that a correlation is not always present (Weersing \& Toonen, 2009). Other authors suggest that sampling design (Selkoe \& Toonen, 2011) and variability in the parameters used to calculate genetic differentiation (Faurby \& Barber, 2012) influence reported correlations between PLD and genetic differentiation. Furthermore, temperature changes can 
modify the duration of the larval stage by influencing the metabolism of pelagic larvae (O'Connor $e t$ al., 2007). Studying larval movement is often a difficult task because larvae are small and difficult to track (Levin, 2006; Cowen \& Sponaugle, 2009), and many larvae do not survive very long in the pelagic environment. Oceanic currents can aid dispersal by transporting pelagic larvae away from their natal location (Cowen et al., 2000), or enhance self-recruitment if larvae become trapped within complex eddies (Lobel \& Robinson, 1986), while changes in salinity or water temperature can restrict the distribution of marine organisms and form impassable physiological barriers to dispersing larvae. Individual species are likely to encounter different barriers to dispersal based upon their geographic distribution and life-history, so connectivity among populations should be considered separately for each species when formulating management plans.

Metanephrops challengeri (M. challengeri) is a member of the Nephropidae family of clawed lobsters. M. challengeri occupy the continental shelf of New Zealand and are harvested commercially. Seventeen extant Metanephrops species are currently recognised (Chan et al., 2009), and many are of economic importance as they support commercial fisheries. Metanephrops species primarily inhabit burrows at depths of 200-700 meters on the continental shelf and slope of Australasia, Asia, Africa, and both North and South America. Primary dispersal for M. challengeri occurs during the pelagic larval life-stage where larvae persist within the water column for approximately 3-5 days (Wear, 1976). Adults principally occupy burrows on the sea floor, and a mark recapture study of adult $M$. challengeri suggests that they do not traverse large distances over an annual period (Cryer \& Stotter, 1999). M. challengeri larvae undergo a pre-zoeal stage where larval development occurs within the egg capsule (Wear, 1976), leading to a short PLD. This short PLD might allow post-larval $M$. challengeri to remain within areas suitable for larval settlement, as they most likely require certain sediment types that are suited for burrow construction. A short PLD may also limit the dispersal potential of $M$. challengeri, and in turn limit demographic and genetic connectivity between geographically isolated populations. Larval behaviour has been shown to modify dispersal distance in other crustacean species (Butler et al., 2011), and may aid dispersal of M. challengeri as $M$. challengeri larvae orient themselves in the water column in a specific "head down" manner where they unfurl their limbs, as if to catch the current (R. Webber, pers. comm. 2017). M. challengeri larvae may be able to travel greater distances than assumed if this behaviour enables them to utilise underwater currents.

Early genetic population studies of the biologically similar species Nephrops norvegicus reported genetic homogeneity among Adriatic populations (Mantovani \& Scali, 1992), and between Scottish and Aegean populations (Passamonti et al., 1997). Limited to small sample sizes, Passamonti et al. (1997) could not attribute the observed homogeneity among populations to any particular cause. 
Maltagliati et al. (1998) studied populations from within the Mediterranean Sea (and a single population from the south of Portugal), detecting significant genetic variation but no clear geographic pattern of genetic differentiation. These results were then corroborated by Stamatis et al. (2004) and Stamatis et al. (2006). Microsatellites for N. norvegicus have been developed, originally by Streiff et al. (2001), who used them to compare two populations from the Portuguese coast and found no significant genetic difference between them. Further DNA microsatellites were developed by Skirnisdottir et al. (2010) and used to examine populations in Icelandic waters (Pampoulie et al., 2011). No significant genetic differentiation was detected, even with the inclusion of a sampling site from the coast of Scotland as an outgroup (Pampoulie et al., 2011). A possible explanation for the lack of genetic structure is that populations of $N$. norvegicus may have recently expanded after environmental changes, such as the last glacial maximum, so insufficient time has passed for populations to diverge and reach mutation/drift equilibrium (Stamatis et al., 2004, 2006; Pampoulie et al., 2011). Post-glacial population expansion has been proposed for a number of Nephropid taxa (see Kennington et al., 2013b) and is often attributed to an increase in available habitat as glaciers melted and sea levels rose. However, the genetic structuring of $N$. norvegicus populations fits an island model of structure (Stamatis et al., 2006), and ongoing gene flow between populations cannot be ruled out (Stamatis et al., 2006).

Analysis of mitochondrial DNA sequences from M. mozambicus (from south-eastern Africa) detected high levels of genetic diversity, evidence of a demographic expansion, and significant genetic structure among populations inhabiting the south western Indian Ocean (Zacarias, 2013). Strong eddies and currents within this region may influence the transport of pelagic larvae, leading to high levels of self-recruitment and population structure if larvae become trapped within eddies and are unable to cross these potential barriers (Zacarias, 2013). One study has investigated the genetic composition and structure of $M$. challengeri populations. Smith (1999) used allozymes to examine genetic diversity and population connectivity among $M$. challengeri populations along the eastern coast of the North Island of New Zealand (Wairarapa to Bay of Plenty), along with areas on the Chatham Rise, and off the Auckland Islands. Smith (1999) reported a significant genetic difference between the Auckland Islands population and all other sampled populations, along with a significant difference between the Bay of Plenty and Chatham Rise populations. However, allozymes do not allow for the direct examination of DNA sequences and may not be sensitive enough to detect genetic differentiation at finer scales (Schlotterer, 2004). Smith (1999) cited the short pelagic larval stage of $M$. challengeri as a possible explanation for the observed genetic differentiation, as individuals may be unable to disperse long distances and maintain regular gene flow among the populations studied. 
The aim of this study was to determine the demographic history, levels of genetic diversity, and gene flow among populations of $M$. challengeri from several regions of the New Zealand EEZ using DNA sequences from the mitochondrial CO1 gene and the nuclear ITS-1 region. Samples were obtained from five sites off the eastern coast of mainland New Zealand, and one site near the subantarctic Auckland Islands.

\section{2: Methods}

\subsection{1: Sample Collection}

Samples were collected in areas off the coasts of Bay of Plenty, Cape Kidnappers and Wairarapa using a trawl net on the RV Kaharoa during a National Institute of Water and Atmospheric Research (NIWA) scampi survey conducted in February 2015, and those from an area near the Auckland Islands during a separate NIWA scampi survey in March-April 2016. Samples from areas on the Chatham Rise were obtained from commercial fishing vessels and were caught in September 2014. Provided sample localities are approximate due to the low density of scampi and amalgamation of several trawled samples from within a small area.

NIWA survey tows used a $25 \mathrm{~m}$ wide net with $80 \mathrm{~mm}$ wide mesh; trawls were conducted at various depths ranging from 300-500 m. Once $M$. challengeri were captured, specimens were frozen to -20 ${ }^{\circ} \mathrm{C}$ in individual bags as soon as possible to prevent degradation. Specimens were transferred to freezers at the NIWA facility at Greta Point, Wellington for temporary storage before being transferred to the laboratory at Victoria University of Wellington. Frozen samples from fishing vessels were delivered directly to the laboratory at Victoria University of Wellington. The samples were thawed and a section of muscle tissue was excised from the tail, transferred into 80\% Ethanol and stored at $4{ }^{\circ} \mathrm{C}$. 


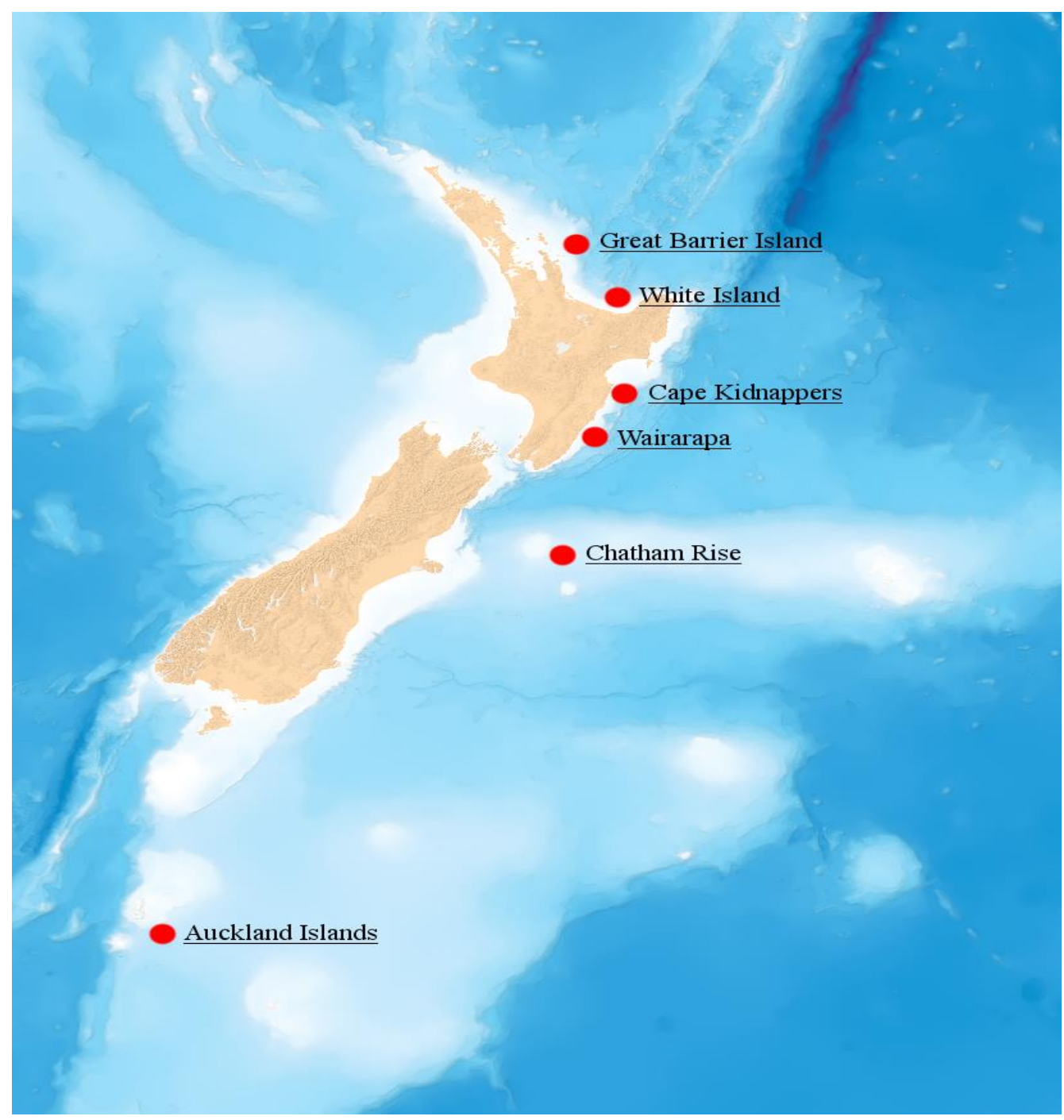

Figure 2.1: Bathymetric map of New Zealand illustrating sampling sites. Cooler colours indicate greater bathymetry

\subsection{2: DNA Extraction, Polymerase Chain Reaction, and DNA Sequencing}

DNA was extracted using a standard phenol-chloroform extraction method (Sambrook et al., 1989). A subsample of tissue was placed in $400 \mu \mathrm{l}$ of extraction buffer $(10 \mathrm{mM}$ TrisHCl pH $8.0,50 \mathrm{mM}$ $\mathrm{NaCl}, 10 \mathrm{mM}$ EDTA, and 0.2\% Sodium Dodecyl Sulphate) along with 10-20 $\mu 1$ of Proteinase-K and incubated at $56{ }^{\circ} \mathrm{C}$ for 1-2 hours to lyse cells and digest tissue. After tissue digestion, DNA was extracted and purified using separate washes of Phenol, Phenol:Chloroform:Isoamyl-Alcohol (25:24:1), and Chloroform:Isoamyl-Alcohol (24:1). Samples were gently rocked for 30 mins and centrifuged at $13,000 \mathrm{rpm}$ during each wash step to remove proteins and fats from the aqueous solution. Following DNA purification, DNA was precipitated by adding $900 \mu 1$ of chilled $99 \%$ Ethanol and $40 \mu \mathrm{l}$ of $3 \mathrm{M}$ Sodium Acetate $(\mathrm{pH} 5.2)$, and left overnight at $-20{ }^{\circ} \mathrm{C}$. DNA was then pelleted by centrifugation at $4{ }^{\circ} \mathrm{C}$ for $30 \mathrm{~min}$. The supernatant was removed and the pellet washed with $70 \%$ chilled Ethanol before centrifugation at $4{ }^{\circ} \mathrm{C}$ for another $10 \mathrm{~min}$. The supernatant was 
removed again and the pellets dried using a vacuum concentrator. Once dry, extracts were resuspended with a Tris-EDTA buffer (10 mM TrisHCL pH 8.0, $1 \mathrm{mM}$ EDTA) and stored at $4{ }^{\circ} \mathrm{C}$. The purified DNA was quantified using a Nanodrop ND1000 spectrophotometer (Thermo Fisher Scientific) and diluted to $50 \mathrm{ng} / \mu \mathrm{L}$.

A 710 base pair (b.p.) fragment of CO1 was amplified using the Polymerase Chain Reaction (PCR) and primers developed for the amplification of mitochondrial DNA from a range of invertebrate phyla, LCO1490 (5'-GGTCAACAAATCATAAAGATATTGG-3') and HCO2198 (5'TAAACTTCAGGGTGACCAAAAAATCA-3') (Folmer et al., 1994). Amplification of the ITS region used primers specifically designed for Crustacea; SP-1-3' (5' ATTTAGCTGCGGTCTTCATC-3') and SP-1-5'138 (5'-CACACCGCCCGTCGCTACTA-3') (Chu et al., 2001). Each PCR contained $1 \mu 1$ of genomic DNA diluted to 50ng/ $\mu \mathrm{L}, 1 x$ PCR Buffer (67 mM Tris- $\mathrm{HCl}, 16 \mathrm{mM}\left(\mathrm{NH}_{4}\right)_{2} \mathrm{SO}_{4}, 0.1 \%$ stabilizer), $3 \mathrm{mM} \mathrm{MgCl} 2,0.06 \mathrm{mM}$ Bovine Serum Albumin, 0.1 $\mu \mathrm{M}$ of each DNA primer (LCO1490 and HCO2198, or SP-1-3' and SP-1-5'138), 0.4 $\mathrm{mM}$ deoxyribonucleotide triphosphate mix (dNTPs), and 1 unit of Biotaq DNA Polymerase (Bioline Reagents Ltd).

Thermal cycling was carried out on a Biometra TProfessional Thermocycler (Göttingen, Germany) and the temperature profile of each target gene differs slightly. The thermal cycle for CO1 is as follows: an initial denaturation step of 3 minutes at $95{ }^{\circ} \mathrm{C}$, then 40 cycles of $95{ }^{\circ} \mathrm{C}$ for 35 seconds, $50{ }^{\circ} \mathrm{C}$ for 35 seconds, and $72{ }^{\circ} \mathrm{C}$ for 45 seconds, followed by a final extension step of $72{ }^{\circ} \mathrm{C}$ for 10 minutes. While the thermal cycle for ITS consisted of: an initial denaturation step of 3 minutes at 95 ${ }^{\circ} \mathrm{C}$, then 40 cycles of $95^{\circ} \mathrm{C}$ for 35 seconds, $55^{\circ} \mathrm{C}$ for 35 seconds, and 60 seconds at $72{ }^{\circ} \mathrm{C}$, followed by $72{ }^{\circ} \mathrm{C}$ for 10 minutes. All batches of PCRs included an additional tube containing reaction mix without any sample to control for the possibility of contamination in the reagents or in the master mix. The resultant PCRs were electrophoresed in a $1.5 \%$ agarose gel stained with ethidium bromide, and visualised using a UV light. PCRs that produced an amplicon of the correct size were purified using ExoSAP-IT (Amersham Parmacia Biotech) following the instructions of the manufacturer. The DNA sequence of each PCR product was determined using a 3730xl Genetic Analyzer (Applied Biosystems) at Macrogen Inc. (Seoul, Korea). The resulting DNA sequences were checked, edited, and aligned using Geneious (Version 8.0.5) (Kearse et al., 2012). 


\subsection{3: Statistical Analyses}

\section{Genetic Diversity and Population Structure}

Estimates of diversity were calculated using both DnaSP (Version 5.10) (Librado \& Rozas, 2009) and Arlequin (Version 3.5.2.2) (Excoffier \& Lischer, 2010). These summary statistics included the number of segregating sites (S), the frequency of transition (Ts) and transversion (Tv) mutations, nucleotide diversity $(\pi)$, haplotype diversity $\left(\mathrm{H}_{\mathrm{D}}\right)$, and the average number of nucleotide differences between sequences $(\mathrm{k})$. A rarefaction analysis (generated by Analytic Rarefaction 1.3 (http://strata.uga.edu/software/index.html., Holland, 2003) was used to approximate the proportion of the total haplotype diversity that was detected by the present sampling.

Population structure was assessed using a Bayesian Analysis of Population Structure (BAPS) (Version 6.0), with the implementation of the linked loci clustering model (Corander \& Tang, 2007) and multiple upper bounds to the number of populations $(\mathrm{k})$. Whole number $\mathrm{k}$ values were set from $2-10$ with each tested 5 times, to determine the most likely number of populations for both the CO1 and ITS-1 datasets. An admixture analysis based on mixture clustering was then performed on the resulting structure analysis for the ITS-1 sequence data using a $\mathrm{k}$ value of 5 , with 5000 iterations, 200 reference individuals from each population, and 50 iterations for each reference individual. PopART (http://popart.otago.ac.nz/) was used to generate a median joining network (Bandelt et al., 1999), to enable the relationships between (and frequency of) haplotypes to be visualised. Each population was assigned a specific colour so the sample location of haplotypes could be seen on the network.

Pairwise $\phi_{\text {ST }}$ values and AMOVAs (analysis of molecular variance) were calculated within Arlequin. Each analysis was bootstrapped with 10,000 permutations and a Bonferroni correction applied to pairwise $\phi_{S T}$ estimates to reduce the chance of type one errors. AMOVAs were used to test support for different scenarios of population structure through the a priori assignment of DNA sequences from different sampling sites into groups. AMOVAs use a hierarchical analysis of variance to partition the total variance into covariance components, which include the variance within all individuals $\left(\phi_{\mathrm{ST}}\right)$, variance within a predefined group $\left(\phi_{\mathrm{SC}}\right)$, and variance between predefined groups $\left(\phi_{\mathrm{CT}}\right)($ Excoffier \& Lischer, 2011).

Three scenarios of population structure were constructed and tested using an AMOVA. 1.) DNA sequences from different sampling sites were placed into two groups, one consisting of the Auckland Islands site, the other comprising all other sites. This grouping was chosen based upon the results of the BAPS analysis and haplotype network. 2.) Sampling sites were placed into three groups, one comprising the four North Island sites, the second group comprising only the Chatham 
Rise site location and the third, the Auckland Islands site. 3.) Sampling sites were placed into two groups, one comprising all sites north of $42{ }^{\circ} \mathrm{S}$ the other comprising the Chatham Rise and Auckland Islands sites. This is based on previously published reports of genetic disjunctions in marine invertebrates around this latitude (e.g.Waters \& Roy, 2004; Ayers \& Waters, 2005; Goldstien et al., 2006; Veale \& Lavery, 2011).

The Isolation By Distance Web Service (http://ibdws.sdsu.edu/ ibdws/) (Jensen et al., 2005) was used to test for a correlation between genetic differentiation and geographic distance (Isolation-byDistance). A Mantel's test with 1000 randomisations was used on the regression analysis to assess statistical significance. Geographic distances $(\mathrm{km})$ between sampling locations were estimated using Google Earth version 7.1 using the shortest distance through water. Genetic distances were

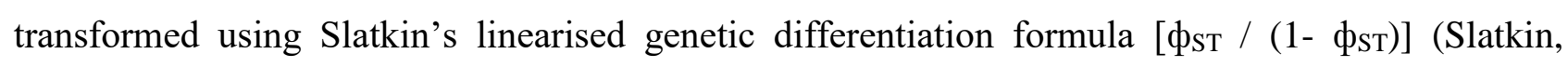
1995), following Rousset (1997) who suggested using Slatkin's linearised distance and geographic distance for one-dimensional habitats, and log geographic distance in two dimensional habitats. A one-dimensional habitat was defined as habitat where the distance between sampled populations is greater than the length of the habitat. Conversely, two-dimensional habitats were defined as those where the distance between sampled habitats is less than the width of the habitat (Rousset, 1997). Habitat within this study was defined as one-dimensional due to the large latitudinal range sampled. Another regression analysis was conducted that did not include the Auckland Islands site; this was done to determine whether the relatively high geographic and genetic distances from other locations strongly influenced the previous analyses. The number of migrants exchanged between populations per generation was calculated using the formula: $[\mathrm{M}=(1-\phi s t) /(2 \times \phi s t)]$ (Excoffier et al., 2005).

\section{Demographic History}

Multiple approaches were used to examine the demographic history of $M$. challengeri. These include measures of Tajima's D (Tajima, 1989), and Fu's F statistic (Fu, 1997), mismatch distributions of pairwise DNA sequence comparisons, along with Harpending's raggedness index, the sum of squared deviations (SSD), and Bayesian skyline plots. Tajima's D and Fu's F-statistic were calculated in Arlequin and bootstrapped with 10000 permutations. Tajima's D was deemed to be statistically significant at p-values of $<0.05$, and Fu's F-statistic was deemed to be statistically significant at p-values of $<0.02$ as per $\mathrm{Fu}(1997)$.

Mismatch distributions and Harpending's raggedness statistic (Harpending et al., 1993) were calculated for each separate population, and the entire dataset using DnaSP, while SSD, tau $(\tau), \Theta_{0}$, and $\Theta_{1}$ were calculated in Arlequin using 10000 replications under the sudden expansion model. The statistical significance of Harpending's raggedness statistic was assessed using 1000 coalescent 
simulations implemented within DnaSP. A significant value for Harpending's raggedness statistic leads to the rejection of the null hypothesis of population expansion, with a raggedness statistic of less than 0.03 considered smooth. Mismatch distributions plot the frequency of each amount of pairwise difference between DNA sequences, a multi-modal graph is indicative of a population that has maintained a constant size for a long period of time. Mutations have had time to arise, and a range of divergent haplotypes persist in the population. A population that has recently experienced a demographic expansion will have a smooth, unimodal distribution.

The parameters tau $(\tau), \theta_{0}$ and $\theta_{1}$ were used to estimate changes in effective population size. The number of generations since population expansion can be calculated using the formula:

$$
t=\frac{\tau}{2 \mu}
$$

Where $\mu$ is the mutation rate of the sequence (not the mutation rate of each individual nucleotide), this can be measured using the formula $\mu=2 \mu k$ where $\mu$ is the mutation rate per nucleotide site, and $k$ is the number of analysed base pair nucleotides. As the mutation rate for M. challengeri is unknown, a mutation rate estimated from other decapod Crustacea was used. Zacarias (2013) used a mutation rate of $2 \%$ sequence divergence per million years for $M$. mozambicus. Considering this, a mutation rate of $1 \%$ sequence divergence per million years was used for the CO1 dataset as divergence rates are twice the substitution rate. If a divergence rate is used the number of generations since population expansion will be half of the actual value (Schenekar \& Weiss, 2011). The number of generations since population expansion $(\tau)$ was converted into years by multiplying $t$ by three as this is the estimated number of years it takes for M. challengeri to reach sexual maturity (Ministry for Primary Industries, 2016).

A Bayesian skyline plot analysis was conducted in BEAST (Version 1.8.2) (Drummond et al., 2012) using Monte Carlo Markov Chains to estimate the effective population size of M. challengeri through time. Two separate analyses were run. One containing the Auckland Islands sequence data, and another containing all other DNA sequences, to meet the assumption of no population structure. A strict clock model was used with a mutation rate of $2 \times 10^{-7}$ substitutions/site/year for the CO1 dataset, along with the nucleotide substitution model of Tamura and Nei (1993) with invariant sites and different substitution rates for each base $(\mathrm{TN} 93+\mathrm{I}+\mathrm{G})$. This model was the best fit for the dataset (from the available models in BEAST) based on Bayesian information criterion (Schwarz, 1978) implemented in jModelTest (Version 2.1.1) (Darriba et al., 2012). A total of $50^{6}$ iterations were analysed and the first $5^{6}$ of these were discarded as the burn-in time. The resulting trace file was viewed in Tracer (Version 1.5) (Rambaut \& Drummond, 2007). The effective sample sizes of priors and posterior probabilities were all more than 100. Bayesian skyline plots and estimates of 
demographic expansion time were not calculated for the ITS-1 dataset, as a reliable estimate of mutation rate for this region could not be found.

\section{3: Results}

\subsection{1: Mitochondrial DNA Cytochrome C Oxidase Subunit 1 (CO1) Sequences}

Genetic Diversity \& Population Structure

A 710 b.p. fragment of the CO1 gene was successfully amplified, subsequently edited and trimmed to 623 b.p., and aligned using Geneious (8.0.5) (Kearse et al., 2012). This alignment of 321 sequences contained 107 different haplotypes and 79 variable sites, of which 39 were parsimony informative, and 40 were singleton sites. All populations contained private haplotypes, with the Auckland Island and Wairarapa sampling sites containing the most $\left(\mathrm{H}_{\mathrm{P}}=21\right.$ for both sites $)$. All sampling sites (except for the Auckland Islands) had similar levels of nucleotide diversity $(\pi=$ 0.00541-0.00724) (Table 2.1), and all populations exhibited similar levels of haplotype diversity $\left(H_{D}=0.839-0.922\right)$. The Wairarapa population contained the largest number of haplotypes $\left(H_{N}=\right.$ 32). The Great Barrier Island population had both the highest level of nucleotide diversity and average number of nucleotide substitutions $(\pi=0.00724, \mathrm{k}=4.479)$. The Auckland Islands population consisted almost entirely of private haplotypes $\left(\mathrm{H}_{\mathrm{N}}=22, \mathrm{H}_{\mathrm{P}}=21\right)$, and displayed lower levels of nucleotide diversity $(\pi=0.00345)$, as well as a lower number of nucleotide substitutions ( $\mathrm{k}$ $=2.136$ ) (Table 2.1). The rarefaction curve generated by the haplotype frequency data did not reach an asymptote, suggesting that greater sampling effort would yield more haplotypes (Figure 2.2)

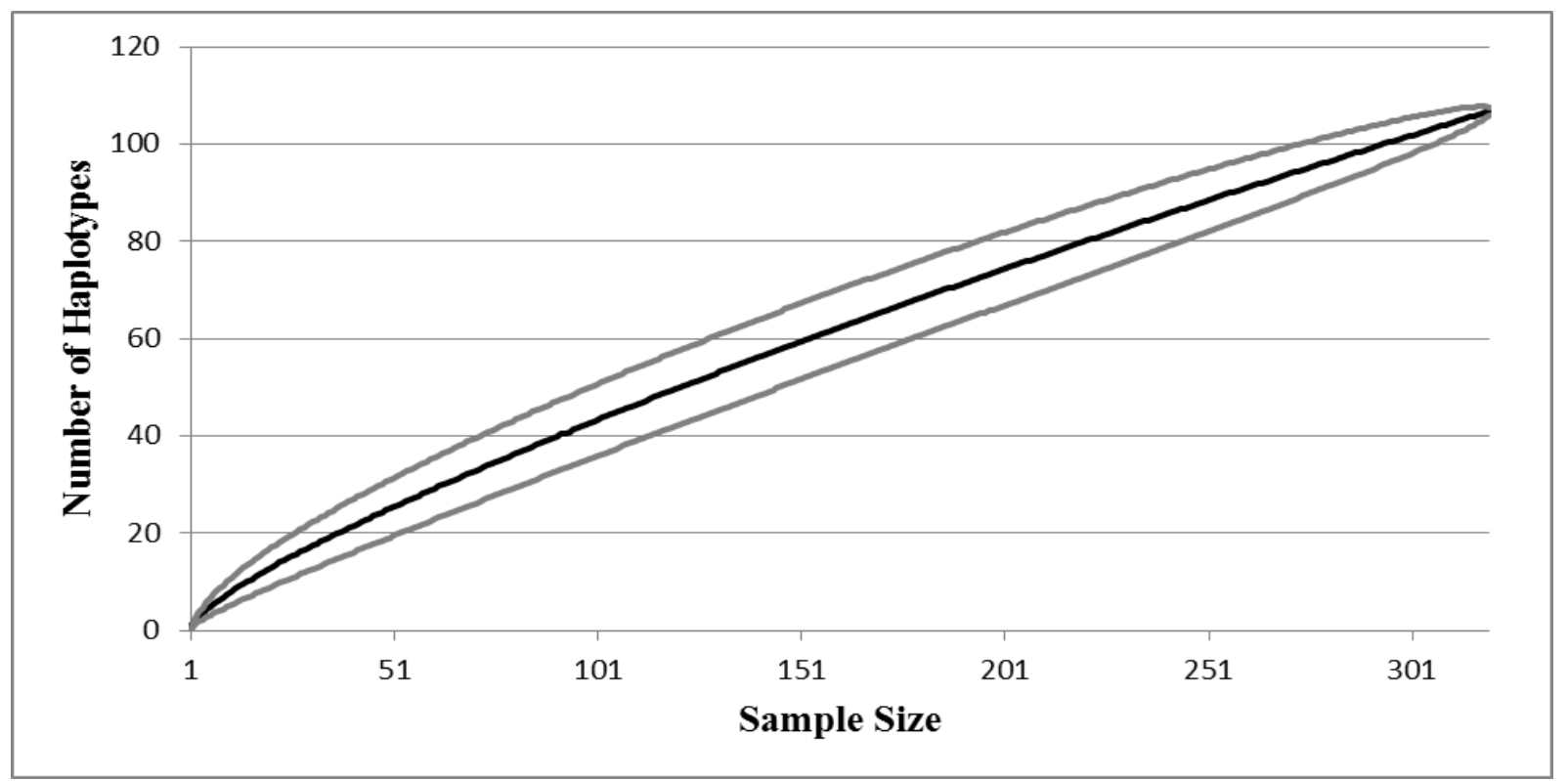

Figure 2.2: Rarefaction Curve of CO1 haplotype frequency. The solid black line represents the number of unique haplotypes discovered vs. the number of individuals sampled; while the grey lines represent the upper and lower confidence intervals for this value. 


\begin{tabular}{|c|c|c|c|c|c|c|c|c|c|c|}
\hline Sample Site & Lat, Long & $\mathrm{n}$ & $S$ & Ts & $\mathrm{Tv}$ & $\mathrm{H}_{\mathrm{N}}$ & $\mathrm{H}_{\mathrm{P}}$ & $\mathrm{H}_{\mathrm{D}}$ & $\pi$ & $\mathrm{k}$ \\
\hline Great Barrier Island & $\begin{array}{l}36^{\circ} 20^{\prime} \mathrm{S}, \\
176^{\circ} 12^{\prime} \mathrm{E}\end{array}$ & 63 & 41 & 29 & 12 & 25 & 16 & 0.882 & 0.00724 & 4.479 \\
\hline White Island & $\begin{array}{l}37^{\circ} 36^{\prime} \mathrm{S}, \\
177^{\circ} 10^{\prime} \mathrm{E}\end{array}$ & 48 & 30 & 24 & 7 & 24 & 15 & 0.922 & 0.00629 & 3.889 \\
\hline Cape Kidnappers & $\begin{array}{l}39^{\circ} 52^{\prime} \mathrm{S}, \\
177^{\circ} 20^{\prime} \mathrm{E}\end{array}$ & 63 & 23 & 17 & 7 & 19 & 9 & 0.839 & 0.00541 & 3.348 \\
\hline Wairarapa & $\begin{array}{l}40^{\circ} 53^{\prime} \mathrm{S}, \\
176^{\circ} 39^{\prime} \mathrm{E}\end{array}$ & 55 & 30 & 19 & 11 & 32 & 21 & 0.919 & 0.00680 & 4.215 \\
\hline Chatham Rise & $\begin{array}{l}43^{\circ} 24^{\prime} \mathrm{S}, \\
176^{\circ} 03^{\prime} \mathrm{E}\end{array}$ & 46 & 24 & 18 & 6 & 21 & 10 & 0.850 & 0.00581 & 3.603 \\
\hline Auckland Islands & $\begin{array}{l}51^{\circ} 12^{\prime} \mathrm{S}, \\
166^{\circ} 41^{\prime} \mathrm{E}\end{array}$ & 46 & 20 & 14 & 7 & 22 & 21 & 0.885 & 0.00345 & 2.136 \\
\hline All Sites & & 321 & 79 & 55 & 27 & 107 & 92 & 0.914 & 0.00810 & 5.004 \\
\hline
\end{tabular}

Table 2.1: Sampling information, summary statistics, and estimates of genetic diversity for 321 partial M. challengeri CO1 sequences. Key: $n=$ Sample Size, $S=$ Segregating Sites, $T_{S}=$ Transitions, $T_{V}=$ Transversions, $H_{N}=$ Number of Haplotypes, $H_{P}=$ Number of Private Haplotypes, $H_{D}=$ Haplotype Diversity, $\pi=$ Nucleotide Diversity, $k=$ Average Number of Nucleotide Substitutions.

The results from the BAPS showed that the data is best arranged into five populations among the six sites sampled. The Auckland Islands samples clustered together within a single group, with some individuals from the Cape Kidnappers and White Island sites also clustering within this group (Figure 2.3), while the haplotypes from other populations were mixed between sampling sites. The White Island samples contained a single individual from a unique population while all others were shared among sampling sites. The median joining haplotype network also recovered the same population structure from the dataset. All samples from the Auckland Islands belonged to a single median joining haplogroup, along with some individuals from the Cape Kidnappers and Great Barrier Island sites (Figure 2.4). This Auckland Islands haplogroup is separated from other haplogroups by at least 5 mutational steps. The network exhibited four expanded starburst-like haplogroups; this shape is indicative of a recent demographic expansion as most haplotypes are separated by only a small number of mutations. All other major haplogroups contained individuals from every population except the Auckland Islands (Figure 2.4), in accordance with the Bayesian analysis of population structure. 


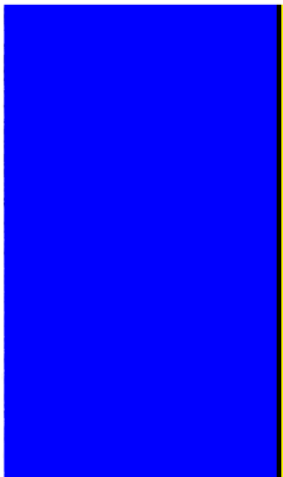

Auckland Islands

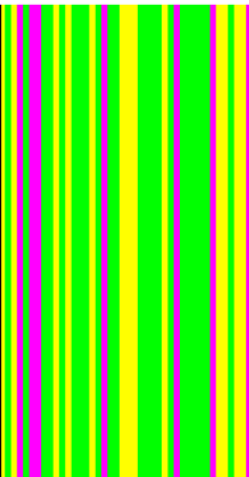

Chatham Rise

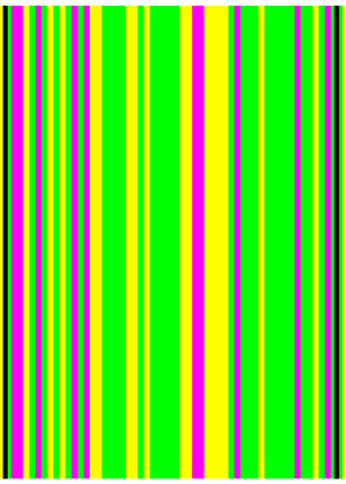

Wairarapa

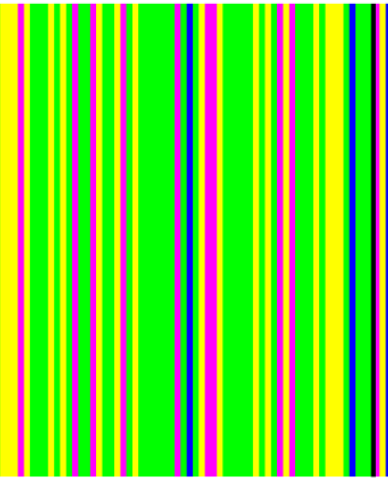

Cape Kidnappers

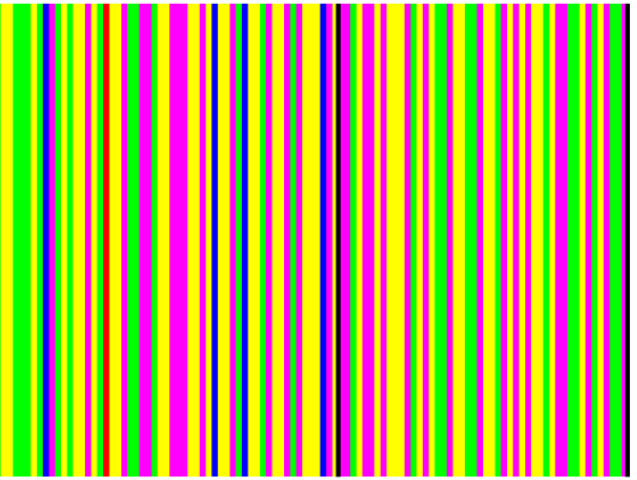

Great Barrier Island

White Island

Figure 2.3: Linked loci clustering of 321 partial M. challengeri CO1 sequences using Bayesian Analysis of Population Structure (BAPS). Individuals are assigned to a population based upon their genetic sequence, with each colour representing a different population.

AMOVA analyses failed to detect a statistically significant difference between groups $\left(\phi_{\mathrm{CT}}\right)$ in all tested scenarios $(\mathrm{p}=0.13129-0.32337)$ (Table 2.2). However, statistically significant differences were detected within sites $(\phi \mathrm{sT})(\mathrm{p}=<0.00000)$ and within predefined groups $(\phi \mathrm{sc})(\mathrm{p}=<0.000)$ for all sample groupings. Most genetic variation within the dataset could be explained by the variance between sites (88.18-94.67\%), with small amounts explainable by the differences within and between groups.

Pairwise $\phi_{\text {ST }}$ values show statistically significant genetic differentiation between individuals from the Auckland Islands sampling site and all other sampling sites (Table 2.3). Individuals from the Chatham Rise are the most genetically distinct from the Auckland Islands site $\left(\phi_{\mathrm{ST}}=0.14058, \mathrm{p}=\right.$ $<0.0000$ ), with all other sampling sites exhibiting similar pairwise $\phi$ st values when compared to the Auckland Islands $\left(\phi_{\mathrm{ST}}=0.09644-0.1385\right)$. Small, yet statistically significant pairwise $\phi \mathrm{ST}$ values were obtained when comparing sampling sites within the Bay of Plenty (Great Barrier Island and White Island) to those along the south eastern coast of the North Island, and the Chatham Rise. But the majority of these were rendered statistically insignificant after Bonferroni correction. Similar $\phi$ ST values are displayed by the comparisons that remain statistically significant, with the highest $\phi$ st value occurring between the Great Barrier Island and Cape Kidnappers sampling sites $(\phi s \mathrm{~s}=$ $0.03878, p=0.00149)$. 


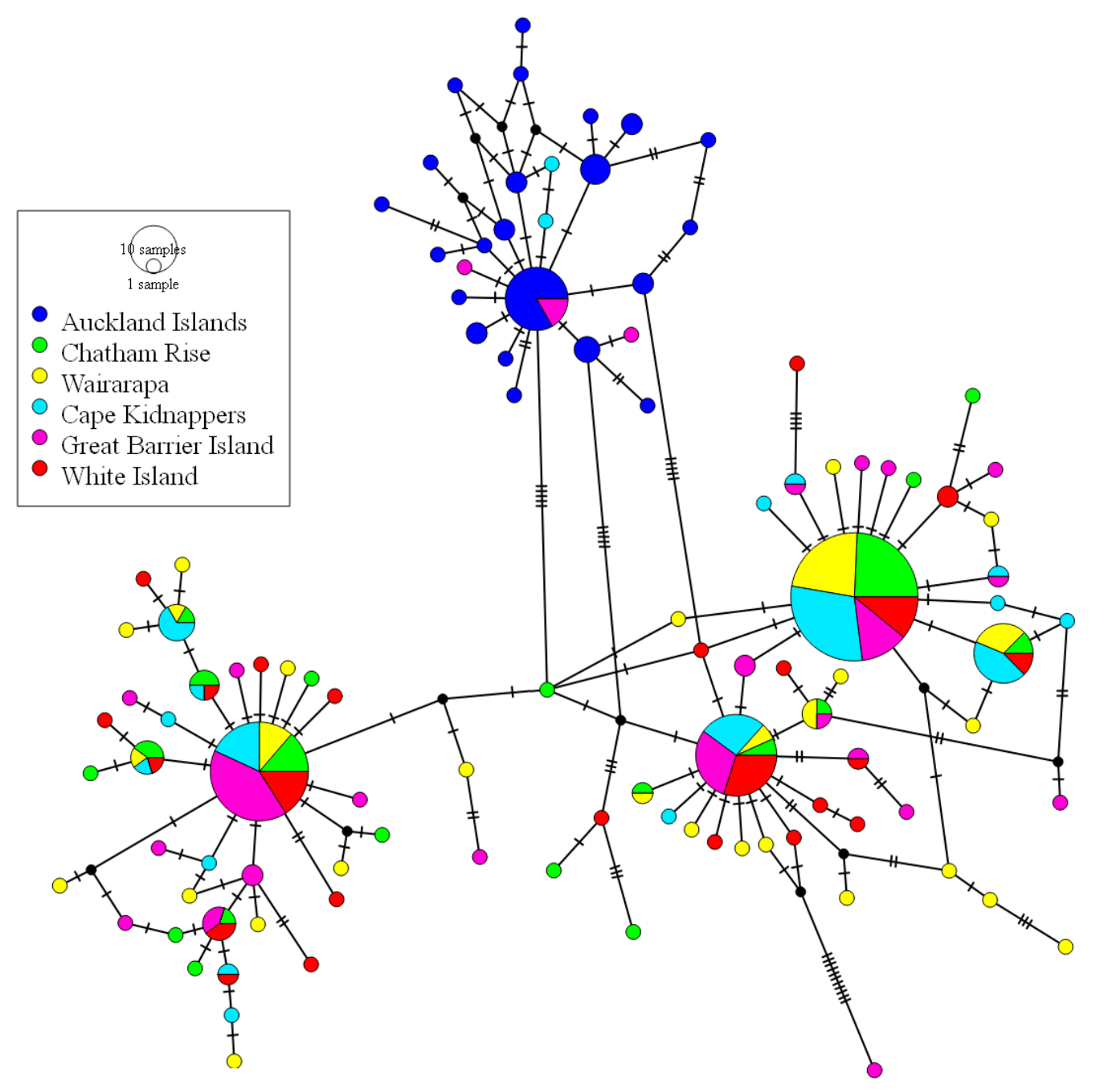

Figure 2.4: Median Joining Haplotype Network of 321 partial M. challengeri CO1 sequences. Each circle represents an individual haplotype. Larger circles mean that more individuals share that haplotype, with different colours representing different sampling sites. Mutations between haplotypes are represented by hatch marks, and hypothetical haplotypes are represented by small black circles.

Mantel tests using Slatkin's linearised distance and geographic distance show a strong positive correlation between genetic and geographic distance (Figure 2.5) $(\mathrm{R}=0.81-0.87)$. Interestingly, this correlation increased upon the removal of the Auckland Islands samples from the dataset (Figure 2.5B) $(\mathrm{R}=0.8724)$ and was deemed to be statistically significant $(\mathrm{p}=0.01)$. In contrast, when all CO1 data was included a slightly weaker, non-statistically significant correlation was detected $(\mathrm{R}=$ $0.81, \mathrm{p}=0.052$, Figure 2.5A). Large correlation coefficients indicate that geographic distance is capable of explaining approximately $80 \%$ of the variation in genetic distance between sampling sites. 
Figure 2.5: Pairwise comparisons of Slatkin's linearised genetic distance derived from partial CO1 sequences plotted against geographic distance $(\mathrm{km})$. A) All sampling sites considered. B) Auckland Islands sampling site removed. The correlation coefficient (R) and p-value (obtained via Mantel test) are displayed
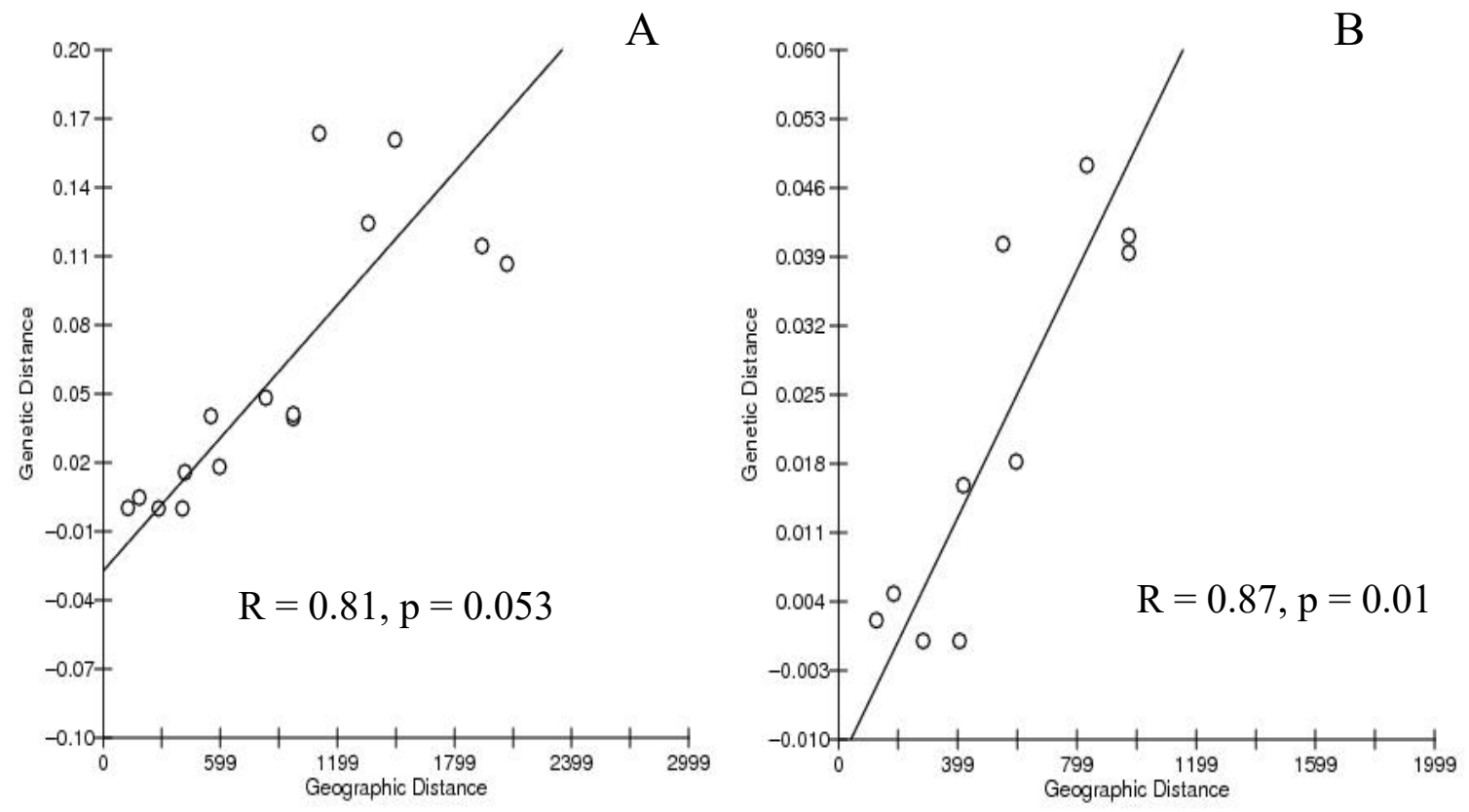


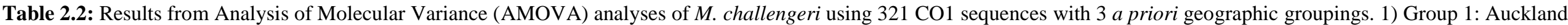

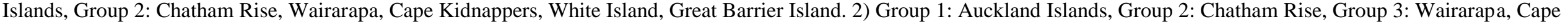

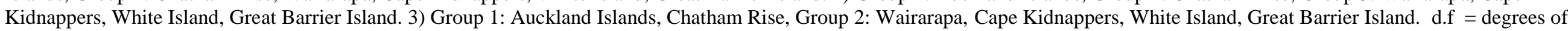
freedom, $\mathrm{Var}=$ variance component, $\% \mathrm{Var}=$ variance component in percentage of total variation .

\begin{tabular}{|c|c|c|c|c|c|c|c|c|c|c|c|c|c|c|c|}
\hline \multirow[t]{2}{*}{ Groups } & \multicolumn{5}{|c|}{ Among Groups } & \multicolumn{5}{|c|}{ Among Populations Within Groups } & \multicolumn{5}{|c|}{ Within Populations } \\
\hline & d.f & Var & $\% \operatorname{Var}$ & $\phi \mathrm{CT}$ & P-Value & d.f & Var & $\% \operatorname{Var}$ & $\phi \mathrm{sC}$ & P-Value & d.f & Var & $\% \operatorname{Var}$ & $\phi \mathrm{sT}$ & P-Value \\
\hline AI, GBI-CR & 1 & 0.0502 & 10.12 & 0.1012 & 0.16901 & 4 & 0.00847 & 1.71 & 0.01899 & 0.00069 & 315 & 0.43751 & 88.18 & 0.11824 & $<0.00000$ \\
\hline AI, CR, GBI-W & 2 & 0.02622 & 5.55 & 0.05545 & 0.13129 & 3 & 0.00910 & 1.93 & 0.02038 & 0.00069 & 315 & 0.43751 & 92.53 & 0.07470 & $<0.00000$ \\
\hline $\mathrm{AI}+\mathrm{CR}, \mathrm{GBI}-\mathrm{W}$ & 1 & 0.00260 & 0.56 & 0.00563 & 0.32337 & 4 & 0.02203 & 4.77 & 0.04795 & $<0.00000$ & 315 & 0.43751 & 94.67 & 0.05331 & $<0.00000$ \\
\hline
\end{tabular}

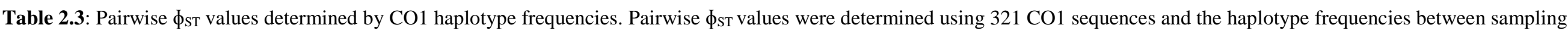

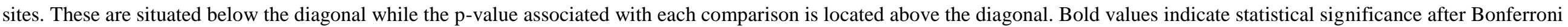
correction.

\begin{tabular}{ccccccc}
\hline & $\begin{array}{c}\text { Auckland } \\
\text { Islands }\end{array}$ & $\begin{array}{c}\text { Chatham } \\
\text { Rise }\end{array}$ & Wairarapa & $\begin{array}{c}\text { Cape } \\
\text { Kidnappers }\end{array}$ & White Island & $\begin{array}{c}\text { Great Barrier } \\
\text { Island }\end{array}$ \\
\hline Auckland Islands & - & $<\mathbf{0 . 0 0 0 0}$ & $<\mathbf{0 . 0 0 0 0}$ & $<\mathbf{0 . 0 0 0 0}$ & $<\mathbf{0 . 0 0 0 0}$ & $<\mathbf{0 . 0 0 0 0}$ \\
Chatham Rise & 0.14058 & - & 0.70003 & 0.55994 & 0.01940 & $\mathbf{0 . 0 0 1 5 8}$ \\
Wairarapa & 0.11063 & 0.0000 & - & 0.51866 & 0.02861 & 0.00554 \\
Cape Kidnappers & 0.13850 & 0.0000 & 0.00208 & - & 0.06009 & $\mathbf{0 . 0 0 1 4 9}$ \\
White Island & 0.10273 & 0.04614 & 0.01786 & 0.01514 & - & 0.21127 \\
Great Barrier Island & 0.09644 & 0.03791 & 0.03946 & 0.03878 & 0.00480 & - \\
\hline
\end{tabular}


The number of migrants per generation between populations was also estimated to assess levels of connectivity between populations (Table 2.4). The number of migrants exchanged per generation between sampling sites is related to the pairwise $\phi_{\text {sT }}$ value between them. Some values could not be calculated as the pairwise $\phi_{\mathrm{ST}}$ value between some populations was zero. Meaning that there was no significant genetic difference between them and enough migrants are exchanged each generation to connect the populations and homogenise genetic variation. The number of migrants exchanged per generation between the Auckland Islands sampling site and other sampling sites ranges from three to five breeding individuals when calculated using pairwise $\phi_{\mathrm{s} T}$ values derived from $\mathrm{CO} 1 \mathrm{data}$. This level of migration is not enough to genetically (or demographically), connect the Auckland Islands site to the other sites sampled. Typically, the highest numbers of migrants are exchanged between sampling sites that are the shortest geographic distance apart. In this study it was found that high levels of migrants have been exchanged between the Wairarapa and Cape Kidnappers sampling sites, and the Great Barrier Island and White Island sampling sites. These sampling sites are separated by the least geographic distance, conforming to expectations that migrant exchange is greatest when sampling sites are closer together.

\begin{tabular}{|c|c|c|c|c|c|c|}
\hline & $\begin{array}{l}\text { Auckland } \\
\text { Islands }\end{array}$ & $\begin{array}{c}\text { Chatham } \\
\text { Rise }\end{array}$ & Wairarapa & $\begin{array}{c}\text { Cape } \\
\text { Kidnappers }\end{array}$ & $\begin{array}{l}\text { White } \\
\text { Island }\end{array}$ & $\begin{array}{c}\text { Great } \\
\text { Barrier } \\
\text { Island } \\
\end{array}$ \\
\hline $\begin{array}{l}\text { Auckland } \\
\text { Islands }\end{array}$ & - & & & & & \\
\hline $\begin{array}{l}\text { Chatham } \\
\text { Rise }\end{array}$ & 3.06 & - & & & & \\
\hline Wairarapa & 4.02 & - & - & & & \\
\hline $\begin{array}{c}\text { Cape } \\
\text { Kidnappers }\end{array}$ & 3.11 & - & 239.88 & - & & \\
\hline $\begin{array}{l}\text { White } \\
\text { Island }\end{array}$ & 4.37 & 10.34 & 27.50 & 32.53 & - & \\
\hline $\begin{array}{c}\text { Great } \\
\text { Barrier } \\
\text { Island }\end{array}$ & 4.68 & 12.69 & 12.17 & 12.39 & 103.67 & - \\
\hline
\end{tabular}

Table 2.4: Estimated number of migrants exchanged per generation between sampling sites according to CO1 data. Some values could not be calculated as the pairwise $\phi_{\mathrm{ST}}$ values between sampling sites was 0 . 


\section{Demographic History}

All neutrality tests returned negative values, but not all of these were statistically significant (Table 2.5). Fu's F-statistic was statistically significant when each sampled site was analysed separately, and when all sampling sites were combined. Tajima's D was statistically significant when considering all sampling sites and when the Great Barrier Island, White Island, and Auckland Islands sampling sites were considered separately. A negative value from a neutrality test can be caused by the population experiencing a bout of purifying selection, or an expansion of population size.

Mismatch distributions and Harpending's raggedness statistic results are consistent with the results returned by the neutrality tests and suggest that $M$. challengeri have potentially undergone a recent demographic expansion as some sampling sites display genetic signatures of this event (Table 2.5). A histogram plot of the differences among pairwise comparisons of CO1 sequences had a multimodal distribution and a significant amount of raggedness within that distribution $(r=0.0124$, $\mathrm{p}=0.042)$ along with the Wairarapa $(\mathrm{r}=0.0082, \mathrm{p}=0.001)$, Cape Kidnappers $(\mathrm{r}=0.0199, \mathrm{p}=$ 0.035), and White Island $(r=0.0162, \mathrm{p}=0.03)$ sampling sites. However, the Auckland Islands $(\mathrm{r}=$ 0.0411, $\mathrm{p}=0.099)$, and Chatham Rise ( $\mathrm{r}=0.0253, \mathrm{p}=0.099)$, sampling sites exhibit a unimodal distribution and non-significant amount of raggedness within the distribution (Table 2.5), which is consistent with a scenario of recent population expansion. The data from the Great Barrier Islands sampling site had a multimodal distribution and statistically non-significant amount of raggedness $(\mathrm{r}=0.0529, \mathrm{p}=0.533$. All SSD values were low and statistically non-significant (Table 2.5).

Bayesian Skyline plots were then generated to investigate changes to the effective population size through time. These plots enable the genetic consequences of demographic changes to be visualised. Bayesian skyline plots report an increase in effective population size approximately 10,000 years before present (Figure 2.6B) for all populations apart from the Auckland Islands. While the Auckland Islands population appears approximately 6000 years ago and maintains a stable population size through to the present (Figure 2.6A). Estimations of demographic expansion parameters $\left(\tau, \theta_{0}\right.$, and $\left.\theta_{1}\right)$ were used to estimate the time since demographic expansion in $M$. challengeri. Estimates of the time since demographic expansion ranged from 217 - 831 kya (Table 2.5). Most of the sampled sites display similar estimates of time since population expansion and there was a general consensus that a population expansion occurred approximately $600 \mathrm{kya}$. But the Auckland Islands sampling site does not follow this trend, and it has a much more recent population expansion estimated to have occurred 200 kya. 

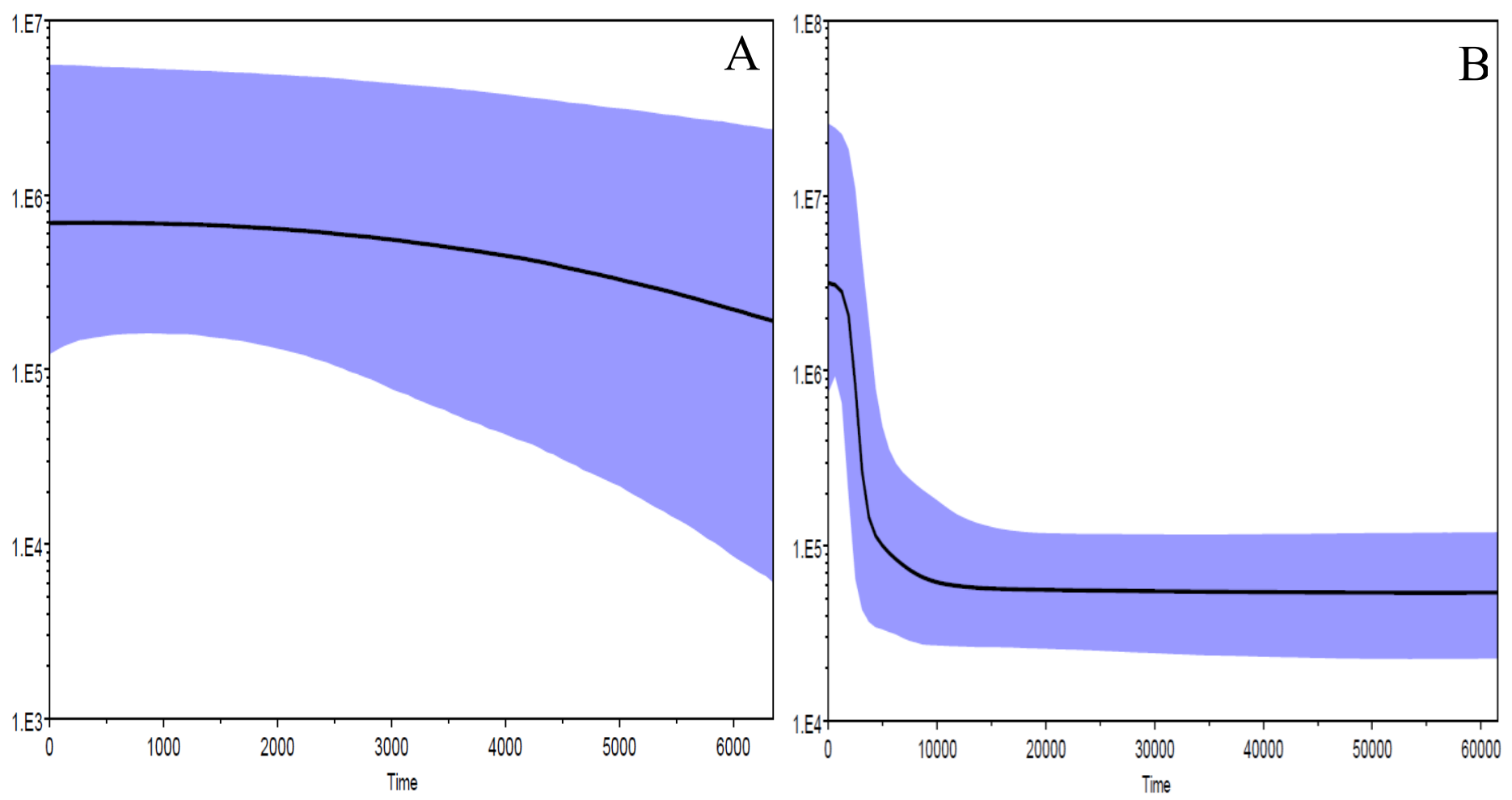

Figure 2.6: Bayesian Skyline Plots generated using CO1 sequences illustrating estimated effective population size (y-axis) through time. A) Estimates of effective population size for the Auckland Islands sampling site. B) Estimates of effective population size for the Chatham Rise, Wairarapa, Cape Kidnappers, White Island, \& Great Barrier Island sampling sites combined. 


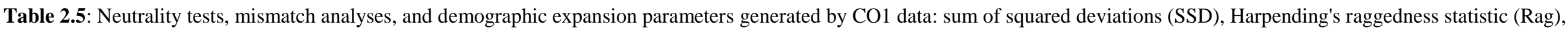

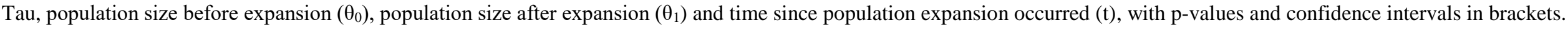

\begin{tabular}{|c|c|c|c|c|c|c|c|c|}
\hline $\begin{array}{l}\text { Sampling } \\
\text { Site }\end{array}$ & $\begin{array}{l}\text { Tajima's D (p- } \\
\text { value) }\end{array}$ & $\begin{array}{l}\text { Fu's F-statistic } \\
\quad \text { (p-value) }\end{array}$ & $\mathrm{SSD}$ (p-value) & $\operatorname{Rag}(p-$ value $)$ & $\operatorname{Tau}(95 \% \mathrm{CI})$ & $\Theta_{0}(95 \% \mathrm{CI})$ & $\Theta_{1}(95 \% \mathrm{CI})$ & $\begin{array}{c}\text { Population } \\
\text { Expansion } \\
\text { Timing (Years } \\
\text { before present) }\end{array}$ \\
\hline $\begin{array}{l}\text { Great } \\
\text { Barrier } \\
\text { Island }\end{array}$ & $-1.604(0.027)$ & $-9.819(0.004)$ & $0.015(0.328)$ & $0.053(0.533)$ & $5.7(1.58-11.98)$ & $0.005(0.0-3.18)$ & $9.463(3.02-296.03)$ & 686,195 \\
\hline $\begin{array}{l}\text { White } \\
\text { Island }\end{array}$ & $-1.421(0.058)$ & $-13.123(<0.000)$ & $0.004(0.588)$ & $0.0162(0.03)$ & $4.8(1.70-8.54)$ & $0.000(0.0-3.54)$ & $14.609(5.63-558.35)$ & 577,849 \\
\hline $\begin{array}{c}\text { Cape } \\
\text { Kidnappers }\end{array}$ & $-0.984(0.168)$ & $-6.145(0.017)$ & $0.007(0.802)$ & $0.020(0.035)$ & $5.4(1.13-30.24)$ & $0.000(0.0-5.03)$ & $5.313(1.25-270.94)$ & 650,080 \\
\hline Wairarapa & $-1.212(0.102)$ & $-19.343(<0.000)$ & $0.003(0.849)$ & $0.008(0.001)$ & $5.2(1.53-10.99)$ & $0.012(0.0-3.34)$ & $10.142(4.74-468.27)$ & 626,003 \\
\hline $\begin{array}{l}\text { Chatham } \\
\text { Rise }\end{array}$ & $-1.05(0.148)$ & $-8.775(0.001)$ & $0.013(0.473)$ & $0.032(0.099)$ & $5.3(1.25-11.16)$ & $0.000(0.0-4.62)$ & $7.773(2.47-384.64)$ & 638,041 \\
\hline $\begin{array}{l}\text { Auckland } \\
\text { Islands }\end{array}$ & $-1.715(0.022)$ & $-18.649(<0.000)$ & $0.002(0.228)$ & $0.041(0.099)$ & $1.8(1.00-5.352)$ & $0.338(0.0-1.23)$ & $3442.499(3.96-599.39)$ & 216,693 \\
\hline All Data & $-1.766(0.007)$ & $-24.952(<0.000)$ & $0.003(0.816)$ & $0.012(0.042)$ & $6.9(1.72-12.81)$ & $0.06(0.0-3.23)$ & $10.579(4.09-133.39)$ & 830,658 \\
\hline
\end{tabular}




\subsection{2: Internal Transcribed Spacer Region One}

\section{Genetic Diversity \& Population Structure}

The dataset from the ITS-1 region represented fewer samples compared to the CO1 dataset. Technical difficulties were encountered when attempting to determine the DNA sequence of ITS-1 because of the number of repetitive sequences within this region. However, the size of the dataset was sufficient for determining whether the nuclear DNA had a similar pattern of diversity across the sampled distribution as was found for the mitochondrial DNA dataset. ITS sequences were trimmed to a length of 600 b.p., then edited and aligned using Geneious. The ITS-1 alignment contained 75 variable sites, including 72 insertions or deletions, 34 parsimony informative sites, and 41 singleton sites. Estimates of haplotype diversity, nucleotide diversity, and average number of nucleotide substitutions varied greatly between sampling sites (Table 2.6), which might have been caused by the variation in sample size among sites. The White Island and Auckland Islands sampling sites contained the highest levels of genetic diversity. They displayed similar estimates for both haplotype and nucleotide diversity, along with a number of private DNA-sequence types (Table 2.6). The other sampling sites contain lower levels of genetic diversity, but some of these (Wairarapa, Cape Kidnappers) also have smaller sample sizes. The rarefaction curve comparing haplotype frequency and sampling effort did not asymptote, suggesting that greater sampling effort is required to detect most of the genetic diversity at the ITS-1 locus (Figure 2.7).

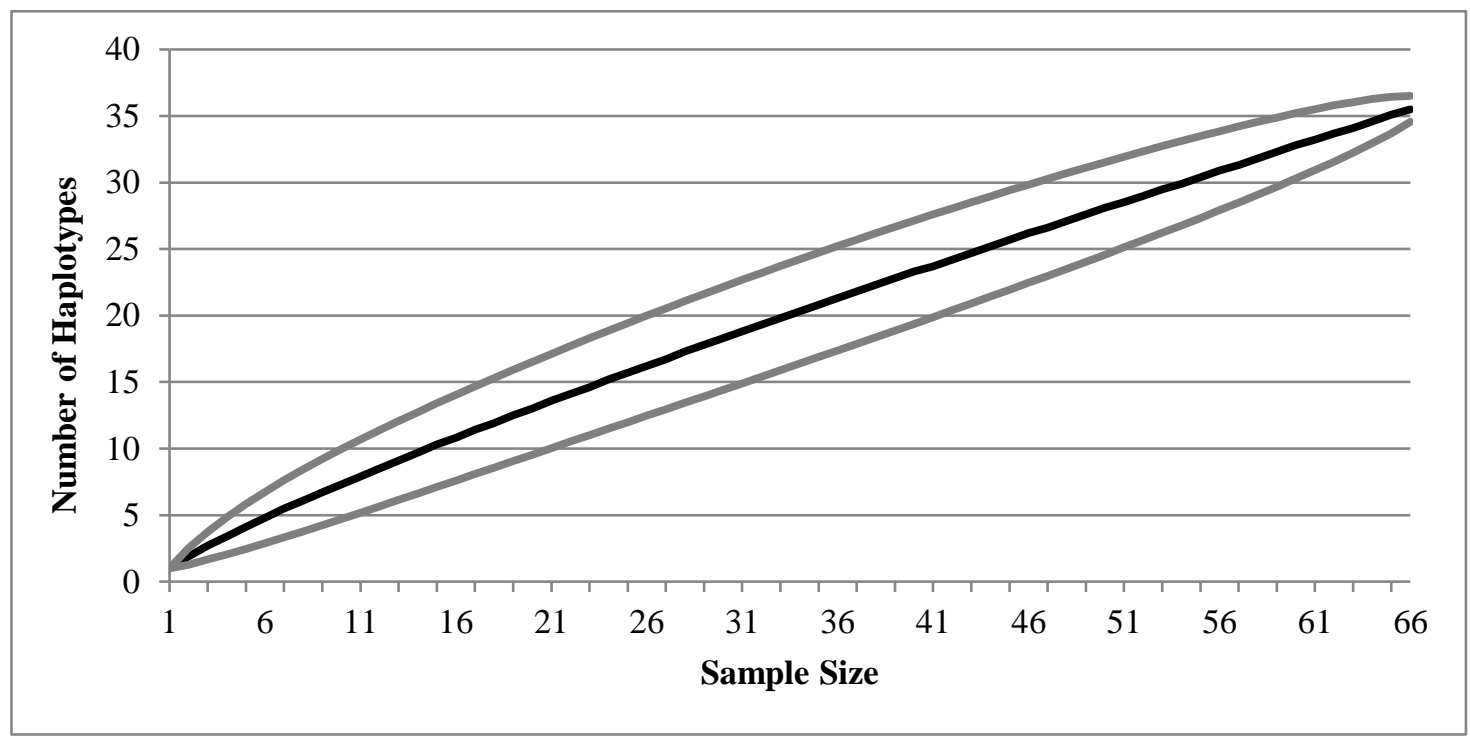

Figure 2.7: Rarefaction Curve for ITS-1 DNA-sequence-type frequency. The solid black line represents the number of different DNA sequences discovered vs. the number of individuals sampled; while the grey lines represent the upper and lower confidence intervals for this value. 
Table 2.6: Sampling information, summary statistics, and estimates of genetic diversity for 67 partial ITS-1 sequences from $M$. challengeri. Key: $\mathrm{n}=$ Sample Size, $\mathrm{S}=$ Segregating Sites, TS $=$ Transitions, $\mathrm{TV}=$ Transversions, $\mathrm{D}_{\mathrm{N}}=\mathrm{Number}$ of DNA-sequence-types, $D_{P}=$ Number of Private DNA-sequence-types, $D_{D}=$ DNA-sequence Diversity, $\pi=$ Nucleotide Diversity, $\mathrm{k}=$ Average Number of Nucleotide Substitutions.

\begin{tabular}{|c|c|c|c|c|c|c|c|c|c|c|}
\hline Sample Site & Lat, Long & $\mathrm{n}$ & $S$ & Ts & $\mathrm{TV}$ & $\mathrm{D}_{\mathrm{N}}$ & $\mathrm{DP}_{\mathrm{P}}$ & $\mathrm{D}_{\mathrm{D}}$ & $\pi$ & $\mathrm{k}$ \\
\hline $\begin{array}{l}\text { Great Barrier } \\
\text { Island }\end{array}$ & $\begin{array}{l}36^{\circ} 20^{\prime} \mathrm{S}, \\
176^{\circ} 12^{\prime} \mathrm{E}\end{array}$ & 10 & 2 & 1 & 1 & 2 & 1 & 0.200 & 0.00071 & 0.400 \\
\hline White Island & $\begin{array}{l}37^{\circ} 36^{\prime} \mathrm{S}, \\
177^{\circ} 10^{\prime} \mathrm{E}\end{array}$ & 18 & 39 & 23 & 19 & 10 & 9 & 0.810 & 0.01409 & 7.680 \\
\hline Cape Kidnappers & $\begin{array}{l}39^{\circ} 52^{\prime} \mathrm{S} \\
177^{\circ} 20^{\prime} \mathrm{E}\end{array}$ & 6 & 1 & 0 & 1 & 2 & 1 & 0.333 & 0.00059 & 0.333 \\
\hline Wairarapa & $\begin{array}{l}40^{\circ} 53^{\prime} \mathrm{S}, \\
176^{\circ} 39^{\prime} \mathrm{E}\end{array}$ & 8 & 13 & 6 & 7 & 4 & 3 & 0.643 & 0.00578 & 3.250 \\
\hline Chatham Rise & $\begin{array}{l}43^{\circ} 24^{\prime} \mathrm{S} \\
176^{\circ} 03^{\prime} \mathrm{E}\end{array}$ & 12 & 7 & 4 & 5 & 5 & 4 & 0.576 & 0.00235 & 1.318 \\
\hline Auckland Islands & $\begin{array}{l}51^{\circ} 12^{\prime} \mathrm{S}, \\
166^{\circ} 41^{\prime} \mathrm{E}\end{array}$ & 13 & 42 & 15 & 31 & 7 & 6 & 0.731 & 0.01447 & 8.077 \\
\hline All Sites & & 67 & 75 & 42 & 49 & 25 & 24 & 0.610 & 0.00765 & 4.195 \\
\hline
\end{tabular}

BAPS clustered the sampled individuals into three populations. Most of the sampled individuals belonged to one of the population clusters, but some individuals from the Auckland Islands constituted a second, separate population, while a number of individuals from White Island were assigned to the third putative population (Figure 2.9A). The admixture analysis suggested that there was mixing between populations. An individual assigned to a BAPS cluster that only contained Auckland Islands individuals, was also partially assigned to a cluster containing samples from all of the sampled sites (Figure 2.9B), but the cluster assignment of all other samples remained unchanged. A median joining haplotype network revealed that there was a sequence-type found at all of the sampled sites, and it was the sequences-type that was found in most individuals (Figure 2.8). The Auckland Islands and White Island sites contained a number of highly divergent and private DNA-sequence-types. These were separated from other DNA-sequence-types by at least, five mutations, while the other sites contain private sequence-types that are more closely related to the most common DNA-sequence-type. 


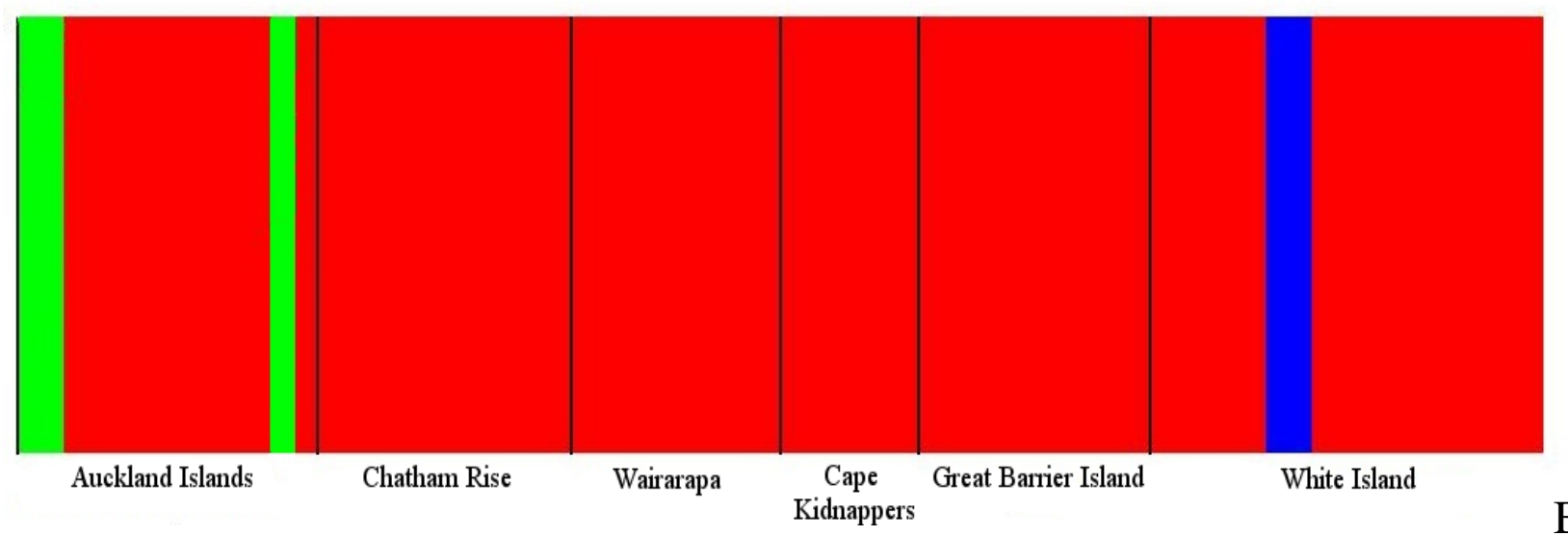

B

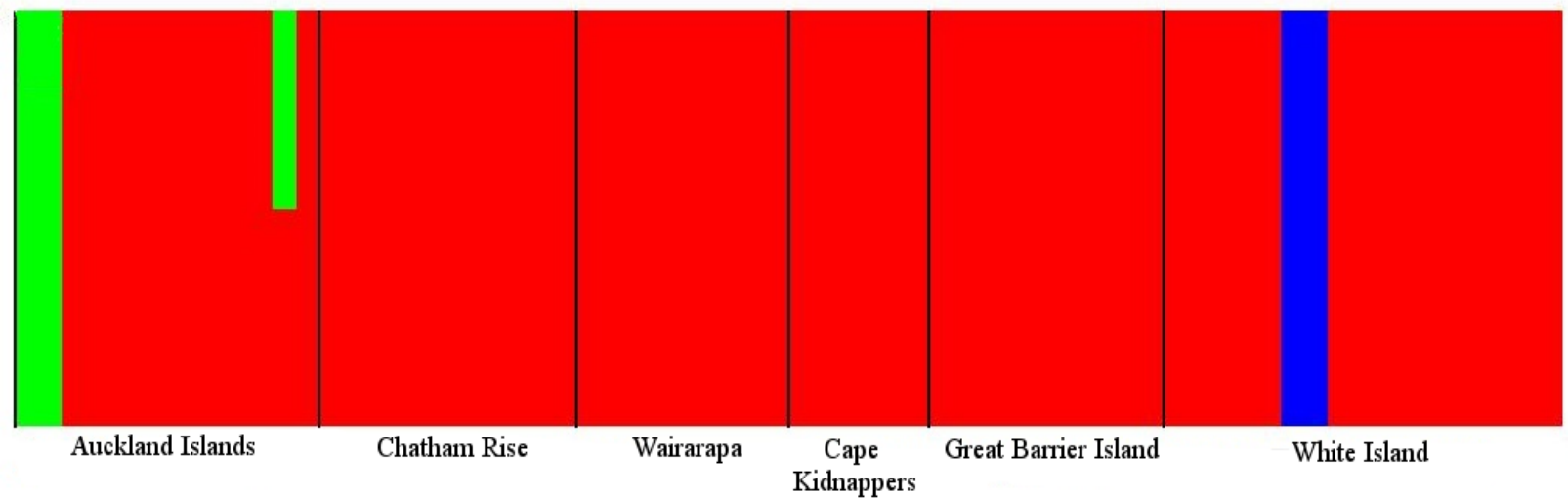

Figure 2.8: A) Linked loci clustering of 67 partial ITS-1 sequences from $M$. challengeri using a Bayesian Analysis of Population Structure (BAPS). B) Admixture analysis based on mixed clustering of the original clustering analysis. Individuals are assigned to a population based upon their genetic sequence. Each colour represents a different population.

Pairwise $\phi_{\mathrm{ST}}$ values indicated significant genetic differentiation between the Auckland Islands site and the group of sites associated with the eastern coast of the North Island (Table 2.7), although the majority of the individual pairwise $\phi$ st comparisons of sites were not statistically significant. No statistically significant difference was detected between the Chatham Rise and Auckland Islands sites. The Chatham Rise is significantly different from the Great Barrier Island site. The largest statistically significant difference was between the Auckland Islands and Great Barrier Island sampling sites $(\phi \mathrm{sT}=0.26469, \mathrm{p}=<0.000)$, while the smallest was the comparison between the Auckland Islands and White Island sites and finds a $\phi_{S T}$ value of $0.08165(\mathrm{p}=0.003)$. The other significantly different comparisons ranged from $0.12295-0.13804$.

Various AMOVA results showed that the majority of the genetic variation was contained within sites (Table 2.8) (87.54-90.58\%), and all $\phi_{\mathrm{ST}}$ values were statistically significant. No statistically significant differences were found between groups $\left(\phi_{\mathrm{CT}}\right)$, regardless of the population structure scenario tested. There were also no statistically significant genetic differences within groups $\left(\phi_{\mathrm{SC}}\right)$ 
in all tested scenarios. The genetic variation within groups $\left(\phi_{\mathrm{SC}}\right)$ only accounted for very small levels of genetic variation, which was most likely because of the large number of individuals that had the same DNA-sequence-type, which was shared across all sampling sites.

Table 2.7: Pairwise $\phi_{\mathrm{ST}}$ values determined by ITS-1 DNA-sequence-type frequencies. Values below the diagonal are the $\phi_{\text {sт }}$ values, while values above the diagonal are the associated p-values. Bold p-values indicate statistical significance after Bonferroni correction.

\begin{tabular}{ccccccc}
\hline & $\begin{array}{c}\text { Auckland } \\
\text { Islands }\end{array}$ & $\begin{array}{c}\text { Chatham } \\
\text { Rise }\end{array}$ & Wairarapa & $\begin{array}{c}\text { Cape } \\
\text { Kidnappers }\end{array}$ & $\begin{array}{c}\text { White } \\
\text { Island }\end{array}$ & $\begin{array}{c}\text { Great } \\
\text { Barrier } \\
\text { Island }\end{array}$ \\
\hline $\begin{array}{c}\text { Auckland } \\
\text { Islands } \\
\text { Chatham } \\
\text { Rise }\end{array}$ & - & 0.177 & $\mathbf{0 . 0 0 1}$ & $\mathbf{0 . 0 0 8}$ & $\mathbf{0 . 0 0 3}$ & $<\mathbf{0 . 0 0 0}$ \\
$\begin{array}{c}\text { Wairarapa } \\
\text { Cape }\end{array}$ & 0.13327 & 0.03742 & - & 0.999 & 0.670 & 0.382 \\
$\begin{array}{c}\text { Kidnappers } \\
\text { White }\end{array}$ & 0.12295 & 0.01124 & 0.000 & - & 0.999 & 0.684 \\
$\begin{array}{l}\text { Island } \\
\text { Great } \\
\text { Barrier } \\
\text { Island }\end{array}$ & 0.08165 & 0.00531 & 0.000 & 0.000 & - & 0.099 \\
\hline
\end{tabular}

The number of migrants exchanged per generation between sampling sites based on the ITS-1 sequence results was similar to the estimates obtained from the CO1 sequences (Table 2.9). Similar to the CO1 data, some values could not be calculated as the pairwise $\phi$ st value between some populations was zero, and for these comparisons it was assumed that there was a high level of migrant exchange between sites. Very few migrants appear to be exchanged between the Auckland Islands sampling site and Wairarapa, Cape Kidnappers, White Island, and Great Barrier Island sites. A higher level of migration was estimated between the Auckland Islands and White Island sites than the levels estimated for sampling sites separated by smaller geographic distances. This may be due to the way $\phi$ st values were calculated (using the frequencies of DNA-sequence-types) and the larger DNA-sequence-type number of unique DNA-sequence-types present within the White Island sampling site. Twenty-two migrants are exchanged between the Auckland Islands and Chatham Rise sampling sites, and this appears to be enough to genetically connect them. All other sampling sites are genetically connected and exchange high numbers of migrants. 
Figure 2.9: Median Joining Network of 67 partial ITS-1 sequences from $M$. challengeri. Each circle represents an individual haplotype. Larger circles mean that more individuals share that haplotype, with different colours representing different sampling sites. Mutations between haplotypes are represented by hatch marks, and hypothetical haplotypes are represented by small black circles.

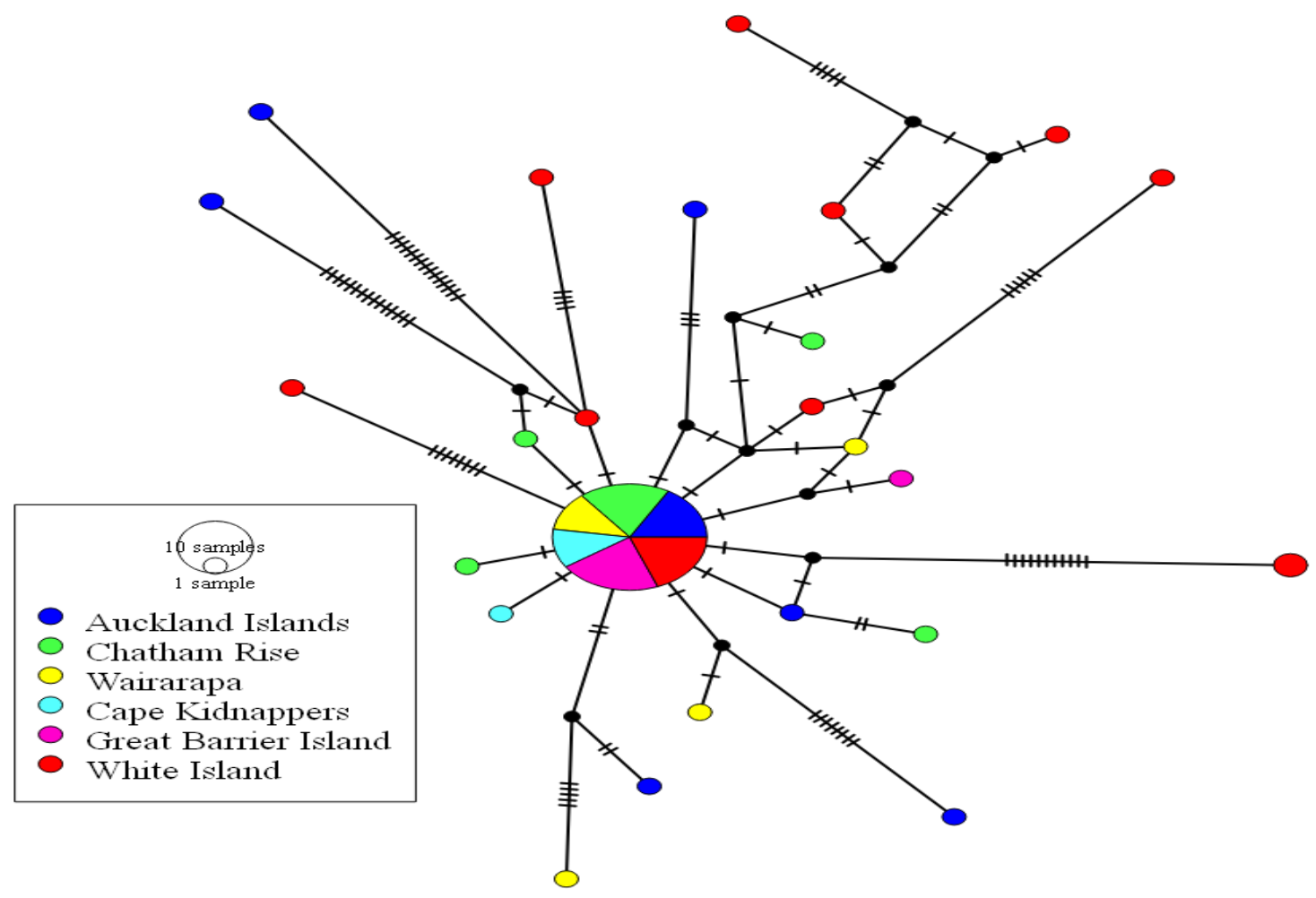

A Mantel test comparing geographic distance and Slatkin's linearised genetic distances for six populations of $M$. challengeri showed a strong statistically significant correlation $(\mathrm{r}=0.755, \mathrm{p}=$ 0.017) (Figure 2.10A) between the two variables. Removal of the Auckland Islands sampling site from this analysis weakened the correlation $(\mathrm{r}=0.411)$ and rendered it statistically nonsignificant $(\mathrm{p}$ $=0.164$ ) (Figure 2.10B). This is likely due to the relatively large genetic and geographic distances displayed between comparisons of the Auckland Islands sampling site to other sites.

Figure 2.10: Pairwise comparisons of Slatkin's linearised distance derived from ITS-1 sequences plotted against geographic distance (km). A) All sampling sites considered. B) Auckland Islands sampling site removed. The correlation coefficient $(\mathrm{R})$ and $\mathrm{p}$-value (obtained via Mantel test) are displayed on each graph.

A

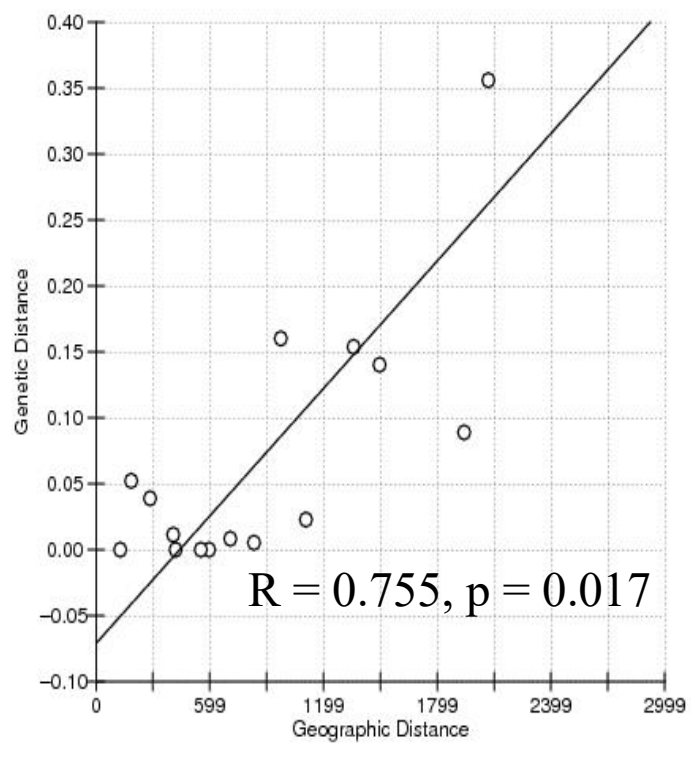

B

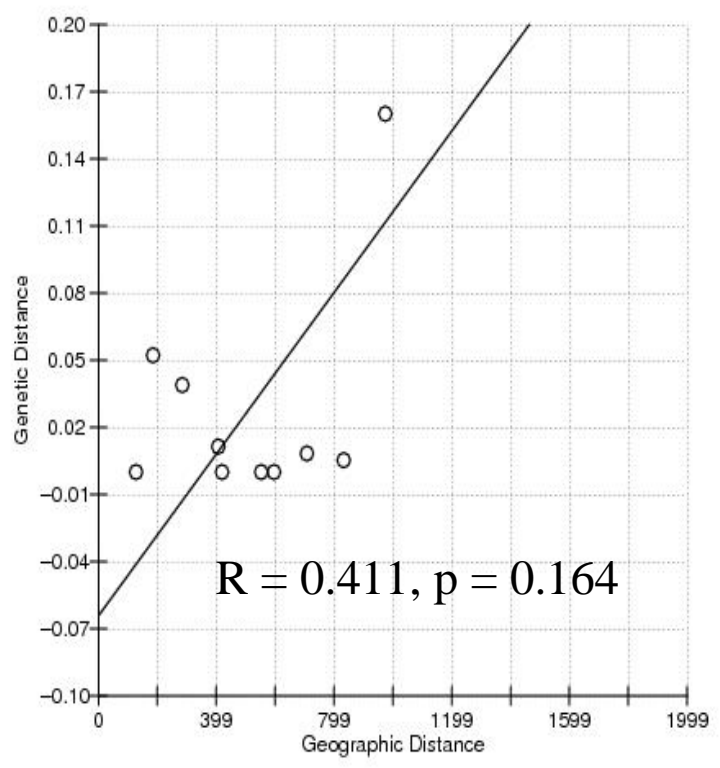




\begin{tabular}{|c|c|c|c|c|c|c|c|c|c|c|c|c|c|c|c|}
\hline \multirow[t]{2}{*}{ Groups } & \multicolumn{5}{|c|}{ Among Groups } & \multicolumn{5}{|c|}{ Among Populations Within Groups } & \multicolumn{5}{|c|}{ Within Populations } \\
\hline & d.f & Var & $\% \operatorname{Var}$ & $\phi_{\mathrm{CT}}$ & P-Value & d.f & Var & $\%$ Var & $\phi \mathrm{sc}$ & P-Value & d.f & Var & $\% \operatorname{Var}$ & $\phi \mathrm{ST}$ & P-Value \\
\hline AI, GBI-CR & 1 & 0.05301 & 11.03 & 0.11029 & 0.17139 & 4 & 0.00686 & 1.43 & 0.01604 & 0.17743 & 61 & 0.42074 & 87.54 & 0.12456 & 0.00356 \\
\hline AI, CR, GBI-W & 2 & 0.04870 & 10.49 & 0.10485 & 0.06851 & 3 & -0.00493 & -1.06 & -0.01186 & 0.46238 & 61 & 0.42074 & 90.58 & 0.09424 & 0.00475 \\
\hline $\mathrm{AI}+\mathrm{CR}, \mathrm{GBI}-\mathrm{W}$ & 1 & 0.04550 & 9.74 & 0.09737 & 0.06782 & 4 & 0.00107 & 0.23 & 0.00254 & 0.34436 & 61 & 0.42074 & 90.03 & 0.09966 & 0.00376 \\
\hline
\end{tabular}

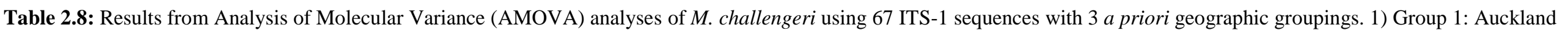

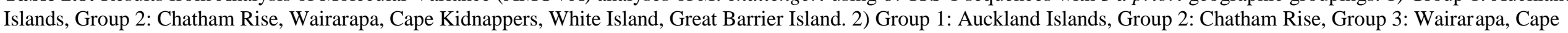

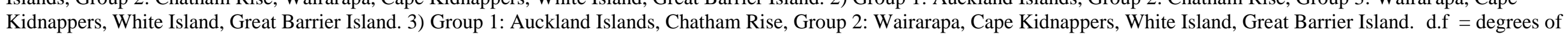
freedom, $\operatorname{Var}=$ variance component, $\%$ Var $=$ variance component in percentage of total variation.

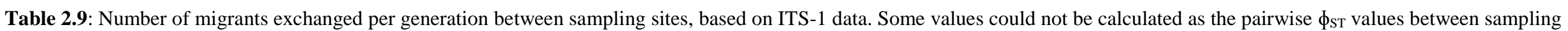
sites was 0 .

\begin{tabular}{|c|c|c|c|c|c|c|}
\hline & Auckland Islands & Chatham Rise & Wairarapa & Cape Kidnappers & White Island & Great Barrier Island \\
\hline Auckland Islands & - & & & & & \\
\hline Chatham Rise & 21.96 & - & & & & \\
\hline Wairarapa & 3.25 & 12.86 & - & & & \\
\hline Cape Kidnappers & 3.57 & 43.98 & - & - & & \\
\hline White Island & 5.62 & 93.66 & - & - & - & \\
\hline Great Barrier Island & 1.39 & 3.122 & 60.33 & - & 9.58 & - \\
\hline
\end{tabular}




\section{Demographic History}

Most of the values returned from the neutrality tests for each sampling site were negative, but not all were significantly different from zero. The Tajima's D values for Great Barrier Island, Wairarapa, Chatham Rise, and the Auckland Islands sampling sites were statistically significant, but all other values, including all Fu's $\mathrm{F}_{\text {stat }}$ values were statistically insignificant (Table 2.10). However, when all sites were pooled into one group both Tajima's D and Fu's $\mathrm{F}_{\text {stat }}$ values were negative and statistically significant (Table 2.10).

Mismatch distributions showed a mixture of results. Most sampling sites exhibiting multimodal distributions indicative of old, stable populations, only the Cape Kidnappers site exhibited a unimodal distribution. These may also have been influenced by the small sample sizes available for some sampling sites. All estimates of Harpending's raggedness statistic were statistically nonsignificant, as were all SSD values, except for the Great Barrier Island sampling site (Table 2.10).

Table 2.10: Neutrality tests and mismatch analyses obtained from analysis of ITS-1 sequences. SSD = sum of squared deviation, Rag = Harpending's raggedness statistic, p-values in brackets.

\begin{tabular}{ccccc}
\hline Sampling Site & $\begin{array}{c}\text { Tajima’s D }(\mathrm{p}- \\
\text { value })\end{array}$ & $\begin{array}{c}\text { Fu's F-statistic } \\
(\mathrm{p} \text {-value })\end{array}$ & $\begin{array}{c}\text { SSD }(\mathrm{p}- \\
\text { value })\end{array}$ & Rag (p-value) \\
\hline Great Barrier Island & $-1.40(0.032)$ & $0.39(0.504)$ & $0.24(<0.00)$ & $0.167(1.00)$ \\
White Island & $-1.30(0.084)$ & $-0.29(0.444)$ & $0.025(0.82)$ & $0.039(0.389)$ \\
Cape Kidnappers & $-0.93(0.255)$ & $-0.99(0.117)$ & $0.028(0.55)$ & $0.222(0.058)$ \\
Wairarapa & $-1.78(0.007)$ & $1.55(0.771)$ & $0.138(0.10)$ & $0.288(0.10)$ \\
Chatham Rise & $-1.66(0.036)$ & $-3.36(0.039)$ & $0.009(0.74)$ & $0.028(0.641)$ \\
Auckland Islands & $-1.67(0.037)$ & $1.20(0.703)$ & $0.021(0.81)$ & $0.025(0.896)$ \\
All Data & $-2.46(<0.000)$ & $-10.78(0.009)$ & $0.104(0.13)$ & $0.172(0.209)$ \\
\hline
\end{tabular}




\section{4: Discussion}

This study used DNA sequences from mitochondrial (CO1) and nuclear (ITS-1) gene-fragments to investigate the genetic diversity, structure, and demographic history of $M$. challengeri populations throughout the New Zealand region. Analyses of mitochondrial CO1 data indicate significant levels of genetic differentiation between $M$. challengeri from near the Auckland Islands and $M$. challengeri from sampling sites on the Chatham Rise and off the eastern coast of the North Island. Sampling sites off the eastern coast of the North Island and the Chatham Rise showed little genetic differentiation and may be isolated by distance. The sampled locations were similar to a previous genetic study of M. challengeri that used allozyme data (Smith, 1999), this study also found that the Auckland Islands sampling site was genetically distinct from the other sampling sites, and that the sampled sites ranging from the Chatham Rise to the Bay of Plenty showed little or no genetic differentiation. Analysis of nuclear ITS-1 data also supports this result, but was less conclusive because of lower levels of variation at this locus. Many individuals display the same ITS-1 sequence-type, which was shared among all sampled sites. The Bayesian analyses of population structure suggested that admixture has occurred between the Auckland Islands sampling site and those off the eastern coast of the North Island and the Chatham Rise. The precise location of the reported genetic break is difficult to determine with widely spaced sample sites, but information about habitat availability and bathymetry may suggest there are appropriate environmental conductions to limit gene flow around $45^{\circ} \mathrm{S}$ (see below). Oceanic currents potentially influence connectivity among populations by transporting pelagic larvae. The historical demography of $M$. challengeri based on molecular evidence suggests that $M$. challengeri populations have undergone a recent demographic expansion.

\subsection{1: Population Structure}

M. challengeri have a wide but patchy distribution encompassing much of the continental shelf and slope off New Zealand. A distribution map for M. challengeri has been produced by the National Aquatic Biodiversity Information System (NABIS), but it is likely a generalisation. For whilst it is based on voucher specimens at the Museum of New Zealand Te Papa Tongarewa (NMNZ) and NIWA, as well as fisheries data similar to that of Tuck (2014; Figure 1), few specimens are held at NMNZ (R. Webber, pers. comm. 2017) and NIWA (S. Mills, pers. comm. 2017). No voucher specimens are known from the east coast of the South Island south of Timaru or east of Stewart Island, and there are no records of any commercial trawls targeting M. challengeri in these regions (Tuck, 2014; Figure 1), suggesting that they may be absent there or occur in low abundance. The species is not known to inhabit the waters off Fiordland as the surface and bottom water conditions 
are quite different from their normal habitat. A potential distribution disjunction between $44^{\circ} \mathrm{S}$ and $46^{\circ} 20^{\prime} \mathrm{S}$ on the west coast, and $45^{\circ} 30^{\prime} \mathrm{S}$ and $47^{\circ} 30^{\prime} \mathrm{S}$ on the east coast, could explain the genetic differentiation between the Auckland Islands and the other sampled locations. Material from the Challenger Plateau, west of Stewart Island, and off the Antipodes Islands was not available for comparison as part of this study.

The sediments off the Otago coast may be too coarse and the depths too shallow for sustainable adult habitation by M. challengeri (K. Probert, pers. comm. 2017). They may occur within muddier sediments on the upper continental slope, including submarine canyons off the Otago peninsula, but there are no known records from these areas despite extensive trawling effort (K. Probert, pers. comm. 2017). Off the south eastern South Island the continental shelf is quite shallow, rarely approaching the upper limit of the bathymetric range of M. challengeri (Mackay et al., 2015) and the continental slope drops off rapidly into unfavourable depths (Carter \& Carter, 1988). Landderived gravels and sands make up the sediments within this area (Carter, 1985) and these may be unsuitable for the construction of burrows by M. challengeri, as suitable habitat for Metanephrops species is often associated with sediment type and grain size (Wallner \& Phillips, 1990). The distribution boundary and habitable area were unlikely to have significantly changed during the height of the last glacial maxima where eustatic sea levels were up to $130 \mathrm{~m}$ lower (Fleming et al., 1998). Furthermore, the Clutha River on the east coast of the South Island has a strong influence on local ocean conditions such as temperature, salinity, and sediment load (Carter \& Carter, 1986; Hawke, 1989), and the continental shelf and slope off the Otago Peninsula is subject to density flows (Hawke, 1989). These factors might present an impassable barrier to dispersing Metanephrops larvae or form unfavourable habitat for adult individuals.

Mantel tests reported a high correlation between geographic and genetic distance, suggesting that genetic structuring among populations could be due to the geographic distance between sites, although this relationship was not always statistically significant. The Auckland Islands sampling site is separated from the nearest sampling site (Chatham Rise) by approximately $1100 \mathrm{~km}$ and significant genetic differentiation is reported between them. However, the Chatham Rise and Great Barrier Island sampling sites are separated by a similar geographic distance (approximately 1000 $\mathrm{km}$ ) and do not exhibit the same amount of genetic structuring, with only a small statistical difference among haplotype frequencies. The putative habitat disjunction most likely isolates the Auckland Islands population from populations further north, restricting gene flow and causing high levels of genetic structuring. Conversely, a continuous population along the eastern coast of the North Island and on the Chatham Rise may promote gene flow between neighbouring areas, as $M$. challengeri larvae only travel short distances before they settle, and then mature and breed. 
Individuals from populations separated by larger geographic distances are less likely to interact, which will limit gene flow and lead to the formation of discrete populations or increasing population isolation with distance. The Auckland Islands population may have been isolated from those on the Chatham Rise and the eastern coast of the North Island for a long period of time, allowing genetic drift to sort the populations into distinct mitochondrial lineages. Recent rare admixture events between populations may have established the presence of a nuclear sequencetype common to all populations, or a low mutation rate at this locus means that divergence at this locus occurs slowly.

Oceanic currents are likely to impact the genetic and demographic connectivity among $M$. challengeri populations because their pelagic larvae are passive dispersers. The main current systems that could influence the dispersal of the M. challengeri populations examined within this study are produced by the Tasman Front in the north and the Subtropical Front in the south (see Figure 1.3). The East Auckland Current flows south along the north eastern coast of New Zealand reaching the East Cape before much of this water is transported offshore. Offshore transport of water may influence the connectivity between populations north and south of the East Cape by transporting larvae offshore and into waters that are unsuitable for larval settlement due to their depth. Populations of the corophiid amphipods Paracophium lucasi and P. excavatum, and the anemone Actinia tenebrosa have been reported as genetically distinct either side of the East Cape (Stevens \& Hogg, 2004; Veale \& Lavery, 2012). However, A. tenebrosa is a coastal, intertidal species with multiple dispersal methods (Veale \& Lavery, 2012), while P. lucasi and P. excavatum are direct developing species which inhabit estuarine areas (Stevens \& Hogg, 2004), so direct comparisons to $M$. challengeri are limited. Populations of $M$. challengeri north and south of the East Cape are certainly genetically connected, but genetic connectivity among populations does not imply that they are also demographically connected (Ovenden, 2013), and the East Cape could constitute a semi-permeable barrier with successful migration occurring around it at low frequencies.

A component of the East Auckland Current flows down the south eastern coast of the North Island as the East Cape Current. As this current flows south it fractures, with some of its flow proceeding to the north east while the remainder continues south and joins the subtropical front (Chiswell, 2005). Dispersal of larvae from northern to southern populations on the east coast may be impeded if larvae carried south by the East Cape Current are returned to the north or swept offshore to the east along the Chatham Rise (Ross et al., 2009). The system of currents within this area are further complicated by the presence of the East Cape and Wairarapa eddies which have the potential to retain small drifting objects for up to 3 years (Chiswell \& Roemmich, 1998). These systems have 
been cited as a driver of self-recruitment in populations of Crustacea with an extremely long pelagic larval duration (PLD) (Chiswell \& Booth, 1999), but for species with a short PLD, such as $M$. challengeri, retention within these eddies is probably terminal as mature larvae will be unable to reach habitat suitable for settlement (Ross et al., 2009). However, the two sites sampled within this area (Wairarapa and Cape Kidnappers) appear well connected; no significant genetic differentiation was detected between them, implying high levels of migration. Portions of the d'Urville and Southland currents flow northward along the Wairarapa coast in the form of the Wairarapa Coastal Current (Chiswell, 2000), and may transport larvae northward, facilitating connectivity between the Wairarapa and Cape Kidnappers sampling sites.

The results of this study did not show any evidence for a north-south phylogeographic break around the Cook Strait. This pattern has been noted in previous phylogeographic studies of marine invertebrates that were sampled in this region (e.g. Waters \& Roy, 2004; Ayers \& Waters, 2005; Veale \& Lavery, 2011). The AMOVA analysis of this scenario found no significant difference between groups, although significant genetic heterogeneity was found among all populations, and among all groups. Populations of $M$. challengeri to the north and south of Cook Strait on the east coast appear to be panmictic, with non-significant CO1 and ITS-1 pairwise $\phi_{\text {ST }}$ values between the Wairarapa and Chatham Rise sampling sites. This suggests that larval dispersal of M. challengeri is not limited by factors such as upwelling or other oceanographic variables, which have been previously implicated in limiting population connectivity for other benthic invertebrates within this region. However, oceanographic data is lacking for these hypotheses and studies of local oceanography and a greater understanding of the consequences of larval behaviour are needed if these hypotheses are to be adequately tested (Ross et al., 2009). The connection observed between the Chatham Rise and Wairarapa sampling sites is probably mediated by the Southland Current. Some of this current continues to flow north and mixes with the waters of the Cook Strait and Wairarapa after the majority is diverted eastward by the Chatham Rise. Larvae drifting within this current system could be transported north to settle off the Wairarapa coast. But the analyses reported in this study could not discern the geographic provenance of larvae from these regions. A mark-recapture analysis would be needed to discern the geographic provenance of larvae at this spatial scale. However, applying this method to M. challengeri larvae would be extremely difficult due to their small size and the limited probability of recapture.

In the south the subtropical front circumvents the southern coast of the South Island before turning north along the south eastern coast of the South Island as the Southland Current until it encounters the Chatham Rise and is diverted eastward. Demographic modelling and genetic analyses indicate high levels of self-recruitment in Jasus edwardsii populations along the southern coast of the South 
Island and Stewart Island (Chiswell \& Booth, 2008; Thomas \& Bell, 2013). This population also acts as a source population for other populations of Jasus edwardsii around New Zealand (Chiswell \& Booth, 2008; Thomas \& Bell, 2013) as larvae released off the coast of the South Island would likely be transported north east by the Southland Current (Thomas \& Bell, 2013). Southern populations of $M$. challengeri are unlikely to act as source populations for northern populations because of their much shorter PLD when compared to Jasus edwardsii, and simulated larval dispersal models examining the subantarctic islands (including the Auckland Islands) demonstrate that larvae with short PLDs can only travel a short distance from their spawning site (Chiswell, 2009). The significant $\phi_{\mathrm{ST}}$ between the Auckland Islands sampling site and sites on the Chatham Rise and off the eastern coast of the North Island supported this hypothesis. The results of the ITS-1 data analyses also showed a similar pattern, although the observation of a common DNA-sequence type across all populations also suggests the possibility of admixture.

Climatic oscillations during the Pleistocene drastically changed oceanographic features around New Zealand, cooling the average surface water temperature off the south eastern coast of the South Island by 3-6 ${ }^{\circ} \mathrm{C}$ (Nelson et al., 1993). The thermal changes could have limited or prevented dispersal for $M$. challengeri, although their thermal tolerance range is unknown. Populations may have persisted within ice-age refugia on the Campbell Plateau, which remained isolated from the cooler waters of the subantarctic front (Neil et al., 2004). Moreover, populations would have persisted in warmer subtropical water further north. Populations on the Campbell Plateau would probably have been isolated from more northern populations, leading to the genetic divergence and the sorting of distinct mitochondrial and nuclear lineages. During glacial minima this barrier could become more permeable and allow for sporadic dispersal of $M$. challengeri larvae between subantarctic and subtropical populations.

The subtropical front has previously been proposed as a potential dispersal barrier to M. challengeri (Smith, 1999), but this hypothesis is unlikely as M. challengeri are known to occur on either side of the subtropical front, as well as within it. The populations sampled on either side of the subtropical front are considered genetically distinct (by this study and that of Smith, 1999), but this can be attributed to a lack of available habitat between northern and southern populations rather than oceanic processes. The Southland Current has a recorded mean velocity of $23.8 \mathrm{~cm} \mathrm{~s}^{-1}$ (Chiswell, 1996), larvae within this current could travel approximately $100 \mathrm{~km}$ assuming a conservative pelagic larval duration estimate of five days. A stepping-stone population model would suggest that there will be populations off the Otago Shelf to connect the populations of the Chatham Rise. Sporadic migration events over this distribution gap can also contribute to connectivity as analyses indicate that a small number of migrants per generation are exchanged between the Auckland 
Islands and the other sampling sites (Tables 2.4, 2.9). Over time, rare dispersal events can lead to a degree of homogenisation of genetic diversity among populations on a large spatial scale. Rare migration events are potentially responsible for the weak genetic population structure displayed by other marine species (Waples, 1987), and M. challengeri.

\subsection{2: Demographic History}

Measures of genetic variation can provide insights into the demographic history of a species. $M$. challengeri exhibit high levels of mitochondrial haplotype diversity. There were 107 different CO1 haplotypes identified from just 321 individuals, which contained low levels of nucleotide diversity overall. These values are comparable to those exhibited by the $\mathrm{CO} 1$ region of $M$. mozambicus (Zacarias, 2013), and slightly lower than observed levels in the deep-sea squat lobster Munida gracilis (Bors et al., 2012), which occurs in partial sympatry, occupies a similar habitat and likely has an extended pelagic larval duration typical of other Munida species (Baba et al., 2011). High levels of haplotype diversity paired with low levels of nucleotide diversity suggests a history of a population size contraction before an expansion (Grant \& Bowen, 1998). When population size increases, the strength of genetic drift decreases, which means low frequency alleles are more likely to persist and get the opportunity to increase to a higher frequency within the population (Rogers \& Harpending, 1992; Excoffier \& Ray, 2008) The high effective population size exhibited by $M$. challengeri may reflect the relatively large area of suitable bathymetry that they inhabit as greater habitat area is available to deep-water species than species constrained to coastal habitat, meaning that there may be more breeding opportunities or food available. Overall, lower levels of haplotype diversity and nucleotide diversity (compared to the CO1 dataset) were observed within the ITS-1 region of $M$. challengeri. Low levels of haplotype and nucleotide diversity are indicative of a recent population bottleneck or founder event (Grant \& Bowen, 1998). However, the low sample size of the ITS-1 dataset calls these values into question as under-sampling can artificially alter genetic diversity estimates (Nei, 1987).

Other analyses of the CO1 dataset also showed patterns of population expansion, including unimodal mismatch distributions, and non-statistically significant raggedness statistics. Although neutrality tests and mismatch distributions derived from ITS-1 data did not detect a demographic expansion within $M$. challengeri populations. The smaller effective population size of mitochondrial DNA (due to its maternal inheritance) makes it more susceptible to demographic changes and may be why a recent demographic expansion was detected in the mitochondrial DNA analyses but was not detected when using the nuclear DNA dataset. During population size increases, mitochondrial DNA can accumulate mutations faster than typical protein-coding nuclear 
loci due to a higher intrinsic rate of mutation (Grant \& Bowen, 1998). Mitochondrial DNA diversity may be higher compared to other genetic markers as the populations of species like $M$. challengeri expand.

Estimations regarding the timing of the population expansion differ between analyses. These types of estimates can be sensitive to differences in the evolutionary rate implemented within each model. While the actual time estimates may be subject to large margins of error the general trends presented by these analyses can still be useful. The Bayesian skyline plots estimate a much earlier population expansion compared to the population expansion parameters $\left(\tau, \Theta_{0}, \Theta_{1}\right)$. The Auckland Islands population is particularly interesting because it displays the strongest signal of demographic expansion (see tables 2.5, 2.10), as the most southern population it may have been the result of an expansion southward as water temperatures rose. Levels of CO1 haplotype diversity were similar across all sampling sites, but the level of nucleotide diversity within the Auckland Islands sampling site was lower than the others, suggesting that this location had experienced a more pronounced genetic bottleneck before expanding. Bayesian skyline plots constructed using CO1 data suggest a recent, post-glacial population expansion (approximately $10 \mathrm{kya}$ ), while the demographic expansion time estimates indicate a much earlier population expansion (approximately $600 \mathrm{kya}$ ) for most populations. A more recent expansion for the Auckland Islands population is observed in the demographic expansion time parameters (approximately 217 kya), while the Bayesian skyline plot suggests that the Auckland Islands population has only been present for $6 \mathrm{ky}$ and may be the product of a range-expansion southward. Although this is unlikely due to the distinct mitochondrial lineages observed within the Auckland Islands population, as they are separated from haplotypes present within the other sampled populations by at least five mutational steps, indicative of a longer period of isolation.

Populations of M. challengeri have expanded in either the Pleistocene or Holocene according to the results presented within this study. The Pleistocene was characterised by a series of glacialinterglacial cycles which have left their mark upon the genetic composition of many organisms within the northern hemisphere (see Hewitt, 2000; Petit et al., 2003; Hewitt, 2004), but less is known about their influence on southern hemisphere taxa. In contrast, the Holocene constitutes only the most recent and present interglacial period, which is characterised by a warm, stable climate that has allowed species to recolonise areas after being extirpated by glaciation (e.g. Hewitt, 1999; Marko, 2004). Glacial-interglacial cycles during the Pleistocene are believed to impact the genetic structure of New Zealand's coastal marine organisms (Wallis \& Trewick, 2009). These cycles may have also led to repeating extirpation-recolonisation events in a number of taxa within the southern ocean (Fraser et al., 2009), along with range shifts in terrestrial taxa (Fraser et al., 2012). The end of 
the last glacial maximum (LGM) and onset of the Holocene has allowed southern-hemisphere species to move southward as global temperatures increased (Fraser et al., 2012). The northern and southern distribution limits of $M$. challengeri are bound by unfavourable bathymetry and it is therefore difficult to determine its thermal tolerance range. Southward isotherm tracking post-last glacial maximum, as recorded for a variety of marine invertebrates (e.g. Maurea blacki, Marshall, 1995; Zygochlamys delicatula, Beu, 1999), could explain the evidence of population expansion that is more marked in the Auckland Islands population. High latitude populations of New Zealand triplefin fishes showed low levels of haplotype and nucleotide diversity (Hickey et al., 2009), indicative of recent population expansion, and a decrease in genetic diversity with latitude has been demonstrated in other species of fish (Hickerson \& Ross, 2001; Hickerson \& Cunningham, 2005).

Post-glacial population expansion has been reported for other crustacean species within New Zealand waters (Nikula et al., 2010), as well as other parts of the world, including the Caribbean Sea and the North Atlantic Ocean (Maggs et al., 2008; Naro-Maciel et al., 2011). Post-glacial expansions among marine lobsters have largely been attributed to an increase in available habitat (Kennington et al., 2013b). As previously noted, sea levels were approximately $130 \mathrm{~m}$ lower during the last glacial maxima (Fleming et al., 1998), this does not appear to drastically alter the amount of habitat available to $M$. challengeri in terms of bathymetry, but may have altered habitat composition, restricting their distribution and population size. Populations of $N$. norvegicus in the North Atlantic Ocean have recolonised areas after extirpation potentially caused by glaciation (Stamatis et al., 2004; Pampoulie et al., 2011), and their genetic homogeneity has been attributed to their recent expansion (Stamatis et al., 2004; Pampoulie et al., 2011). M. challengeri inhabit similar habitat to $N$. norvegicus and may have been subject to comparable extirpation events. Cooler water temperatures or changes in habitat composition during glacial periods may have restricted the distribution of $M$. challengeri to refugia followed by population expansion during warmer interglacial periods.

\subsection{3: Conclusions}

A genetic disjunction exists between populations of M. challengeri near the Auckland Islands and the other sampled populations further north, but there is little or no genetic differentiation between northern populations along the eastern coast of the North Island and the Chatham Rise. The observed genetic structuring could have been caused by a lack of suitable breeding habitat along the south eastern coast of the South Island. Oceanic currents most likely facilitate gene flow between largely continuous populations along the eastern coast of the North Island but cannot reliably transport larvae of subantarctic origin over the putative gap in suitable habitat along the Otago 
Shelf. The contrasting levels of haplotype and nucleotide diversity suggest that there were population size reductions during glacial periods, where populations probably persisted within refugia, before rapidly expanding during interglacial periods. This study provides evidence that species that appear to have limited dispersal potential can still maintain high levels of population connectivity, but circumstances where there are significant gaps between suitable habitat can genetically isolate populations. Future population genetic research of $M$. challengeri could improve on this study by adding more sampling sites from the southern part of their distribution and from the Challenger Plateau and by using different molecular markers. 


\section{Chapter Three: General Discussion \& Implications for Fisheries}

\section{Management}

The primary goal of this study was to investigate the genetic structure of $M$. challengeri populations throughout the New Zealand region. This study reports that M. challengeri from the Auckland Islands region are genetically distinct from individuals upon the Chatham Rise and off the eastern coast of the North Island, and that sampling sites along the eastern coast of the North Island and the Chatham Rise are primarily isolated by distance and some populations may be demographically disconnected. Analyses examining the demographic history of $M$. challengeri also report a population expansion during the late Pleistocene or early Holocene, possibly linked to changes in climate. The information obtained from this study can now be used to identify independent populations and aid the effective management of $M$. challengeri.

\section{1: Population Structure}

Revealing patterns of intraspecific genetic and demographic connectivity promotes understanding of the ecological and evolutionary processes operating on a species. Genetic analyses can elucidate historical and contemporary gene flow between populations, and the effect of historical events on population size and genetic diversity. Identification of population structure is especially important for harvested organisms as overexploitation can result in the depletion or extinction of localised subpopulations, along with a loss in genetic diversity (Carvalho \& Hauser, 1994; Begg et al., 1999). Benthic invertebrates may be particularly vulnerable to overexploitation due to their largely sessile nature limiting dispersal between geographically isolated populations (Thorpe et al., 2000). Many variables influence the genetic population structure between populations and the degree of genetic structuring is often species-specific. Genetic surveys need to be undertaken separately for individual species, and management plans designed to accommodate species-specific patterns of genetic structure and population connectivity (Wennerström et al., 2013). The number of molecular studies carried out on lobsters has increased significantly through time (Kennington et al., 2013b), but they remain poorly studied in relation to other harvested marine organisms.

Molecular studies of commercially harvested lobsters have revealed different patterns of population structure depending on the species studied and molecular marker(s) used (e.g. Stamatis et al., 2006; Pérez-Barros et al., 2014; Benestan et al., 2015). Panmixia (or very low levels of population structure) is often reported among populations of lobster species (Tolley et al., 2005; Kennington et 
al., 2013a; Jeena et al., 2016), but the application of next generation sequencing (NGS) techniques has revealed fine-scale genetic structure among populations of a commercially harvested lobster where more traditional markers had only detected panmixia, or low levels of genetic structuring (Tracey et al., 1975; Harding et al., 1997; Kenchington et al., 2009). Benestan et al. (2015) used single nucleotide polymorphisms (SNPs) derived from RAD (restriction site associated DNA) sequencing to investigate genetic structure among populations of Homarus americanus (American lobster) throughout much of their range within Canada and North America. The authors report a hierarchical genetic structure whereby northern and southern locations were genetically distinct, and a total of eleven genetically distinguishable populations were detected. These results allowed the authors to examine whether or not genetically distinguished populations matched management areas for $H$. americanus. Management areas generally matched the reported genetically differentiated populations, indicative of appropriate management, although some populations within separate management areas displayed no significant genetic differentiation. Therefore, populations of $H$. americanus appear to be well-managed spatially, but some populations may be allocated an overabundance of management resources because they are assigned to multiple management units. This situation is preferable to assigning multiple populations to the same management unit as it primarily involves economic, rather than ecological, consequences.

Knowledge of genetic structure should be used to inform fisheries management. The current literature surrounding genetic population structure in Nephrops and Metanephrops has already been summarised within this thesis (see section 2.1), concluding that $N$. norvegicus displays limited genetic structure among populations throughout its range (Stamatis et al., 2004, 2006; Pampoulie et al., 2011) possibly caused by dispersal of pelagic larvae, or recent demographic expansion. Contrastingly, genetic studies of Metanephrops populations have reported significant levels of population structure (Smith, 1999; Zacarias, 2013), potentially due to their much shorter pelagic larval phase and larval interactions with oceanographic features. This study extends the knowledge surrounding the genetic population structuring within $M$. challengeri and reports significant genetic differentiation between similar populations as Smith (1999), the management implications of which are later discussed in section 3.3 of this thesis. A recent demographic expansion is also reported within $M$. challengeri populations and potentially impacts the observed genetic structuring among them. 


\section{2: Demographic History and Genetic Diversity}

Historical demographic processes affect patterns of genetic diversity and structure within contemporary populations. Analysis of genetic data can provide invaluable insight into the demographic history of populations by examining historical demography on an evolutionary timescale. Changes in climate are often implicated as the drivers of demographic expansions as climatic changes impact environmental variables, potentially making areas uninhabitable for particular species, or allowing species to (re)colonise new areas. Post-glaciation population expansions have been reported in multiple lobster taxa (Gopal et al., 2006; Palero et al., 2008; Babbucci et al., 2010; Naro-Maciel et al., 2011; Rodríguez-Rey et al., 2013; Pérez-Barros et al., 2014), with many of these authors citing an increase in available habitat during inter-glacial periods as a potential cause (Tolley et al., 2005; Gopal et al., 2006; Babbucci et al., 2010; Naro-Maciel et al., 2011). Glacial-interglacial cycles drastically modify sea levels (Fleming et al., 1998; Clark \& Mix, 2002; Lea et al., 2002) and can alter the amount of habitat available to marine organisms. One example being that of the population expansion reported in populations of Munida gregaria off the coast of Patagonia (Pérez-Barros et al., 2014). Sea-level change during the Pleistocene glacialinterglacial cycles caused large areas of the South-American continental shelf to be exposed (Cavallotto et al., 2011), which led to a cooling of sea surface temperatures in this area. The distribution of $M$. gregaria was possibly restricted to lower latitudes during glacial periods before warmer sea-water temperatures during inter-glacial periods allowed them to expand southward (Pérez-Barros et al., 2008). Extirpation-recolonisation events can lead to low levels of genetic diversity within populations, but selective sweeps and small effective population sizes also play a role in structuring genetic diversity (Hedrick, 2011).

Historical demographic patterns require consideration when interpreting contemporary patterns of genetic diversity and population structure. For lobster populations, low levels of population structure potentially reflect ongoing larval dispersal, but may also be a consequence of demographic history (Kennington et al., 2013b). Levels of population connectivity may be lower than contemporary observations suggest. Recent demographic expansions can obscure genetic population structuring if populations are not in Hardy-Weinberg equilibrium and phylogenetic relationships between localities have not had enough time to resolve. This has been postulated as a potential cause for the lack of genetic structure observed among populations in multiple commercially harvested lobster taxa (Stamatis et al., 2004; Triantafyllidis et al., 2005; Kenchington et al., 2009), and the results of this study suggest that this may be the case for M. challengeri as well, but it is difficult to differentiate between ongoing gene flow and the effects of recent population expansion. 
Species with higher levels of genetic diversity are typically more adaptable to changes in their environment (Reed \& Frankham, 2003), because advantageous alleles are more likely to be present in genetically diverse populations. Populations with limited genetic diversity may not be able to adapt to changes in environmental variables. It has been hypothesised that shallow-water species typically have lower levels of genetic diversity relative to deep-sea species because shallow-water species are more sensitive to extirpation events caused by climate-induced habitat modification (Fauvelot et al., 2003). A positive correlation between depth and mitochondrial genetic diversity has been detected within populations of a number of New Zealand's triplefin fish species (Hickey et al., 2009), and two species of spiny lobster (Palero et al., 2008). Contrastingly, commercially exploited shallow-water populations of spiny lobster species exhibited higher levels of genetic diversity than deep-water species when microsatellite markers were used (Palero et al., 2010). If demographic processes alone shaped the genetic diversity of these species then similar patterns of diversity would be exhibited by both mitochondrial and nuclear markers (Palero et al., 2010). A potential explanation for this discordance is that the variable nature of shallow-water environments may lead to selective-sweeps, reducing mitochondrial DNA diversity as it acts as a single nonrecombining molecular marker (Palero et al., 2010). Higher levels of genetic diversity in shallowwater species have also been reported in populations of decapod crustaceans on either side of the Atlantic-Mediterranean transition (García-Merchán et al., 2012), but the differing levels of genetic diversity were only significant in some taxa, and such patterns could be species specific (GarcíaMerchán et al., 2012). Despite commercial exploitation, genetic diversity within lobster populations appears to remain stable. Kennington et al. (2013a) reported no evidence for a decline in genetic diversity within populations of Panulirus cygnus over a fourteen year period, and Palero et al. (2011) did not detect a population bottleneck within populations of commercially harvested Palinurus elephas. The effective population sizes of these species may be large enough to prevent the loss of genetic diversity via genetic drift and current harvest levels, but more studies should be undertaken to determine whether these studies are representative of all lobster taxa.

\section{3: Management Implications for Metanephrops challengeri}

As mentioned throughout this thesis, the correct identification of independent populations through genetic or demographic means is vital to the sustainable management of fisheries. Independent populations can be defined as management units, but problems arise when too many or too few management units are assigned to populations. If independent populations are assigned to the same management unit then local extinctions and/or a loss of genetic diversity may occur. Conversely, a single population that is assigned to multiple management units may be allocated an inflated 
number of management resources (Palsboll et al., 2007). Portions of New Zealand's exclusive economic zone are separated into management areas/units (termed Quota Management Areas) by the Quota Management System to facilitate the sustainable management of harvested species. The number and geographical extent of these areas are dependent on the species being managed e.g. the rock lobster (Jasus edwardsii) fishery is separated into ten management areas which encompass the entire exclusive economic zone of New Zealand, while the Arrow Squid (Nototodarus species) fisheries are divided into three management areas throughout the same area and incorporate the trawl and jigging fisheries (Ministry for Primary Industries, 2016).

M. challengeri are currently managed as eleven separate units throughout the entirety of New Zealand's EEZ (see Figure 1.2), each with its own catch limit. Most landings occur within areas SCI1, SCI2, SCI3, and SCI 6A, and the effect of fishing on M. challengeri populations is assessed using both photographic and trawl-based surveys. According to these surveys, M. challengeri biomass within both SCI1 and SCI3 increased during the early 1990's, declined throughout the late 1990's and early 2000's, but has been stable since (Tuck, 2013, 2014). SCI2 also experienced an initial increase followed by a decline over the same time periods, but then increased steadily from 2008-2014, before declining slightly (Tuck, 2014). There is more uncertainty surrounding the effects of fishing on M. challengeri populations within SCI6A as less surveying research has been undertaken within this region. Catch per unit effort data suggest that the stock might have declined during the early years of the fishery, but has remained stable since the mid-1990's (Ministry for Primary Industries, 2016). With photographic and trawl-based surveys also suggesting that the stock has remained stable over recent years (Ministry for Primary Industries, 2016). Photographic surveys have detected more M. challengeri emerged from their burrows within SCI6A relative to other surveyed management areas (Tuck et al., 2015a). This may be related to the larger size of individuals or sediment characteristics within the area. If emergence levels for M. challengeri within this region are greater, their susceptibility to trawl-based fisheries is also greater, as the light trawl gear used to target $M$. challengeri can only target emerged individuals (Cryer et al., 2003).

Overfishing of $M$. challengeri is considered unlikely according to data generated by photographic and trawl-based surveys (Ministry for Primary Industries, 2016). Estimates of genetic diversity and effective population size generated by this study support this conclusion and show no indications that $M$. challengeri are being overfished as estimates of these values remain high (but are influenced by historical demographic processes). The commercial harvest of $M$. challengeri is unlikely to greatly impact their overall population dynamics and genetic diversity. Populations are only exploited within a small proportion of their overall range. Although they live within burrows in 
mud substrate, much of their range also incorporates rocky ground within such areas (Wahle et al., 2011), which is not conducive to trawl-based fisheries. A pot-based M. challengeri fishery is currently under development as an alternative fishing method (Major et al., 2017) to reduce the high levels of by-catch associated with the $M$. challengeri trawl fishery. The $M$. challengeri trawl fishery has the highest bycatch discard rate of all New Zealand deep-water fisheries (Anderson, 2012), but improvements to potting equipment still need to be made before utilisation of pot-based methods for the M. challengeri fishery becomes a commercially viable option (Major et al., 2017).

The present study encompasses four of the eleven management areas assigned to M. challengeri. These results indicate that populations of $M$. challengeri consist of at least two genetically distinct groups. One genetic group consists of the Auckland Islands sampling site while the other includes all other sites (stretching from the northern Chatham Rise to the northern Bay of Plenty). $M$. challengeri populations can certainly be managed as separate units at this spatial scale as populations are separated by large geographic distances and are not genetically or demographically connected. However, the presence of genetic connectivity among populations does not automatically imply demographic connectivity (Ovenden, 2013). Populations of M. challengeri are genetically connected over a large spatial scale (approximately $1000 \mathrm{~km}$ ) but it is unlikely that they are also demographically connected across this same spatial scale due to their short pelagic larval life stage. When there is no evidence for distinct genetic structuring among populations it can be difficult to draw conclusions regarding population connectivity as only a small number of migrants may be needed to render populations genetically homogenous. Low levels of migration may not be enough to demographically connect populations (Lowe \& Allendorf, 2010), and so migration levels will not be large enough to support the recovery of populations depleted by harvesting mortality.

The dispersal potential of $M$. challengeri is limited by the duration of their pelagic larval life stage as they are reliant upon dispersal via oceanic currents, and mark-recapture studies have identified that adult individuals do not move over long distances within an annual period (Cryer \& Stotter, 1999). Large areas of suitable habitat along the eastern coast of the North Island and atop the Chatham Rise likely lead to a patchy, yet continuous distribution of M. challengeri throughout these areas. A largely continuous distribution facilitates gene flow as individuals do not need to disperse over great distances to find conspecifics and contribute their genes to the next generation. The short duration of the pelagic larval phase may aid larvae looking to settle by ensuring they do not travel a large distance and are more likely to find habitat suitable for settlement. Small pairwise $\phi$ ST values are displayed between sampling sites along the eastern coast of the North Island and the Chatham Rise. Most of these are statistically non-significant, but statistically significant values (indicative of genetic differentiation) are reported between the Bay of Plenty and Cape Kidnappers sampling sites, 
as well as the Bay of Plenty and the Chatham Rise sites. As discussed in Chapter Two, the East Cape may act as a dispersal barrier to $M$. challengeri larvae, as much of the East Auckland Current flows offshore, potentially taking larvae with it and limiting connectivity between populations. The border between management areas SCI1 and SCI2 lies between the Bay of Plenty and East Cape regions, and SCI2 stretches from the East Cape to the top of the South Island. Results from these analyses support the current positioning of the northern border of SCI2 as some sampling sites on either side of the border appear to be poorly genetically connected, and may not be demographically connected.

Based purely on results from this study, the management areas SCI2 and SCI3 could potentially be combined, as individuals sampled from these areas show no statistically significant genetic differentiation. SCI3 may also contain an area of distribution disjunction for M. challengeri (located on the Otago Shelf) due to unsuitable bathymetry and sediment composition. Connectivity between sampling sites within SCI2 and SCI3 is likely facilitated by the Southland Current transporting larvae north from the Chatham Rise onto the continental shelf off the Wairarapa coast. However, more research would need to be undertaken utilising sampling sites throughout the entire distribution range of $M$. challengeri, including SCI2 and SCI3, and other areas not sampled within this study. A direct measure of demographic connectivity should also be used to characterise populations of $M$. challengeri before any management decisions are confidently made.

\section{4: Future Directions}

Genetic analyses provide a means to investigate a diverse range of issues relating to the biology and management of harvested species. Increases in computing power and accessibility to software now allow researchers to utilise computer simulations and model the complex processes influencing genetic structure and population connectivity (Hoban et al., 2012), and the advent of NGS techniques have shifted the focus from genes to genome-wide research in molecular studies of fisheries and aquaculture (Kumar \& Kocour, 2017). The field of seascape genetics takes a multidisciplinary approach by utilising both genetic data and data from environmental variables to investigate their impact on the spatial genetic patterns of marine organisms (Liggins et al., 2013). Studies within this field have already examined organisms endemic to New Zealand, Perna canaliculus and Pecten novaezelandiae (Wei et al., 2013; Silva \& Gardner, 2016), as well as commercially relevant Crustacea, H. americanus and Panulirus argus (Benestan et al., 2016; Truelove et al., 2017). Studies focusing on New Zealand species have revealed that sea surface temperature plays a role in genetic structuring of $P$. canaliculus (greenshell mussel) populations 
(Wei et al., 2013), and freshwater discharge along with suspended particulate matter influences the genetic structure of the P. novaezelandiae (New Zealand Scallop) (Silva \& Gardner, 2016). Sea surface temperature may also structure populations of $H$. americanus as different populations display adaptations related to thermal tolerance (Benestan et al., 2016), and a biophysical model combining both oceanographic circulation and genetic data explained the structuring present among P. argus populations in the Caribbean sea (Truelove et al., 2017). In the case of M. challengeri a proposed habitat disjunction may impact the distribution of populations and limit connectivity between them by separating them geographically. Juvenile $M$. challengeri require sediment of a certain grain size and cohesiveness in order to settle, form burrows, and survive to mature and reproduce. Combining both marine sediment and genetic data using multi-variate analyses may help explain the observed patterns of genetic structuring within this species.

Next generation sequencing has allowed the genome-wide detection and characterisation of genetic markers such as microsatellites and single nucleotide polymorphisms (SNPs) in non-model species which often lack genomic resources (Kumar \& Kocour, 2017). NGS-based techniques represent an important tool for improving both knowledge of genetic population structure within highly connected marine species and knowledge to improve the management of harvested species (Benestan et al., 2015), but are underutilised in fisheries research when compared to their application in other research fields (Cuellar-Pinzon et al., 2016). Bi-parentally inherited molecular markers are currently in development for M. challengeri in the form of microsatellites (P. Ritchie, pers. comm. 2017), and could be used to further discern genetic patterns of connectivity between $M$. challengeri populations. However, to effectively identify independent populations, genetic techniques should be applied in conjunction with other measures of connectivity (Begg \& Waldman, 1999; Ovenden, 2013), preferably including a direct measure of demographic connectivity (e.g. mark-recapture, or satellite telemetry). Implementation of direct measures of population connectivity would be difficult for $M$. challengeri as primary dispersal occurs during their larval phase. SNP genotyping has enabled the assignment of American Lobsters to their population of origin with a high rate of success (Benestan et al., 2015). 94\% were correctly assigned to their region of origin, while $80 \%$ were assigned correctly to their location of origin. SNPs have also been used to detect cryptic genetic differentiation between populations of Baltic Sea Herring on a smaller spatial scale (387 km; Corander et al., 2013), which was previously undetected by putatively neutral markers (Jørgensen et al., 2005; André et al., 2011). Similar techniques could be applied to $M$. challengeri to resolve any ambiguity regarding population structure along the eastern coast of the North Island and the Chatham Rise. 


\section{$\underline{\text { References }}$}

Allendorf, F. W., Berry, O., \& Ryman, N. (2014). So long to genetic diversity, and thanks for all the fish. Molecular Ecology, 23(1), 23-25.

Allendorf, F. W., England, P. R., Luikart, G., Ritchie, P. A., \& Ryman, N. (2008). Genetic effects of harvest on wild animal populations. Trends in Ecology \& Evolution, 23(6), 327-337.

Anderson, O. F. (2012). Fish and invertebrate bycatch and discards in new zealand scampi fisheries from 1990-91 until 2009-10. New Zealand aquatic environment and biodiversity report(100), 65.

André, C., Larsson, L. C., Laikre, L., Bekkevold, D., Brigham, J., Carvalho, G., et al. (2011). Detecting population structure in a high gene-flow species, atlantic herring (clupea harengus): Direct, simultaneous evaluation of neutral vs putatively selected loci. Heredity, 106(2), 270-280.

Apte, S., \& Gardner, J. P. (2001). Absence of population genetic differentiation in the new zealand greenshell mussel perna canaliculus (gmelin 1791) as assessed by allozyme variation. Journal of experimental marine biology and ecology, 258(2), 173-194.

Apte, S., \& Gardner, J. P. A. (2002). Population genetic subdivision in the new zealand greenshell mussel (perna canaliculus) inferred from single-strand conformation polymorphism analysis of mitochondrial DNA. Molecular Ecology, 11(9), 1617-1628.

Apte, S., Star, B., \& Gardner, J. P. (2003). A comparison of genetic diversity between cultured and wild populations, and a test for genetic introgression in the new zealand greenshell mussel perna canaliculus (gmelin 1791). Aquaculture, 219(1), 193-220.

Avise, J. C. (1994). Molecular markers, natural history and evolution: Springer Science \& Business Media.

Ayers, K., \& Waters, J. (2005). Marine biogeographic disjunction in central new zealand. Marine Biology, 147(4), 1045-1052.

Baba, K., Fujita, Y., Wehrtmann, I. S., \& Scholtz, G. (2011). Developmental biology of squat lobsters. Crustacean Issues. The biology of squat lobsters, 105-149.

Babbucci, M., Buccoli, S., Cau, A., Cannas, R., Goñi, R., Díaz, D., et al. (2010). Population structure, demographic history, and selective processes: Contrasting evidences from mitochondrial and nuclear markers in the european spiny lobster palinurus elephas (fabricius, 1787). Molecular Phylogenetics and Evolution, 56(3), 1040-1050.

Baco, A. R., Etter, R. J., Ribeiro, P. A., Von der Heyden, S., Beerli, P., \& Kinlan, B. P. (2016). A synthesis of genetic connectivity in deep-sea fauna and implications for marine reserve design. Molecular Ecology, 25(14), 3276-3298.

Bandelt, H.-J., Forster, P., \& Röhl, A. (1999). Median-joining networks for inferring intraspecific phylogenies. Molecular biology and evolution, 16(1), 37-48.

Begg, G. A., Friedland, K. D., \& Pearce, J. B. (1999). Stock identification and its role in stock assessment and fisheries management: An overview. Fisheries Research, 43(1), 1-8. 
Begg, G. A., \& Waldman, J. R. (1999). An holistic approach to fish stock identification. Fisheries Research, 43(1), 35-44.

Benestan, L., Gosselin, T., Perrier, C., Sainte-Marie, B., Rochette, R., \& Bernatchez, L. (2015). Rad genotyping reveals fine-scale genetic structuring and provides powerful population assignment in a widely distributed marine species, the american lobster (homarus americanus). Molecular Ecology, 24(13), 3299-3315.

Benestan, L., Quinn, B. K., Maaroufi, H., Laporte, M., Clark, F. K., Greenwood, S. J., et al. (2016). Seascape genomics provides evidence for thermal adaptation and current-mediated population structure in american lobster (homarus americanus). Molecular Ecology, 25(20), 5073-5092.

Beu, A. G. (1999). Fossil records of the cold-water scallop zygochlamys delicatula (mollusca: Bivalvia) off northernmost new zealand: How cold was the last glacial maximum? New Zealand Journal of Geology and Geophysics, 42(4), 543-550.

Bhargava, A., \& Fuentes, F. F. (2010). Mutational dynamics of microsatellites. Molecular Biotechnology, 44(3), 250-266.

Birky, C., Fuerst, P., \& Maruyama, T. (1989). Organelle gene diversity under migration, mutation, and drift: Equilibrium expectations, approach to equilibrium, effects of heteroplasmic cells, and comparison to nuclear genes. Genetics, 121(3), 613-627.

Boessenkool, S., Austin, J. J., Worthy, T. H., Scofield, P., Cooper, A., Seddon, P. J., et al. (2009). Relict or colonizer? Extinction and range expansion of penguins in southern new zealand. Proceedings of the Royal Society B: Biological Sciences, 276(1658), 815-821.

Bohonak, A. J. (1999). Dispersal, gene flow, and population structure. Quarterly review of biology, 21-45.

Bors, E. K., Rowden, A. A., Maas, E. W., Clark, M. R., \& Shank, T. M. (2012). Patterns of deepsea genetic connectivity in the new zealand region: Implications for management of benthic ecosystems. Plos One, 7(11), e49474.

Bromham, L. (2011). The genome as a life-history character: Why rate of molecular evolution varies between mammal species. Philosophical Transactions of the Royal Society B: Biological Sciences, 366(1577), 2503-2513.

Butler, M. J., Paris, C. B., Goldstein, J. S., Matsuda, H., \& Cowen, R. K. (2011). Behavior constrains the dispersal of long-lived spiny lobster larvae. Marine Ecology Progress Series, $422,223-237$.

Cadrin, S. X. (2000). Advances in morphometric identification of fishery stocks. Reviews in Fish Biology and Fisheries, 10(1), 91-112.

Carter, L., \& Carter, R. M. (1986). Holocene evolution of the nearshore sand wedge, south otago continental shelf, new zealand. New Zealand Journal of Geology and Geophysics, 29(4), 413-424.

Carter, L., \& Carter, R. M. (1988). Late quaternary development of left-bank-dominant levees in the bounty trough, new zealand. Marine Geology, 78(3-4), 185-197. 
Carter, R. M. (1985). Modern and relict sedimentation on the south otago continental shelf, new zealand: New Zealand Dept. of Scientific and Industrial Research.

Carvalho, G., \& Hauser, L. (1994). Molecular genetics and the stock concept in fisheries Molecular genetics in fisheries (pp. 55-79): Springer.

Cavallotto, J. L., Violante, R. A., \& Hernandez-Molina, F. J. (2011). Geological aspects and evolution of the patagonian continental margin. Biological Journal of the Linnean Society, 103(2), 346-362.

Chan, T. Y., Ho, K. C., Li, C. P., \& Chu, K. H. (2009). Origin and diversification of the clawed lobster genus metanephrops (crustacea: Decapoda: Nephropidae). Molecular Phylogenetics and Evolution, 50(3), 411-422.

Chiswell, S. M. (1996). Variability in the southland current, new zealand. New Zealand Journal of Marine and Freshwater Research, 30(1), 1-17.

Chiswell, S. M. (2000). The wairarapa coastal current. New Zealand Journal of Marine and Freshwater Research, 34(2), 303-315.

Chiswell, S. M. (2005). Mean and variability in the wairarapa and hikurangi eddies, new zealand. New Zealand Journal of Marine and Freshwater Research, 39(1), 121-134.

Chiswell, S. M. (2009). Colonisation and connectivity by intertidal limpets among new zealand, chatham and sub-antarctic islands. Ii. Oceanographic connections. Marine Ecology Progress Series, 388, 121-135.

Chiswell, S. M., \& Booth, J. D. (1999). Rock lobster jasus edwardsii larval retention by the wairarapa eddy off new zealand. Marine Ecology Progress Series, 183, 227-240.

Chiswell, S. M., \& Booth, J. D. (2008). Sources and sinks of larval settlement in jasus edwardsii around new zealand: Where do larvae come from and where do they go? Marine Ecology Progress Series, 354, 201-217.

Chiswell, S. M., Bostock, H. C., Sutton, P. J. H., \& Williams, M. J. M. (2015). Physical oceanography of the deep seas around new zealand: A review. New Zealand Journal of Marine and Freshwater Research, 49(2), 286-317.

Chiswell, S. M., \& Roemmich, D. (1998). The east cape current and two eddies: A mechanism for larval retention? New Zealand Journal of Marine and Freshwater Research, 32(3), 385-397.

Chu, K. H., Li, C. P., \& Ho, H. Y. (2001). The first internal transcribed spacer (its-1) of ribosomal DNA as a molecular marker for phylogenetic and population analyses in crustacea. Marine Biotechnology, 3(4), 355-361.

Clark, P. U., \& Mix, A. C. (2002). Ice sheets and sea level of the last glacial maximum. Quaternary Science Reviews, 21(1-3), 1-7.

Collins, C. J., Rawlence, N. J., Prost, S., Anderson, C. N. K., Knapp, M., Scofield, R. P., et al. (2014). Extinction and recolonization of coastal megafauna following human arrival in new zealand. Proceedings of the Royal Society B: Biological Sciences, 281(1786).

Connor, R. (2001). Initial allocation of individual transferable quota in new zealand fisheries. FAO Fisheries Technical Paper., 222-250. 
Corander, J., Majander, K. K., Cheng, L., \& Merilä, J. (2013). High degree of cryptic population differentiation in the baltic sea herring clupea harengus. Molecular Ecology, 22(11), 29312940.

Corander, J., \& Tang, J. (2007). Bayesian analysis of population structure based on linked molecular information. Mathematical Biosciences, 205(1), 19-31.

Cowen, R. K., Lwiza, K. M. M., Sponaugle, S., Paris, C. B., \& Olson, D. B. (2000). Connectivity of marine populations: Open or closed? Science, 287(5454), 857-859.

Cowen, R. K., \& Sponaugle, S. (2009). Larval dispersal and marine population connectivity. Annual review of marine science, 1, 443-466.

Cryer, M., Downing, K., Hartill, B., Drury, J., Armiger, H., Middleton, C., et al. (2003). Digital photography as a stock assessment tool for metanephrops challengeri on new zealand's continental slope. Paper presented at the Deep Sea 2003: Conference on the Governance and Management of Deep-Sea Fisheries. Part 1. Conference Reports.

Cryer, M., \& Stotter, D. R. (1999). Movement and growth rates of scampi inferred from tagging, alderman islands, western bay of plenty. NIWA Technical Report, 49.

Cuellar-Pinzon, J., Presa, P., Hawkins, S. J., \& Pita, A. (2016). Genetic markers in marine fisheries: Types, tasks and trends. Fisheries Research, 173, 194-205.

Darriba, D., Taboada, G. L., Doallo, R., \& Posada, D. (2012). Jmodeltest 2: More models, new heuristics and parallel computing. Nature methods, 9(8), 772-772.

Drummond, A. J., Suchard, M. A., Xie, D., \& Rambaut, A. (2012). Bayesian phylogenetics with beauti and the beast 1.7. Molecular biology and evolution, 29(8), 1969-1973.

Dunn, M., Horn, P., Connell, A., Stevens, D., Forman, J., Pinkerton, M., et al. (2009). Ecosystemscale trophic relationships: Diet composition and guild structure of middle-depth fish on the chatham rise. Final Research Report for Ministry of Fisheries Research Project ZBD200402 Objectives $1-5$.

Elshire, R. J., Glaubitz, J. C., Sun, Q., Poland, J. A., Kawamoto, K., Buckler, E. S., et al. (2011). A robust, simple genotyping-by-sequencing (gbs) approach for high diversity species. Plos One, 6(5), e19379.

Excoffier, L., Laval, G., \& Schneider, S. (2005). Arlequin (version 3.0): An integrated software package for population genetics data analysis. Evolutionary bioinformatics, 1 .

Excoffier, L., \& Lischer, H. (2011). An integrated software package for population genetics data analysis. Bern, Switzerland: Swiss Institute of Bioinformatics.

Excoffier, L., \& Lischer, H. E. (2010). Arlequin suite ver 3.5: A new series of programs to perform population genetics analyses under linux and windows. Molecular ecology resources, 10(3), 564-567.

Excoffier, L., \& Ray, N. (2008). Surfing during population expansions promotes genetic revolutions and structuration. Trends in Ecology \& Evolution, 23(7), 347-351.

Farmer, A. S. D. (1974). Reproduction in nephrops norvegicus (decapoda: Nephropidae). Journal of Zoology, 174(2), 161-183. 
Faurby, S., \& Barber, P. H. (2012). Theoretical limits to the correlation between pelagic larval duration and population genetic structure. Molecular Ecology, 21(14), 3419-3432.

Fauvelot, C., Bernardi, G., Planes, S., \& Wallis, G. (2003). Reductions in the mitochondrial DNA diversity of coral reef fish provide evidence of population bottlenecks resulting from holocene sea-level change. Evolution, 57(7), 1571-1583.

Feldmann, R. M. (1989). Metanephrops jenkinsi n. Sp. (decapoda: Nephropidae) from the cretaceous and paleocene of seymour island, antarctica. Journal of Paleontology, 63(1), 6469.

Feldmann, R. M., Tshudy, D. M., \& Michael, R. A. T. (1993). Late cretaceous and paleocene decapod crustaceans from james ross basin, antarctic peninsula. Memoir (The Paleontological Society), 28, 1-41.

Fenaughty, C. (1989). Reproduction in metanephrops challengeri. Unpublished Report, Ministry of Fisheries

Fleming, K., Johnston, P., Zwartz, D., Yokoyama, Y., Lambeck, K., \& Chappell, J. (1998). Refining the eustatic sea-level curve since the last glacial maximum using far- and intermediate-field sites. Earth and Planetary Science Letters, 163(1-4), 327-342.

Folmer, O., Hoeh, W., Black, M., \& Vrijenhoek, R. (1994). Conserved primers for pcr amplification of mitochondrial DNA from different invertebrate phyla. Molecular Marine Biology and Biotechnology, 3, 294-299.

Fraser, C. I., Nikula, R., Ruzzante, D. E., \& Waters, J. M. (2012). Poleward bound: Biological impacts of southern hemisphere glaciation. Trends in Ecology \& Evolution, 27(8), 462-471.

Fraser, C. I., Nikula, R., Spencer, H. G., \& Waters, J. M. (2009). Kelp genes reveal effects of subantarctic sea ice during the last glacial maximum. Proceedings of the National Academy of Sciences, 106(9), 3249-3253.

Fraser, C. I., Nikula, R., \& Waters, J. M. (2011). Oceanic rafting by a coastal community. Proceedings of the Royal Society B: Biological Sciences, 278(1706), 649-655.

Fu, Y. X. (1997). Statistical tests of neutrality of mutations against population growth, hitchhiking and background selection. Genetics, 147(2), 915-925.

Funk, W. C., McKay, J. K., Hohenlohe, P. A., \& Allendorf, F. W. (2012). Harnessing genomics for delineating conservation units. Trends in Ecology \& Evolution, 27(9), 489-496.

Gaggiotti, O. E., Bekkevold, D., Jørgensen, H. B., Foll, M., Carvalho, G. R., Andre, C., et al. (2009). Disentangling the effects of evolutionary, demographic, and environmental factors influencing genetic structure of natural populations: Atlantic herring as a case study. Evolution, 63(11), 2939-2951.

García-Merchán, V. H., Robainas-Barcia, A., Abelló, P., Macpherson, E., Palero, F., GarcíaRodríguez, M., et al. (2012). Phylogeographic patterns of decapod crustaceans at the atlantic-mediterranean transition. Molecular Phylogenetics and Evolution, 62(2), 664-672.

Gardner, J., Bell, J., Constable, H., Hannan, D., Ritchie, P., \& Zuccarello, G. (2010). Multi-species coastal marine connectivity: A literature review with recommendations for further research. New Zealand aquatic environment and biodiversity report(58), 47. 
Gardner, M. G., Fitch, A. J., Bertozzi, T., \& Lowe, A. J. (2011). Rise of the machines recommendations for ecologists when using next generation sequencing for microsatellite development. Molecular ecology resources, 11(6), 1093-1101.

Garrick, R. C., Bonatelli, I. A. S., Hyseni, C., Morales, A., Pelletier, T. A., Perez, M. F., et al. (2015). The evolution of phylogeographic data sets. Molecular Ecology, 24(6), 1164-1171.

Gharrett, A. J., Shirley, S. M., \& Tromble, G. R. (1987). Genetic relationships among populations of chinook salmon (oncorhynchus tshaawytscha). Canadian Journal of Fisheries and Aquatic Sciences, 44(4), 765-774.

Goldstien, S. J., Schiel, D. R., \& Gemmell, N. J. (2006). Comparative phylogeography of coastal limpets across a marine disjunction in new zealand. Molecular Ecology, 15(11), 3259-3268.

Gopal, K., Tolley, K. A., Groeneveld, J. C., \& Matthee, C. A. (2006). Mitochondrial DNA variation in spiny lobster palinurus delagoae suggests genetically structured populations in the southwestern indian ocean. Marine Ecology Progress Series, 319, 191-198.

Grant, W. S., \& Bowen, B. (1998). Shallow population histories in deep evolutionary lineages of marine fishes: Insights from sardines and anchovies and lessons for conservation. Journal of Heredity, 89(5), 415-426.

Green, A. J., \& Figuerola, J. (2005). Recent advances in the study of long-distance dispersal of aquatic invertebrates via birds. Diversity and Distributions, 11(2), 149-156.

Hannan, D., Constable, H., Silva, C., Bell, J., Ritchie, P., \& Gardner, J. (2016). Genetic connectivity amongst new zealand's open sandy shore and estuarine coastal taxa.

Harding, G. C., Kenchington, E. L., Bird, C. J., Pezzack, D. S., \& Landry, D. C. (1997). Genetic relationships among subpopulations of the american lobster (homarus americanus) as revealed by random amplified polymorphic DNA. Canadian Journal of Fisheries and Aquatic Sciences, 54(8), 1762-1771.

Harpending, H. C., Sherry, S. T., Rogers, A. R., \& Stoneking, M. (1993). The genetic structure of ancient human populations. Current Anthropology, 34(4), 483-496.

Hauser, L., \& Carvalho, G. R. (2008). Paradigm shifts in marine fisheries genetics: Ugly hypotheses slain by beautiful facts. Fish and Fisheries, 9(4), 333-362.

Hawke, D. J. (1989). Hydrology and near-surface nutrient distribution along the south otago continental shelf, new zealand, in summer and winter 1986. New Zealand Journal of Marine and Freshwater Research, 23(3), 411-420.

Heath, R. A. (1985). A review of the physical oceanography of the seas around new zealand 1982. New Zealand Journal of Marine and Freshwater Research, 19(1), 79-124.

Hebert, P. D. N., Ratnasingham, S., \& de Waard, J. R. (2003). Barcoding animal life: Cytochrome oxidase subunit 1 divergences among closely related species. Proceedings of the Royal Society of London. Series B: Biological Sciences, 270(Suppl 1), S96-S99.

Hedrick, P. W. (2011). Genetics of populations: Jones \& Bartlett Learning.

Hellberg, M. E., Burton, R. S., Neigel, J. E., \& Palumbi, S. R. (2002). Genetic assessment of connectivity among marine populations. Bulletin of Marine Science, 70(1), 273-290. 
Hewitt, G. M. (1999). Post-glacial re-colonization of european biota. Biological Journal of the Linnean Society, 68(1-2), 87-112.

Hewitt, G. M. (2000). The genetic legacy of the quaternary ice ages. Nature, 405(6789), 907-913.

Hewitt, G. M. (2004). Genetic consequences of climatic oscillations in the quaternary.

Philosophical Transactions of the Royal Society of London B: Biological Sciences, 359(1442), 183-195.

Hickerson, M. J., \& Cunningham, C. W. (2005). Contrasting quaternary histories in an ecologically divergent sister pair of low-dispersing intertidal fish (xiphister) revealed by multilocus DNA analysis. Evolution, 59(2), 344-360.

Hickerson, M. J., \& Ross, J. R. (2001). Post-glacial population history and genetic structure of the northern clingfish (gobbiesox maeandricus), revealed from mtdna analysis. Marine Biology, $138(2), 407-419$.

Hickey, A. J. R., Lavery, S. D., Hannan, D. A., Baker, C. S., \& Clements, K. D. (2009). New zealand triplefin fishes (family tripterygiidae): Contrasting population structure and mtdna diversity within a marine species flock. Molecular Ecology, 18(4), 680-696.

Hilário, A., Metaxas, A., Gaudron, S. M., Howell, K. L., Mercier, A., Mestre, N. C., et al. (2015). Estimating dispersal distance in the deep sea: Challenges and applications to marine reserves. Frontiers in Marine Science, 2(6).

Hoban, S., Bertorelle, G., \& Gaggiotti, O. E. (2012). Computer simulations: Tools for population and evolutionary genetics. Nature Reviews Genetics, 13(2), 110-122.

Holland, S. M. (2003). Analytic rarefaction 1.3. University of Georgia, Athens.

Jeena, N. S., Gopalakrishnan, A., Kizhakudan, J. K., Radhakrishnan, E. V., Kumar, R., \& Asokan, P. K. (2016). Population genetic structure of the shovel-nosed lobster thenus unimaculatus (decapoda, scyllaridae) in indian waters based on rapd and mitochondrial gene sequences. Hydrobiologia, 766(1), 225-236.

Jenkins, R. J. F. (1972). Metanephrops a new genus of late pliocene to recent lobsters (decapoda, nephropidae). Crustaceana (Leiden), 22(2), 161-177.

Jensen, J. L., Bohonak, A. J., \& Kelley, S. T. (2005). Isolation by distance, web service. BMC Genetics, 6, 13-13.

Jones, G. P., Planes, S., \& Thorrold, S. R. (2005). Coral reef fish larvae settle close to home. Current Biology, 15(14), 1314-1318.

Jørgensen, H. B., Hansen, M. M., Bekkevold, D., Ruzzante, D. E., \& Loeschcke, V. (2005). Marine landscapes and population genetic structure of herring (clupea harengus $l$.) in the baltic sea. Molecular Ecology, 14(10), 3219-3234.

Kearse, M., Moir, R., Wilson, A., Stones-Havas, S., Cheung, M., Sturrock, S., et al. (2012). Geneious basic: An integrated and extendable desktop software platform for the organization and analysis of sequence data. Bioinformatics, 28(12), 1647-1649. 
Kenchington, E. L., Harding, G. C., Jones, M. W., \& ProdÖHl, P. A. (2009). Pleistocene glaciation events shape genetic structure across the range of the american lobster, homarus americanus. Molecular Ecology, 18(8), 1654-1667.

Kennington, W. J., Cadee, S. A., Berry, O., Groth, D. M., Johnson, M. S., \& Melville-Smith, R. (2013a). Maintenance of genetic variation and panmixia in the commercially exploited western rock lobster (panulirus cygnus). Conservation Genetics, 14(1), 115-124.

Kennington, W. J., Melville-Smith, R., \& Berry, O. (2013b). Genetics of wild and captive lobster populations Lobsters: Biology, management, aquaculture and fisheries (pp. 36-63): John Wiley \& Sons, Ltd.

Kumar, G., \& Kocour, M. (2017). Applications of next-generation sequencing in fisheries research: A review. Fisheries Research, 186, Part 1, 11-22.

Laikre, L., Palm, S., \& Ryman, N. (2005). Genetic population structure of fishes: Implications for coastal zone management. AMBIO: A Journal of the Human Environment, 34(2), 111-119.

Larson, W. A., Seeb, L. W., Everett, M. V., Waples, R. K., Templin, W. D., \& Seeb, J. E. (2014). Genotyping by sequencing resolves shallow population structure to inform conservation of chinook salmon (oncorhynchus tshawytscha). Evolutionary Applications, 7(3), 355-369.

Laugen, A. T., Engelhard, G. H., Whitlock, R., Arlinghaus, R., Dankel, D. J., Dunlop, E. S., et al. (2014). Evolutionary impact assessment: Accounting for evolutionary consequences of fishing in an ecosystem approach to fisheries management. Fish and Fisheries, 15(1), 65-96.

Law, R. (2007). Fisheries-induced evolution: Present status and future directions. Marine Ecology Progress Series, 335, 271-277.

Lea, D. W., Martin, P. A., Pak, D. K., \& Spero, H. J. (2002). Reconstructing a 350 ky history of sea level using planktonic $\mathrm{mg} / \mathrm{ca}$ and oxygen isotope records from a cocos ridge core. Quaternary Science Reviews, 21(1-3), 283-293.

Leung, B., Bossenbroek, J. M., \& Lodge, D. M. (2006). Boats, pathways, and aquatic biological invasions: Estimating dispersal potential with gravity models. Biological Invasions, 8(2), 241-254.

Levin, L. A. (2006). Recent progress in understanding larval dispersal: New directions and digressions. Integrative and Comparative Biology, 46(3), 282-297.

Lewis, K. B., Carter, L., \& Davey, F. J. (1994). The opening of cook strait: Interglacial tidal scour and aligning basins at a subduction to transform plate edge. Marine Geology, 116(3), 293312.

Librado, P., \& Rozas, J. (2009). Dnasp v5: A software for comprehensive analysis of DNA polymorphism data. Bioinformatics, 25(11), 1451-1452.

Liggins, L., Treml, E. A., \& Riginos, C. (2013). Taking the plunge: An introduction to undertaking seascape genetic studies and using biophysical models. Geography Compass, 7(3), 173-196.

Lobel, P. S., \& Robinson, A. R. (1986). Transport and entrapment of fish larvae by ocean mesoscale eddies and currents in hawaiian waters. Deep Sea Research Part A. Oceanographic Research Papers, 33(4), 483-500. 
Lowe, W. H., \& Allendorf, F. W. (2010). What can genetics tell us about population connectivity? Molecular Ecology, 19(15), 3038-3051.

Mackay, K. A., Mitchell, J. S., Neil, H. L., \& Mackay, E. J. (2015). New zealand's marine realm. NIWA Chart Miscellaneous Series

Maggs, C. A., Castilho, R., Foltz, D., Henzler, C., Jolly, M. T., Kelly, J., et al. (2008). Evaluating signatures of glacial refugia for north atlantic benthic marine taxa Ecology, 89(sp11), S108S122.

Major, R. N., Taylor, D. I., Connor, S., Connor, G., \& Jeffs, A. G. (2017). Factors affecting bycatch in a developing new zealand scampi potting fishery. Fisheries Research, 186, Part 1, 55-64.

Maltagliati, F., Camilli, L., Biagi, F., \& Abbiati, M. (1998). Genetic structure of norway lobster, nephrops norvegicus (1.) (crustacea: Nephropidae), from the mediterranean sea. 1998, 62(S1), 9.

Mantovani, B., \& Scali, V. (1992). Allozyme characterization of the norway lobster, nephrops norvegicus, of two adriatic trawling grounds. Acta Adriatica, 33, 209-213.

Marko, P. B. (2004). 'What's larvae got to do with it?' Disparate patterns of post-glacial population structure in two benthic marine gastropods with identical dispersal potential. Molecular Ecology, 13(3), 597-611.

Marshall, B. A. (1995). A revision of the recent calliostoma species of new zealand (mollusca: Gastropoda: Trochoidea). Nautilus, 108(4), 83.

Meyer, A. (1993). Evolution of mitochondrial DNA in fishes. Biochemistry and molecular biology of fishes, 2, 1-38.

Meynier, L., Morel, P., Mackenzie, D., MacGibbon, A., Chilvers, B., \& Duignan, P. (2008). Proximate composition, energy content, and fatty acid composition of marine species from campbell plateau, new zealand. New Zealand Journal of Marine and Freshwater Research, 42(4), 425-437.

Miller, M. R., Dunham, J. P., Amores, A., Cresko, W. A., \& Johnson, E. A. (2007). Rapid and costeffective polymorphism identification and genotyping using restriction site associated DNA (rad) markers. Genome Research, 17(2), 240-248.

Ministry for Primary Industries. (2016). Fisheries assessment plenary, may 2016: Stock assessments and stock status.

Naro-Maciel, E., Reid, B., Holmes, K. E., Brumbaugh, D. R., Martin, M., \& DeSalle, R. (2011). Mitochondrial DNA sequence variation in spiny lobsters: Population expansion, panmixia, and divergence. Marine Biology, 158(9), 2027-2041.

Nei, M. (1987). Molecular evolutionary genetics: Columbia University Press.

Neil, H. L., Carter, L., \& Morris, M. Y. (2004). Thermal isolation of campbell plateau, new zealand, by the antarctic circumpolar current over the past 130 kyr. Paleoceanography, 19(4).

Nelson, C. S., Cooke, P. J., Hendy, C. H., \& Cuthbertson, A. M. (1993). Oceanographic and climatic changes over the past 160,000 years at deep sea drilling project site 594 off southeastern new zealand, southwest pacific ocean. Paleoceanography, 8(4), 435-458. 
Nielsen, E., Hemmer-Hansen, J., Larsen, P. F., \& Bekkevold, D. (2009a). Population genomics of marine fishes: Identifying adaptive variation in space and time. Molecular Ecology, 18(15), 3128-3150.

Nielsen, E., Hemmer-Hansen, J., Poulsen, N., Loeschcke, V., Moen, T., Johansen, T., et al. (2009b). Genomic signatures of local directional selection in a high gene flow marine organism; the atlantic cod (gadus morhua). BMC Evolutionary Biology, 9(1), 276.

Nikula, R., Fraser, C., Spencer, H., \& Waters, J. (2010). Circumpolar dispersal by rafting in two subantarctic kelp-dwelling crustaceans. Marine Ecology Progress Series, 405, 221-230.

O'Connor, M. I., Bruno, J. F., Gaines, S. D., Halpern, B. S., Lester, S. E., Kinlan, B. P., et al. (2007). Temperature control of larval dispersal and the implications for marine ecology, evolution, and conservation. Proceedings of the National Academy of Sciences, 104(4), 1266-1271.

Ovenden, J. R. (2013). Crinkles in connectivity: Combining genetics and other types of biological data to estimate movement and interbreeding between populations. Marine and Freshwater Research, 64(3), 201-207.

Palero, F., Abello, P., Macpherson, E., Beaumont, M., \& Pascual, M. (2011). Effect of oceanographic barriers and overfishing on the population genetic structure of the european spiny lobster (palinurus elephas). Biological Journal of the Linnean Society, 104(2), 407418.

Palero, F., Abelló, P., Macpherson, E., Gristina, M., \& Pascual, M. (2008). Phylogeography of the european spiny lobster (palinurus elephas): Influence of current oceanographical features and historical processes. Molecular Phylogenetics and Evolution, 48(2), 708-717.

Palero, F., Abelló, P., Macpherson, E., Matthee, C. A., \& Pascual, M. (2010). Genetic diversity levels in fishery-exploited spiny lobsters of the genus palinurus (decapoda: Achelata). Journal of Crustacean Biology, 30(4), 658-663.

Palsboll, P. J., Berube, M., \& Allendorf, F. W. (2007). Identification of management units using population genetic data. Trends in Ecology \& Evolution, 22(1), 11-16.

Palstra, F. P., \& Ruzzante, D. E. (2008). Genetic estimates of contemporary effective population size: What can they tell us about the importance of genetic stochasticity for wild population persistence? Molecular Ecology, 17(15), 3428-3447.

Palumbi, S. R. (2003). Population genetics, demographic connectivity, and the design of marine reserves. Ecological Applications, 13(1), S146-S158.

Pampoulie, C., Skirnisdottir, S., Hauksdottir, S., Olafsson, K., Eiriksson, H., Chosson, V., et al. (2011). A pilot genetic study reveals the absence of spatial genetic structure in norway lobster (nephrops norvegicus) on fishing grounds in icelandic waters. Ices Journal of Marine Science, 68(1), 20-25.

Papadopoulou, A., Anastasiou, I., \& Vogler, A. P. (2010). Revisiting the insect mitochondrial molecular clock: The mid-aegean trench calibration. Molecular biology and evolution, 27(7), 1659-1672. 
Paris, C. B., Chérubin, L. M., \& Cowen, R. K. (2007). Surfing, spinning, or diving from reef to reef: Effects on population connectivity. Marine Ecology Progress Series, 347, 285-300.

Passamonti, M., Mantovani, B., Scali, V., \& Froglia, C. (1997). Allozymic characterization of scottish and aegean populations of nephrops norvegicus. Journal of the Marine Biological Association of the United Kingdom, 77(3), 727-735.

Pérez-Barros, P., D'amato, M. E., Guzman, N. V., \& Lovrich, G. A. (2008). Taxonomic status of two south american sympatric squat lobsters, munida gregaria and munida subrugosa (crustacea: Decapoda: Galatheidae), challenged by DNA sequence information. Biological Journal of the Linnean Society, 94(2), 421-434.

Pérez-Barros, P., Lovrich, G. A., Calcagno, J. A., \& Confalonieri, V. A. (2014). Is munida gregaria (crustacea: Decapoda: Munididae) a truly transpacific species? Polar Biology, 37(10), 14131420 .

Petit, R. J., Aguinagalde, I., de Beaulieu, J.-L., Bittkau, C., Brewer, S., Cheddadi, R., et al. (2003). Glacial refugia: Hotspots but not melting pots of genetic diversity. Science, 300(5625), $1563-1565$.

Pinsky, M. L., \& Palumbi, S. R. (2014). Meta-analysis reveals lower genetic diversity in overfished populations. Molecular Ecology, 23(1), 29-39.

Rainer, S. F. (1988). Growth of the australian scampi, metanephrops australiensis. The fisheries biology of deepwater crustacea and finfish on the continental slope of Western Australia

Rambaut, A., \& Drummond, A. (2007). Tracer 1.5. University of Edinburgh, Edinburgh, UK Available at: http://tree.bio.ed.ac.uk/software/tracer.

Reed, D. H., \& Frankham, R. (2003). Correlation between fitness and genetic diversity. Conservation Biology, 17(1), 230-237.

Reiss, H., Hoarau, G., Dickey-Collas, M., \& Wolff, W. J. (2009). Genetic population structure of marine fish: Mismatch between biological and fisheries management units. Fish and Fisheries, 10(4), 361-395.

Robey, J., \& Groeneveld, J. C. (2014). Fecundity of the langoustine metanephrops mozambicus macpherson, 1990 (decapoda, nephropidae) in eastern south africa. Crustaceana, 87(7), 814826.

Rodríguez-Rey, G. T., Solé-Cava, A. M., \& Lazoski, C. (2013). Genetic homogeneity and historical expansions of the slipper lobster, scyllarides brasiliensis, in the south-west atlantic. Marine and Freshwater Research, 65(1), 59-69.

Rogers, A. R., \& Harpending, H. (1992). Population growth makes waves in the distribution of pairwise genetic differences. Molecular biology and evolution, 9(3), 552-569.

Ross, P. M., Hogg, I. D., Pilditch, C. A., \& Lundquist, C. J. (2009). Phylogeography of new zealand's coastal benthos. New Zealand Journal of Marine and Freshwater Research, 43(5), 1009-1027.

Rousset, F. (1997). Genetic differentiation and estimation of gene flow from f-statistics under isolation by distance. Genetics, 145(4), 1219-1228. 
Sambrook, J., Fritsch, E. F., \& Maniatis, T. (1989). Molecular cloning (Vol. 2): Cold spring harbor laboratory press New York.

Savolainen, V., Cowan, R. S., Vogler, A. P., Roderick, G. K., \& Lane, R. (2005). Towards writing the encyclopaedia of life: An introduction to DNA barcoding. Philosophical Transactions of the Royal Society B: Biological Sciences, 360(1462), 1805-1811.

Scheltema, R. S. (1986). On dispersal and planktonic larvae of benthic invertebrates: An eclectic overview and summary of problems. Bulletin of Marine Science, 39(2), 290-322.

Schenekar, T., \& Weiss, S. (2011). High rate of calculation errors in mismatch distribution analysis results in numerous false inferences of biological importance. Heredity, 107(6), 511-512.

Schlotterer, C. (2004). The evolution of molecular markers [mdash] just a matter of fashion? Nat Rev Genet, 5(1), 63-69.

Schwartz, M. K., Luikart, G., \& Waples, R. S. (2007). Genetic monitoring as a promising tool for conservation and management. Trends in Ecology \& Evolution, 22(1), 25-33.

Schwarz, G. (1978). Estimating the dimension of a model. The annals of statistics, 6(2), 461-464.

Seeb, J. E., Carvalho, G., Hauser, L., Naish, K., Roberts, S., \& Seeb, L. W. (2011). Singlenucleotide polymorphism (snp) discovery and applications of snp genotyping in nonmodel organisms. Molecular ecology resources, 11, 1-8.

Selkoe, K. A., \& Toonen, R. J. (2011). Marine connectivity: A new look at pelagic larval duration and genetic metrics of dispersal. Marine Ecology Progress Series, 436, 291-305.

Shanks, A. L., Grantham, B. A., \& Carr, M. H. (2003). Propagule dispersal distance and the size and spacing of marine reserves. Ecological Applications, 13(sp1), 159-169.

Silva, C. N. S., \& Gardner, J. P. A. (2016). Identifying environmental factors associated with the genetic structure of the new zealand scallop: Linking seascape genetics and ecophysiological tolerance. Ices Journal of Marine Science, 73(7), 1925-1934.

Skirnisdottir, S., Olafsson, K., Hauksdottir, S., Pampoulie, C., Hreggvidsson, G., Gunnarsson, G., et al. (2010). Isolation and characterisation of eight new microsatellite loci in the norway lobster, nephrops norvegicus (linnaeus, 1758). Molecular Ecology Resources Database.

Slatkin, M. (1987). Gene flow and the geographic structure of natural populations. Science, 236(4803), 787-792.

Slatkin, M. (1995). A measure of population subdivision based on microsatellite allele frequencies. Genetics, 139(1), 457-462.

Smith, P. J. (1999). Allozyme variation in scampi (metanephrops challengeri) fisheries around new zealand. New Zealand Journal of Marine and Freshwater Research, 33(3), 491-497.

Stamatis, C., Triantafyllidis, A., Moutou, K. A., \& Mamuris, Z. (2004). Mitochondrial DNA variation in northeast atlantic and mediterranean populations of norway lobster, nephrops norvegicus. Molecular Ecology, 13(6), 1377-1390. 
Stamatis, C., Triantafyllidis, A., Moutou, K. A., \& Mamuris, Z. (2006). Allozymic variation in northeast atlantic and mediterranean populations of norway lobster, nephrops norvegicus. Ices Journal of Marine Science, 63(5), 875-882.

Star, B., Apte, S., \& Gardner, J. P. (2003). Genetic structuring among populations of the greenshell mussel perna canaliculus revealed by analysis of randomly amplified polymorphic DNA. Marine Ecology Progress Series, 249, 171-182.

Stevens, M. I., \& Hogg, I. D. (2004). Population genetic structure of new zealand's endemic corophiid amphipods: Evidence for allopatric speciation. Biological Journal of the Linnean Society, 81(1), 119-133.

Streiff, R., Guillemaud, T., Alberto, F., Magalhães, J., Castro, M., \& Cancela, M. L. (2001). Isolation and characterization of microsatellite loci in the norway lobster (nephrops norvegicus). Molecular Ecology Notes, 1(1-2), 71-72.

Swain, D. P., Sinclair, A. F., \& Mark Hanson, J. (2007). Evolutionary response to size-selective mortality in an exploited fish population. Proceedings of the Royal Society B: Biological Sciences, 274(1613), 1015-1022.

Tajima, F. (1989). Statistical method for testing the neutral mutation hypothesis by DNA polymorphism. Genetics, 123(3), 585-595.

Tamura, K., \& Nei, M. (1993). Estimation of the number of nucleotide substitutions in the control region of mitochondrial DNA in humans and chimpanzees. Molecular biology and evolution, 10(3), 512-526.

Templin, W. D., Seeb, J. E., Jasper, J. R., Barclay, A. W., \& Seeb, L. W. (2011). Genetic differentiation of alaska chinook salmon: The missing link for migratory studies. Molecular ecology resources, 11, 226-246.

Teske, P. R., Sandoval-Castillo, J., van Sebille, E., Waters, J., \& Beheregaray, L. B. (2016). Oceanography promotes self-recruitment in a planktonic larval disperser. Scientific Reports, 6,34205 .

Thomas, L., \& Bell, J. J. (2013). Testing the consistency of connectivity patterns for a widely dispersing marine species. Heredity, 111(4), 345-354.

Thornhill, D. J., Mahon, A. R., Norenburg, J. L., \& Halanych, K. M. (2008). Open-ocean barriers to dispersal: A test case with the antarctic polar front and the ribbon worm parborlasia corrugatus (nemertea: Lineidae). Molecular Ecology, 17(23), 5104-5117.

Thorpe, J., Solé-Cava, A., \& Watts, P. (2000). Exploited marine invertebrates: Genetics and fisheries. Hydrobiologia, 420(1), 165-184.

Thorrold, S. R., Zacherl, D. C., \& Levin, L. A. (2007). Population connectivity and larval dispersal: Using geochemical signatures in calcified structures.

Thorson, G. (1950). Reproductive and larval ecology of marine bottom invertebrates. Biological reviews, 25(1), 1-45.

Tolley, K. A., Groeneveld, J. C., Gopal, K., \& Matthee, C. A. (2005). Mitochondrial DNA panmixia in spiny lobster palinurus gilchristi suggests a population expansion. Marine Ecology Progress Series, 297, 225-231. 
Tracey, M. L., Nelson, K., Hedgecock, D., Shleser, R. A., \& Pressick, M. L. (1975). Biochemical genetics of lobsters: Genetic variation and the structure of american lobster (homarus americanus) populations. Journal of the Fisheries Board of Canada, 32(11), 2091-2101.

Treml, E. A., Halpin, P. N., Urban, D. L., \& Pratson, L. F. (2008). Modeling population connectivity by ocean currents, a graph-theoretic approach for marine conservation. Landscape Ecology, 23(1), 19-36.

Triantafyllidis, A., Apostolidis, A. P., Katsares, V., Kelly, E., Mercer, J., Hughes, M., et al. (2005). Mitochondrial DNA variation in the european lobster (homarus gammarus) throughout the range. Marine Biology, 146(2), 223-235.

Truelove, N. K., Kough, A. S., Behringer, D. C., Paris, C. B., Box, S. J., Preziosi, R. F., et al. (2017). Biophysical connectivity explains population genetic structure in a highly dispersive marine species. Coral Reefs, 36(1), 233-244.

Tuck, I. D. (2013). Characterisation and length-based population model for scampi (metanephrops challengeri) on the mernoo bank (sci 3). New Zealand Fisheries Assessment Report

Tuck, I. D. (2014). Characterisation and length-based assessment model for scampi (metanephrops challengeri) in the bay of plenty (sci 1) and hawke bay/wairarapa (sci 2). New Zealand Fisheries Assessment Report

Tuck, I. D., Parkinson, D., Armiger, H., Smith, M., Miller, A., Rush, N., et al. (2015a). Estimating the abundance of scampi in sci6a (auckland islands) in 2013. New Zealand Fisheries Assessment Report, 10.

Tuck, I. D., Parsons, D. M., Hartill, B. W., \& Chiswell, S. M. (2015b). Scampi (metanephrops challengeri) emergence patterns and catchability. Ices Journal of Marine Science, 72, 199210.

Veale, A. J., \& Lavery, S. D. (2011). Phylogeography of the snakeskin chiton sypharochiton pelliserpentis (mollusca: Polyplacophora) around new zealand: Are seasonal near-shore upwelling events a dynamic barrier to gene flow? Biological Journal of the Linnean Society, 104(3), 552-563.

Veale, A. J., \& Lavery, S. D. (2012). The population genetic structure of the waratah anemone (actinia tenebrosa) around new zealand. New Zealand Journal of Marine and Freshwater Research, 46(4), 523-536.

Wahle, R., MacDiarmid, A., Butler, M., Cockcroft, A., \& Chan, T. Y. (2011). Metanephrops challengeri. The IUCN Red List of Threatened Species 2011

Wallis, G. P., \& Trewick, S. A. (2009). New zealand phylogeography: Evolution on a small continent. Molecular Ecology, 18(17), 3548-3580.

Wallner, B., \& Phillips, B. F. (1990). Development of a trawl fishery for deepwater metanephropid lobsters off the north west continental slope of australia: Designing a management strategy compatible with species life history: CSIRO Division of Fisheries.

Waples, R. S. (1987). A multispecies approach to the analysis of gene flow in marine shore fishes. Evolution, 41(2), 385-400. 
Waples, R. S., \& Gaggiotti, O. (2006). What is a population? An empirical evaluation of some genetic methods for identifying the number of gene pools and their degree of connectivity. Molecular Ecology, 15(6), 1419-1439.

Waters, J., \& Roy, M. (2004). Phylogeography of a high-dispersal new zealand sea-star: Does upwelling block gene-flow? Molecular Ecology, 13(9), 2797-2806.

Waters, J. M. (2011). Competitive exclusion: Phylogeography's 'elephant in the room'? Molecular Ecology, 20(21), 4388-4394.

Waters, J. M., Fraser, C. I., \& Hewitt, G. M. (2013). Founder takes all: Density-dependent processes structure biodiversity. Trends in Ecology \& Evolution, 28(2), 78-85.

Wear, R. G. (1976). Studies on the larval development of metanephrops challengeri (balss, 1914) (decapoda, nephropidae). Crustaceana (Leiden), 30(2), 113-122.

Webster, M. S., Marra, P. P., Haig, S. M., Bensch, S., \& Holmes, R. T. (2002). Links between worlds: Unraveling migratory connectivity. Trends in Ecology \& Evolution, 17(2), 76-83.

Weersing, K., \& Toonen, R. J. (2009). Population genetics, larval dispersal, and connectivity in marine systems. Marine Ecology Progress Series, 393, 1-12.

Wei, K. J., Wood, A. R., \& Gardner, J. P. A. (2013). Seascape genetics of the new zealand greenshell mussel: Sea surface temperature explains macrogeographic scale genetic variation. Marine Ecology Progress Series, 477, 107-121.

Wennerström, L., Laikre, L., Ryman, N., Utter, F. M., Ab Ghani, N. I., André, C., et al. (2013). Genetic biodiversity in the baltic sea: Species-specific patterns challenge management. Biodiversity and Conservation, 22(13-14), 3045-3065.

White, C., Selkoe, K. A., Watson, J., Siegel, D. A., Zacherl, D. C., \& Toonen, R. J. (2010). Ocean currents help explain population genetic structure. Proceedings of the Royal Society of London B: Biological Sciences.

Whitlock, M. C., \& McCauley, D. E. (1999). Indirect measures of gene flow and migration: Fst $\neq 1 /(4 \mathrm{~nm}+1)$. Heredity, 82(2), 117-125.

Wilcox, R. Z. (2015). A population genetic analysis of the new zealand spotty (notolabrus celidotus) using mitochondrial DNA and microsatellite DNA markers. (Masters Thesis), Victoria University of Wellington.

Wilson, A. C., Cann, R. L., Carr, S. M., George, M., Gyllensten, U. B., Helmbychowski, K. M., et al. (1985). Mitochondrial DNA and two perspectives on evolutionary genetics. Biological Journal of the Linnean Society, 26(4), 375-400.

Wright, S. (1931). Evolution in mendelian populations. Genetics, 16(2), 97-159.

Wright, S. (1943). Isolation by distance. Genetics, 28(2), 114.

Yaldwyn, J. C., \& Webber, W. R. (2011). Annotated checklist of new zealand decapoda (arthropoda: Crustacea). Tuhinga, 22, 171-272.

Zacarias, L. D. (2013). Genetic population structure of deep-water prawns haliporoides triarthrus and langoustines metanephrops mozambicus in the south west indian ocean: Use of 
mitochondrial DNA to investigate metapopulation structure. (Masters Thesis), University of KwaZulu-Natal, Durban, South Africa. 


\section{Appendix}

1.) Mismatch distributions for each sampling site, and all sampling sites combined, generated by the $\mathrm{CO} 1$ dataset. The expected number of pairwise differences between DNA sequences is represented by the green line, while the red line represents the observed frequency of pairwise differences between DNA sequences.
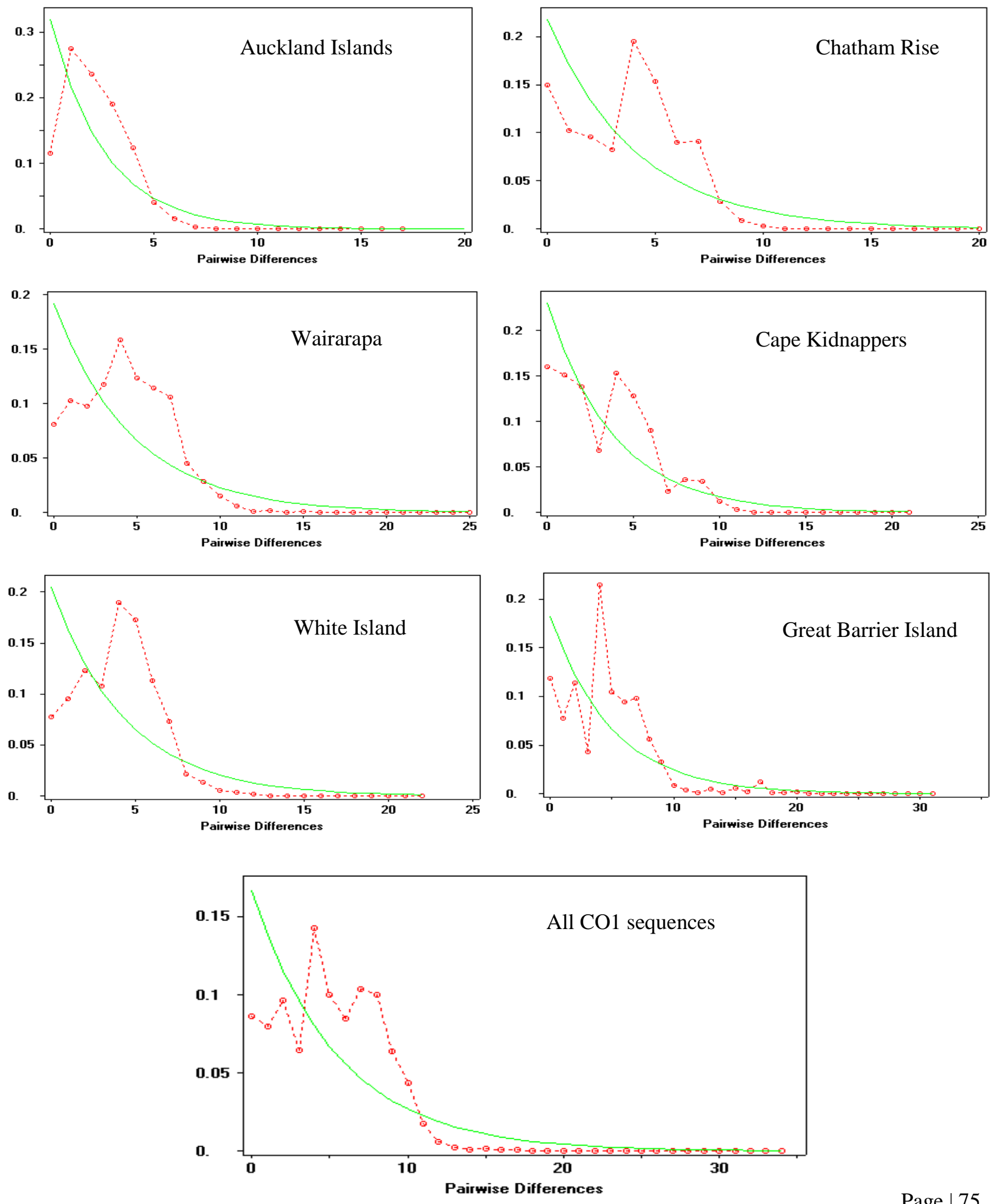
2.) Mismatch distributions for each sampling site, and all sampling sites combined, generated by the ITS-1 dataset. The expected number of pairwise differences between DNA sequences is represented by the green line, while the red line represents the observed frequency of pairwise differences between DNA sequences.
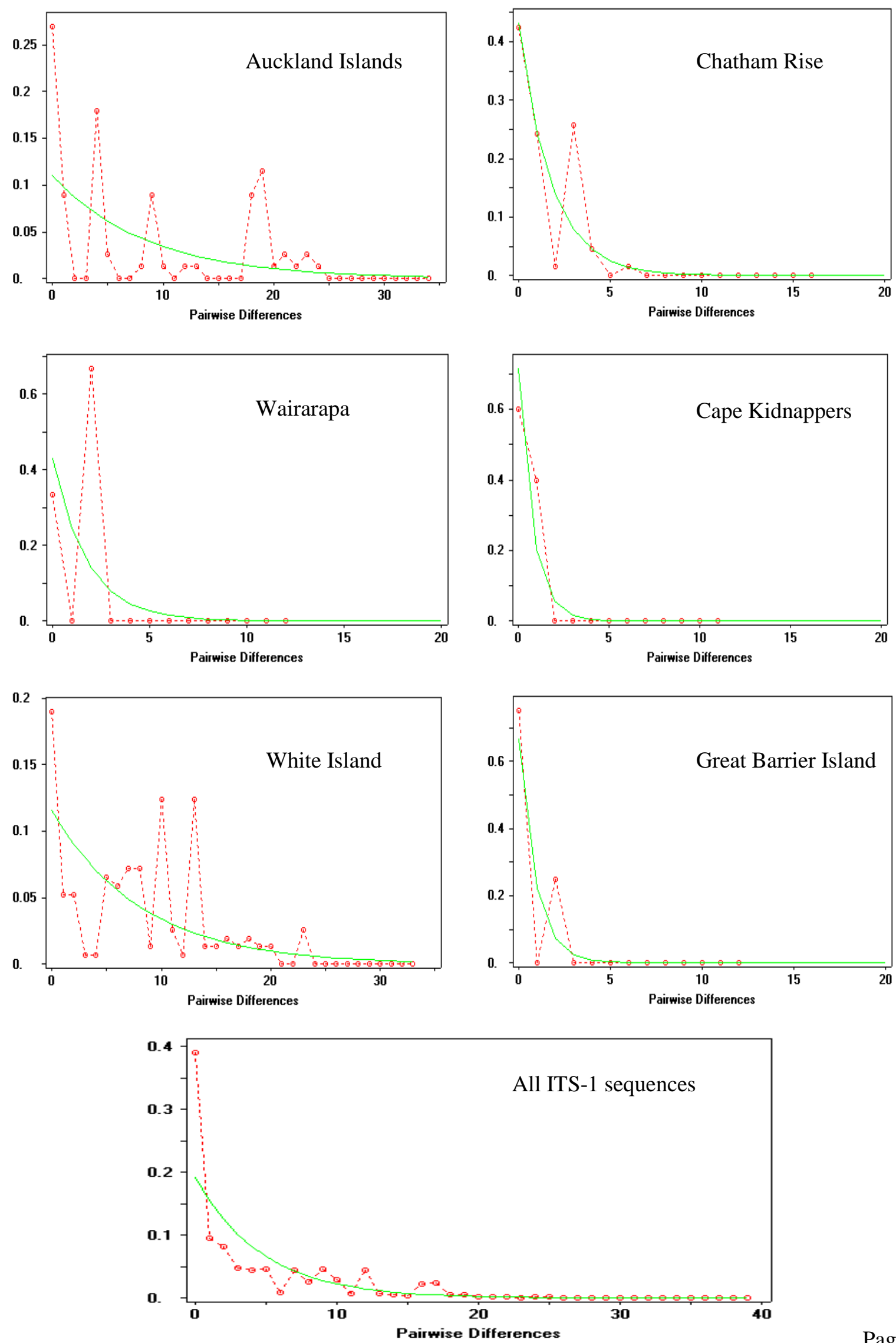